Florida International University

FIU Digital Commons

FIU Electronic Theses and Dissertations

University Graduate School

3-22-1994

\title{
Initial placement methods for Haitian adult ESOL students : the NYS place test plus profile data compared to subjective assessment
}

Dorothy R. Alterman

Florida International University

DOI: $10.25148 /$ etd.FI13101610

Follow this and additional works at: https://digitalcommons.fiu.edu/etd

Part of the Education Commons

\section{Recommended Citation}

Alterman, Dorothy R., "Initial placement methods for Haitian adult ESOL students : the NYS place test plus profile data compared to subjective assessment" (1994). FIU Electronic Theses and Dissertations. 1115.

https://digitalcommons.fiu.edu/etd/1115 
FLORIDA INTERNATIONAL UNIVERSITY

Miami, Florida

INITIAL PLACEMENT METHODS FOR HAITIAN ADULT ESOL STUDENTS:

THE NYS PLACE TEST PLUS PROFILE DATA

COMPARED TO SUBJECTIVE ASSESSMENT

A dissertation submitted in partial satisfaction of the

requirements for the degree of

DOCTOR OF EDUCATION

IN

ADULT EDUCATION AND HUMAN RESOURCE DEVELOPMENT

by

Dorothy R. Alterman 
To: Dean I. Ira Goldenberg

College of Education

This dissertation, written by Dorothy Alterman, and entitled Initial Placement Methods for Haitian Adult ESOL Students: The NYS Place Test plus Profile Data Compared to Subjective Assessment, having been approved in respect to style and intellectual content, is referred to you for judgement.

We have read this dissertation and recommend that it be approved.

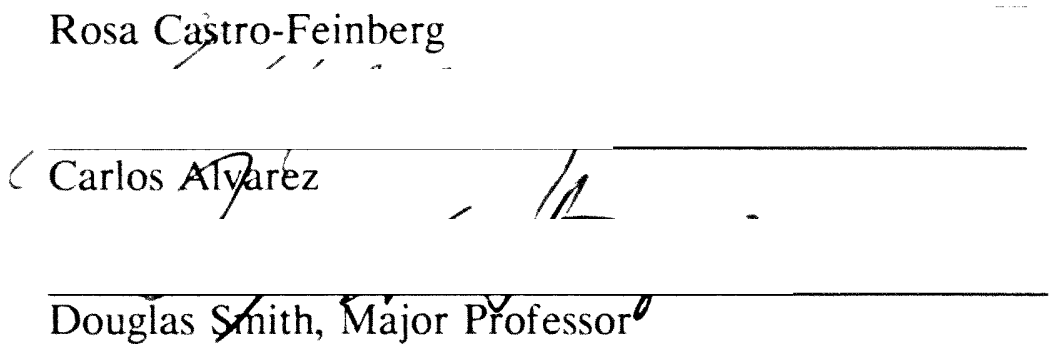

Date of Defense: March 22, 1994

The dissertation of Dorothy R. Alterman is approved.

Dean I. Pra Goldenberg

College of Education

Dr. Richard L. Campbell

Dean of Graduate Studies

Florida International University, 1994 
Copyright $\odot$ Dorothy R. Alterman, 1994

All rights reserved 
To my husband Gene, and our daughters, Karen and Randi 


\section{ACKNOWLEDGEMENTS}

My sincerest appreciation is extended to my dissertation committee for their continued support and guidance throughout this study: Dr. Douglas Smith, committee chairperson, for his insights in adult education; Dr. Rosa Castro-Feinberg, for her attention to detail; and Dr. Carlos Alvarez, for his confidence in me. A special thanks is extended to Dr. Barry Greenberg, who was not an official member of my committee, but provided invaluable assistance in the statistical analyses.

I am grateful to Mr. Edward Light and Ms. Rochelle Yarish, administrators at the Gene A. Whiddon Adult Center, for allowing me to conduct the study at that site. Their encouragement during this project helped me bring it to conclusion.

I express my appreciation to Ms. Jean Wilson who patiently administered the test and collected the test data. Her efforts made it possible to carry out the study. My appreciation also goes to Mr. Pierre Holly who administered the profile data survey and helped with translation. A special thank-you goes to the ESOL teachers and students at Whiddon for their participation in this study.

My gratitude is extended to Mr. Roger Savain for his willingness to translate. His expertise in Haitian language and culture provided me with a greater understanding of the Haitian people.

The generosity of the New York State Education Department for permission to include portions of the NYS Place Test and manual is gratefully acknowledged.

Finally, I express my appreciation to my family for their support and sacrifice so that I could accomplish my goal. 


\author{
INITIAL PLACEMENT METHODS \\ FOR HAITIAN ADULT ESOL STUDENTS: \\ THE NYS PLACE TEST PLUS PROFILE DATA \\ COMPARED TO SUBJECTIVE ASSESSMENT
}

by

Dorothy R. Alterman

Florida International University, 1994

Professor Douglas Smith, Major Professor

Few valid and reliable placement procedures are available to assess the English language proficiency of adults who enroll in English for Speakers of Other Languages (ESOL) programs. Whereas placement material exists for children and university ESOL students, the needs of students in adult community education programs have not been adequately addressed.

Furthermore, the research suggests that a number of variables, such as, native language, age, prior schooling, length of residence, and employment are related to second language acquisition. Numerous studies contribute to our understanding of the relationship of these factors to second language acquisition of Spanish-speaking students. Again, there is a void in the research investigating the factors affecting 
second language acquisition and consequently, appropriate placement of Haitian Creole-speaking students.

This study compared a standardized instrument, the NYS Place Test, used alone and in combination with a writing sample in English, to subjective judgement of a department coordinator for initial placement of Haitian adult ESOL students in a community education program. The study also investigated whether or not consideration of student profile data improved the accuracy of the test. Finally, the study sought to determine if a relationship existed between student profile data and those who withdrew from the program or did not enter a class after registering.

Analysis of the data by crosstabulation and chi-square revealed that the standardized NYS Place Test was at least as accurate as subjective de tment coordinator placement and that one procedure could be substituted for the other. Although the writing sample in English improved accuracy of placement by the NYS test, the results were not significant. Of the profile variables, only length of residence was found to be significantly related to accuracy of placement using the NYS Place Test. The number of incorrect placements was higher for those students who lived in the host country from twenty-five to one hundred ten months. A post hoc analysis of NYS test scores according to level showed that those learners who placed in level three also had a significantly higher incidence of incorrect placements. No significant relationship was observed between the profile variables and those who withdrew from the program or registered but did not enter a class. 


\section{TABLE OF CONTENTS}

CHAPTER

PAGE

I. INTRODUCTION

Introduction to the Problem $\ldots \ldots \ldots \ldots \ldots \ldots \ldots \ldots \ldots$

Immigrants in Florida Schools $\ldots \ldots \ldots \ldots \ldots \ldots \ldots \ldots$

Limitations of the Available Data $\ldots \ldots \ldots \ldots \ldots \ldots \ldots$

Background of the Haitian People $\ldots \ldots \ldots \ldots \ldots \ldots$

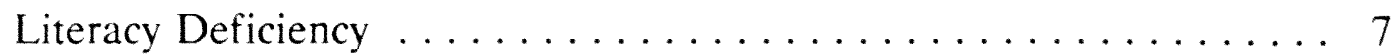

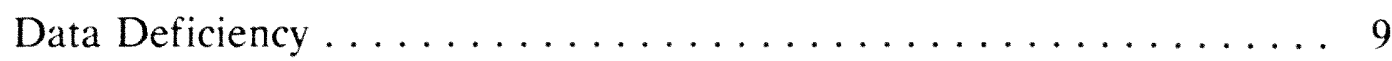

Florida Laws Related to Student Placement . . . . . . . . . . 10

Statement of the Problem $\ldots \ldots \ldots \ldots \ldots \ldots \ldots \ldots \ldots$

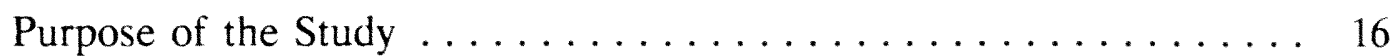

Research Questions .................... 18

Hypotheses . . . . . . . . . . . . . . . . 19

Assurance of Correct Test Administration $\ldots \ldots \ldots \ldots \ldots \ldots 20$

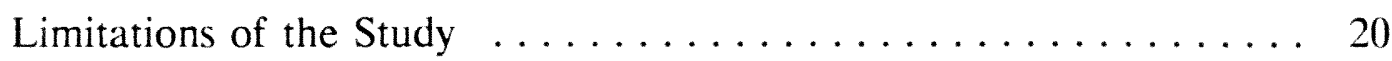

II. REVIEW OF RELATED LITERATURE $\ldots \ldots \ldots \ldots \ldots \ldots \ldots \ldots$

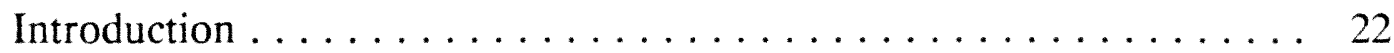

Literature Related to Placement . . . . . . . . . . . 22

Literature Related to the Principles of Second Language Acquisition . 23

Literature Related to Objective Methods of Evaluation as Compared to Subjective Methods of Evaluation $\ldots \ldots \ldots \ldots \ldots \ldots \ldots$ 
Tests Currently in Use for Placement of Adult ESOL Students . . . . 26

Learner Differences and Second Language Acquisition . . . . . . 31

Studies Focusing on the Variables Related to Second Language

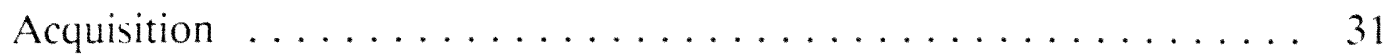

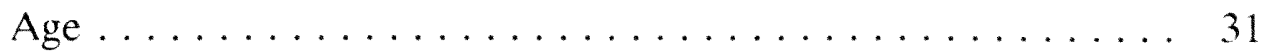

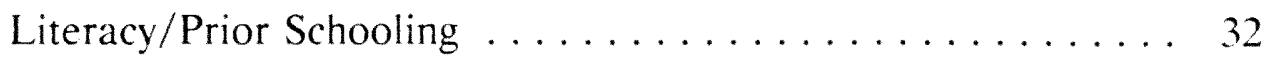

Length of Residence ................ 33

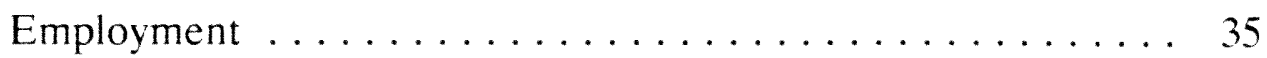

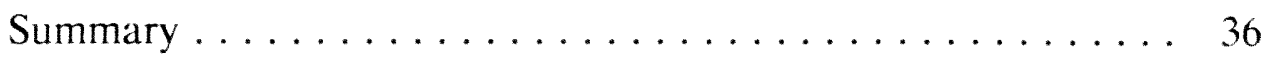

III. METHODOLOGY $\ldots \ldots \ldots \ldots \ldots \ldots \ldots \ldots \ldots \ldots \ldots \ldots$

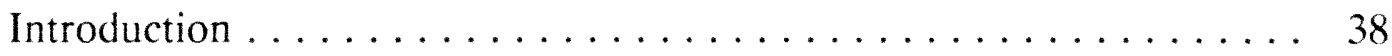

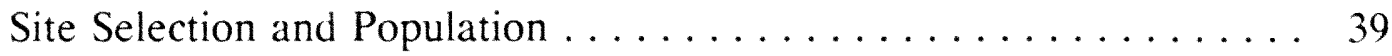

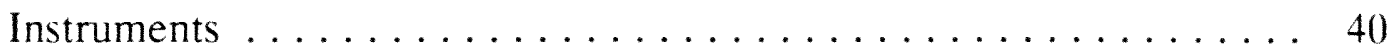

NYS Place Test . . . . . . . . . . . . . 4 40

Writing Sample and Guidelines $\ldots \ldots \ldots \ldots \ldots \ldots \ldots \ldots$

Test of Adult Basic Education (TABE) $\ldots \ldots \ldots \ldots \ldots \ldots 42$

Profile Data Survey . . . . . . . . . . . . . . . 42

Teacher-Validation-of-Placement Form (TVOP) . . . . . 43

Pilot Study . . . . . . . . . . . . . . . . . . . . 44

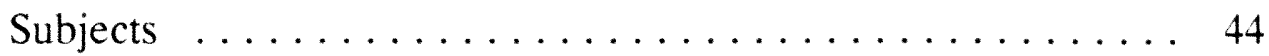

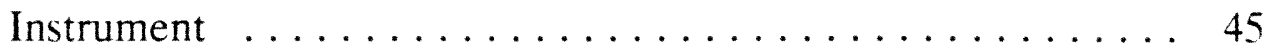

Procedure $\ldots \ldots \ldots \ldots \ldots \ldots \ldots \ldots \ldots \ldots \ldots \ldots$ 
Phase One (Initial Placement) . . . . . . . . . . . . 45

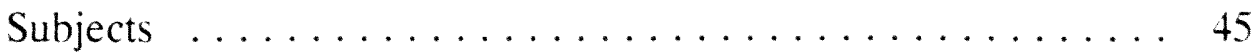

Instruments $\ldots \ldots \ldots \ldots \ldots \ldots \ldots \ldots \ldots \ldots \ldots \ldots$

Procedure $\ldots \ldots \ldots \ldots \ldots \ldots \ldots \ldots \ldots \ldots \ldots \ldots$

Phase Two (Profile Variables) . . . . . . . . . . . . . . . 47

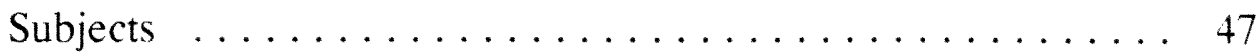

Instruments $\ldots \ldots \ldots \ldots \ldots \ldots \ldots \ldots \ldots \ldots \ldots \ldots$

Procedure ....................... 47

Procedure for Analysis of the Data . . . . . . . . . . . . . 49

Primary Research Question . . . . . . . . . . . . . . 49

Null Hypothesis, $\mathrm{H}_{0} \ldots \ldots \ldots \ldots \ldots \ldots \ldots$. . . . . . . 49

Subsidiary Research Question One ............. 50

Null Hypothesis, $\mathrm{H}_{1} \ldots \ldots \ldots \ldots \ldots \ldots \ldots \ldots$

Subsidiary Research Question Two ............. 51

Null Hypothesis, $\mathrm{H}_{2} \ldots \ldots \ldots \ldots \ldots \ldots \ldots \ldots \ldots$

Subsidiary Research Question Three ............. 52

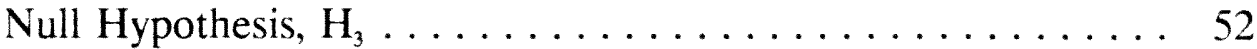

Subsidiary Research Question Four ............ 52

Null Hypothesis, $\mathrm{H}_{4} \ldots \ldots \ldots \ldots \ldots \ldots \ldots \ldots$

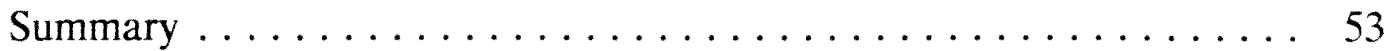

IV. ANALYSIS OF THE DATA $\ldots \ldots \ldots \ldots \ldots \ldots \ldots \ldots \ldots \ldots$

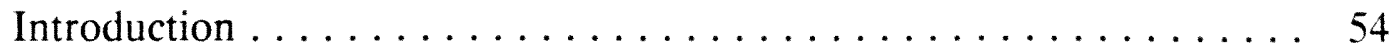


Analysis of the Data for the Pilot Study . . . . . . . . . . . . . 54

Pilot Sample .................... 54

Correct and Incorrect Placements $\ldots \ldots \ldots \ldots \ldots \ldots \ldots$

Summary of Correct and Incorrect Placement Data in the

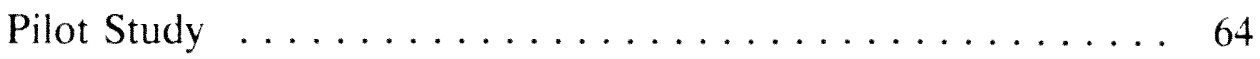

Comparison of Descriptive Data for Whiddon Levels and NYS

Place Test Levels in the Pilot Study . . . . . . . . . . . 64

Summary of Descriptive Data for Whiddon Levels and NYS

Place Test Levels in the Pilot Study . . . . . . . . . 70

Analysis of the Sample for Phases One and Two $\ldots \ldots \ldots \ldots 70$

Analysis of the Data for Null Hypothesis, $\mathrm{H}_{0} \ldots \ldots \ldots \ldots \ldots$

Summary of the Data Analysis for $\mathrm{H}_{0} \ldots \ldots \ldots \ldots \ldots 72$

Analysis of the Data for Null Hypothesis, $\mathrm{H}_{1} \ldots \ldots \ldots \ldots \ldots$

Summary of the Data Analysis for $\mathrm{H}_{1} \ldots \ldots \ldots \ldots \ldots 77$

Analysis of the Data for Null Hypothesis, $\mathrm{H}_{2} \ldots \ldots \ldots \ldots 1$

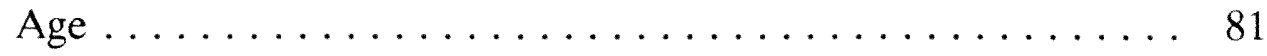

Prior Schooling $\ldots \ldots \ldots \ldots \ldots \ldots \ldots \ldots \ldots \ldots \ldots$

Length of Residence $\ldots \ldots \ldots \ldots \ldots \ldots \ldots \ldots \ldots \ldots$

Employment $\ldots \ldots \ldots \ldots \ldots \ldots \ldots \ldots \ldots \ldots \ldots \ldots$

Summary of the Data Analysis for $\mathrm{H}_{2} \ldots \ldots \ldots \ldots 4$

Analysis of the Data for Null Hypothesis, $\mathrm{H}_{3} \ldots \ldots \ldots \ldots \ldots$

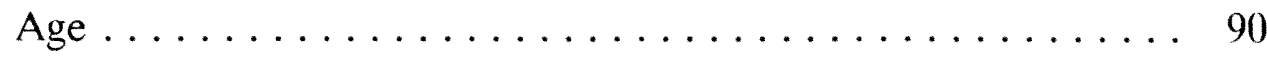


Length of Residence $\ldots \ldots \ldots \ldots \ldots \ldots \ldots \ldots$

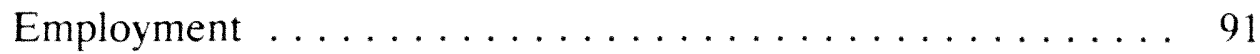

Summary of the Data Analysis for $\mathrm{H}_{3} \ldots \ldots \ldots \ldots$. . . 91

Analysis of the Data for Null Hypothesis, $\mathrm{H}_{4} \ldots \ldots \ldots \ldots$

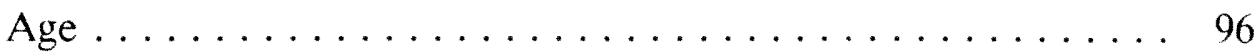

Prior Schooling $\ldots \ldots \ldots \ldots \ldots \ldots \ldots \ldots \ldots \ldots$

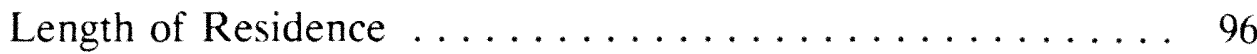

Employment $\ldots \ldots \ldots \ldots \ldots \ldots \ldots \ldots \ldots \ldots \ldots$

Summary of the Data Analysis for $\mathrm{H}_{4} \ldots \ldots \ldots \ldots \ldots$

V. Conclusion, Discussion, Implications, and Recommendations . . . . . 100

Introduction . . . . . . . . . . . . . . . . . . . . 100

Pilot Study: Conclusions and Discussion $\ldots \ldots \ldots \ldots \ldots \ldots \ldots$

Phase One and Phase Two: Conclusions and Discussion . . . . . . 101

Implications and Recommendations . . . . . . . . . . . . 104

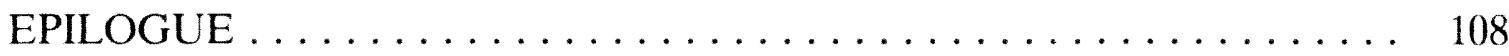

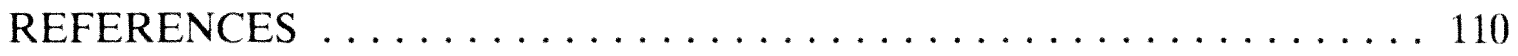

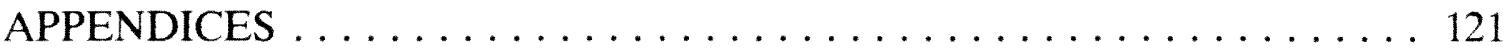

Appendix A, Interviews With Haitian Educators and

Community Leaders . . . . . . . . . . . . . . . . 121

Appendix B, Description of MELT Levels . . . . . . . . . . 123

Appendix C, Description of Whiddon's ESOL Levels . . . . . . . . 125 
Appendix D, Student Writing Sample ............... 146

Appendix E, Portions of the NYS Place Test and New York State Adult

ESOL Curriculum ........................ 149

Appendix F, Profile Data Survey . . . . . . . . . . . . . . 179

Appendix G, Teacher-Validation-Of-Placement Form . . . . . . . 181

Appendix H, Registration Form $\ldots \ldots \ldots \ldots \ldots \ldots \ldots \ldots$

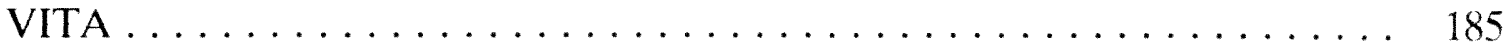




\section{LIST OF TABLES}

Table

Title

Page

1. Placement Results According to Teacher Level (TLEV) and NYS Place

Test Level (NYSLEV) in the Pilot Study . . . . . . . . . . . . 57

2. Placement Results According to Teacher Level (TLEV) and Department

Coordinator Level (DCLEV) in the Pilot Study $\ldots \ldots \ldots \ldots \ldots$

3. Comparison of the Number of Correct and Incorrect Placements

According to NYS Place Test Level (NYSLEV) and Department

Coordinator Level (DCLEV) in the Pilot Study . . . . . . . . . . 59

4. Placement Results According to Teacher Level (TLEV) and NYS Place

Test Level (NYSLEV) for Haitian Creole-Speaking Students in the

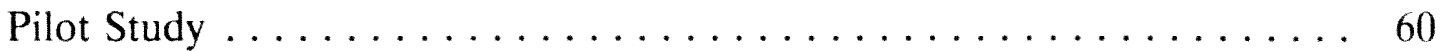

5. Placement Results According to Teacher Level (TLEV) and Department

Coordinator Level (DCLEV) for Haitian Creole-Speaking Students in

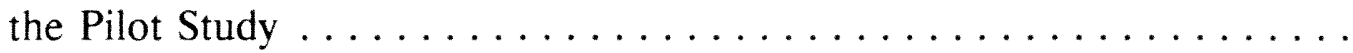

6. Placement Results According to Teacher Level (TLEV) and NYS Place

Test Level (NYSLEV) for Spanish-Speaking Students in the Pilot Study . 62

7. Placement Results According to Teacher Level (TLEV) and Department

Coordinator Level (DCLEV) for Spanish-Speaking Students in the Pilot

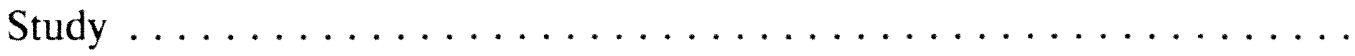

8. Descriptive Data for Department Coordinator Level (DCLEV) and

Teacher Level (TLEV) for Level One in the Pilot Study $\ldots . \ldots \ldots 6$ 
9. Descriptive Data for Department Coordinator Level (DCLEV) and

Teacher Level (TLEV) for Level Two in the Pilot Study . . . . . . . . 67

10. Descriptive Data for Department Coordinator Level (DCLEV) and

Teacher Level (TLEV) for Level Three in the Pilot Study . . . . . . . . 68

11. Descriptive Data for Department Coordinator Level (DCLEV) and

Teacher Level (TLEV) for Level Four in the Pilot Study . . . . . . . . . 69

12. Placement Results According to Teacher Level (TLEV) and NYS Place

Test Level (NYSLEV) for Null Hypothesis, $\mathrm{H}_{0} \ldots \ldots \ldots \ldots \ldots$

13. Placement Results According to Teacher Level (TLEV) and Department Coordinator Level (DCLEV) for Null Hypothesis, $\mathrm{H}_{0} \ldots \ldots \ldots \ldots 74$

14. Number of Correct and Incorrect Placements According to NYS Place Test Level (NYSLEV) and Department Coordinator Level (DCLEV) for Null Hypothesis, $\mathrm{H}_{0} \ldots \ldots \ldots \ldots \ldots \ldots \ldots \ldots \ldots \ldots$

15. Placement Results According to Teacher Level (TLEV) and NYS Place Test Level plus Writing Sample (NYSWRITE) for Null Hypothesis, $\mathrm{H}_{1} \ldots 78$

16. Number of Correct and Incorrect Placements According to NYS Place Test Level (NYSLEV) and NYS Place Test Level plus Writing Sample (NYSWRITE) for Null Hypothesis, $\mathrm{H}_{1} \ldots \ldots \ldots \ldots \ldots \ldots$

17. Summary of Data for Paired T-Test Comparing Degree of Correct Placement According to the NYS Place Test (DOCPNYS) and Degree of Correct Placement According to the NYS Place Test plus Writing Sample (DOCPNW) for Null Hypothesis, $\mathrm{H}_{1} \ldots \ldots \ldots \ldots$ 
18. Comparison of Age and Number of Correct and Incorrect Placements According to the NYS Place Test for Null Hypothesis, $H_{2} \ldots \ldots \ldots$

19. Comparison of Prior Schooling and Number of Correct and Incorrect Placements According to the NYS Place Test for Null Hypothesis, $\mathrm{H}_{2} \ldots 86$

20. Comparison of Length of Residence and Number of Correct and Incorrect Placements According to the NYS Place Test for Null Hypothesis, $\mathrm{H}_{2} \ldots 87$

21. Post Hoc Comparison of Score by Level on the NYS Place Test and Number of Correct and Incorrect Placements for Null Hypothesis, $\mathrm{H}_{2} \ldots 88$

22. Comparison of Employment and Number of Correct and Incorrect Placements According to the NYS Place Test for Null Hypothesis, $\mathrm{H}_{2} \ldots 89$

23. Comparison of Age and Attendance for Null Hypothesis, $\mathrm{H}_{3} \ldots \ldots \ldots 92$

24. Comparison of Prior Schooling and Attendance for Null Hypothesis, $\mathrm{H}_{3}$. 93

25. Comparison of Length of Residence and Attendance for Null

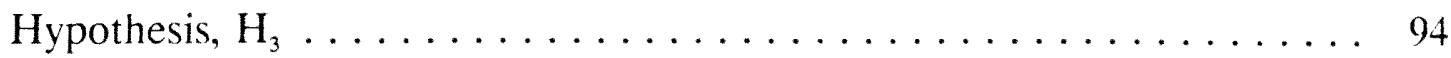

26. Comparison of Employment and Attendance for Null Hypothesis, $\mathrm{H}_{3} \ldots 95$

27. Percentages of Haitian Creole-Speaking Students who Did Not Enter (DNE) Compared to Percentages of Haitian Creole-Speaking Students

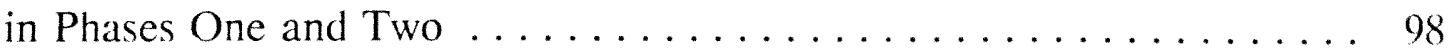




\section{CHAPTER I \\ INTRODUCTION}

Introduction to the Problem

Census data and projections are evidence of the growing number of immigrants in the United States and more specifically, in South Florida. Figures show that, in 1990, the number of immigrants admitted into the United States was 2,598,338 of which 133,333 were admitted into Florida (Shermyen, 1992).

Haitians began arriving in the United States in large numbers in the 1960s. Since the 1970s, increasingly large numbers have settled in South Florida. Their motivation is to escape the oppressive and corrupt political system of Haiti. As a result of this system, the majority of Haitians live near starvation with little hope for the future.

As conditions in Haiti worsen, the number fleeing their country increases. The Sun-Sentinel (Pierre-Pierre, 1992, December) reported that approximately 34,000 Haitian refugees were intercepted at sea in 1991 as they headed for South Florida, a point of illegal entry. Figures for 1992 approached the same number (Ocker \& Pierre-Pierre, Miami Herald, 1992, December). The Miami Herald (Wallace, 1992, May) reports that the total Haitian population in Florida is 84,183 . Florida International University anthropologist, Alex Stepick, challenges these figures as an underestimate of the state's Haitian population by fifty to one hundred percent (Miami Herald, 1992, May). Based on his study for the U.S. Census Bureau, he believes a more accurate figure for the state population lies between 125,000 and 
170,000. Other sources estimate that there are 90,000 Haitians residing in Dade County and approximately 40,000 to 50,000 in Broward (Dibble, Miami Herald, 1990 , January).

Inconsistencies in these data stem from the fact that the 1990 Census did not distinguish Haitians from the total black population, nor did it collect specific information regarding speakers of Haitian Creole (Wingerd, 1990). Although it is generally believed that an undercount exists for immigrant populations who are known to be minimally literate and especially fearful of answering official government questions, Wingerd (1990; personal communication, May, 1993), who conducted an alterative enumeration of a one-block area in Fort Lauderdale, found the census data to be generally accurate for that sample area. She believes that local Haitian mass media had successfully prepared the community for the census process. Furthermore, she feels that the American black population was more difficult to enumerate. Nevertheless, since the census failed to collect accurate ethnicity data regarding minority populations, and Haitians were not distinguished from other black populations, it was virtually impossible to determine their true numbers in the U.S. or in Florida based on these figures. However, recent re-examination of demographic data by the Census Bureau now shows that the number of Haitians in the United States increased by $144 \%$ between 1980 and 1990 from 92,000 to 225,000 (Waggoner, 1993). According to Savain, bilingual education consultant on Haitian language and culture, these figures still underestimate the size of the Haitian population since the estimated Haitian population in Florida is close to 200,000 and 
Haitian populations in New York City and Boston are nearly as large (R. E. Savain. personal communication, August 25, 1993).

The influx of immigrants noticeably impacts the job market. Labor projections indicate that the majority of new entrants into the workforce in the next fifteen years will be women, minorities, and immigrants (Kolberg \& Smith, 1992). Skill shortages will arise in middle level jobs which require formal education beyond high school (Kolberg \& Smith, p. 125). A recent study of male immigrant earnings indicates that, in 1988 , one third of the male immigrant population did not have a high school diploma as compared to thirteen percent of the native male workforce population (Sorenson \& Enchautegui, 1992). In the same study, Sorenson and Enchautegui state that the male immigrant workforce population increased from six to nine percent between 1979 and 1989 . The fact remains that the immigrant population is not only increasing, but largely unprepared to function within the community and unable to meet the demands of the workforce (Carnevale, Gainer, \& Meltzer, 1990). In South Florida, the Haitian immigrant population will be one of the major groups to require immediate attention and assistance.

Immigrants in Florida Schools

According to the fiscal report for 1991 prepared by Gardner, a University of South Florida professor, the number of limited English proficient (LEP) students served in Florida's adult education programs increased from 86,160 students in 1986 to 113,233 students in 1991 (Gardner, 1992). Figures presented in Florida's Multicultural Review Task Force Report (1991) indicate that one hundred countries 
of origin outside of the United States are represented in Florida's student population. Florida school districts reported more than forty-nine native languages (1991). According to the School Board of Broward County, in South Florida, its Department of Adult and Community Education documented seventy-five countries of origin for its adult students in March, 1991. The highest percentage (30.93\%) of LEP students came from Haiti. (Please note that the term LEP is used here interchangeably with PEP, potentially English proficient).

Broward County Schools' 1992-1993 report, Foreign/PEP Student Impact, which includes data for kindergarten through twelfth grade children, describes its diverse student population with over one hundred countries of origin and more than sixty-six languages. Numbers collected by country for the 1992-1993 school year indicate the largest number of Broward's newly registered school children (521) from a non-English speaking country came from Haiti. Numbers collected by language show that new registrations for Haitian Creole-speakers $(1,131)$ were second in number to Spanish-speakers $(3,186)$, who obviously represent many more countries. It is likely that this report on Broward's school children reflects comparable data for Broward's adult population.

Demographic information obtained from Broward County Schools Information Services in May, 1993 documents a total of 3,522 Haitian limited English proficient (LEP) students in Broward's Adult and Community Education programs. Among the adult centers and community schools, the Whiddon Adult Center served the largest number of Haitian adults (571), surpassed only by Off-Campus North 
(746). However, the latter is not a single site but is comprised of numerous smaller sites.

Clearly, the immigrant population on the national, state, and local levels is growing, as well as its enormous impact on school systems. Providing education to this diverse and expanding LEP population is a tremendous challenge. Thus far, much of the focus has been on the education of LEP children. In Broward County, with its large Haitian population, the accurate and efficient assessment and placement of Haitian adult LEP students is a matter which demands additional investigation.

\section{Limitations of the Available Data}

It is important to note the limitations of the currently available data. Recently, Florida statewide student surveys have begun to collect national origin data on "speakers of languages other than English (SLOTE)" profiles (Olsen, 1991). This documentation will enable researchers to extract descriptive data for specific populations, such as Haitians. Unfortunately, these data also have limitations. Although there appears to be an increased concern for the number of LEP students as evidenced by more counties reporting LEP figures, data collection methods among districts within the state vary and reveal a lack of uniformity (Olsen, 1991; personal communication, May, 1993).

Other inconsistencies exist regarding ethnic information which is self-reported on student registration forms. Since the individual may designate any racial group he/she desires to affiliate with, it is the researcher's experience that Haitians may 
write $\underline{\mathrm{H}}$ for Haitian unaware that this letter represents Hispanic in ethnic coding. To undermine data accuracy even more, individuals may not report their true country of origin. For example, some Haitians identify themselves as Bahamians. Background of the Haitian people

Haiti is situated in the Caribbean about five hundred fifty miles from the United States. It occupies the western third of the island of Hispaniola, sharing it with its Spanish-speaking neighbors in the Dominican Republic. The national language of Haiti is Creole; the official languages are Creole and French. According to Rorro (1992), whose 1988 doctoral dissertation deals with academic achievement of Haitian LEP students in New Jersey public high schools, French was used as the language of the government, the school, and the educated elite while Creole was spoken by the total population. As described in an official document published by the Haitian government, La Reforme Educative (1982), and also in Rorro (1992), the education reform movement of the 1980 s introduced Creole in the schools as the language of instruction for the primary grades. Creole was recognized in the 1987 Haitian Constitution as one of the two official languages of the country (1992). Usage of Creole in government and in business is increasing.

Although the government has adopted an official spelling of Creole, continuing disagreement and debate regarding a standardized written form has limited the availability of written material. As a result, many Haitians, including teachers, are still unable to read and write Creole. There are now programs for teachers to receive training to improve their skills in Creole. These programs are 
still in the beginning stages (R. E. Savain, personal communication, August 25, 1993).

Savain notes there is increasing discussion as to the name of the language, Haitian Creole or Haitian, with the latter slowly gaining support.

Nevertheless, the available written material, in French or Creole, is largely beyond the economic means of the general population. Consequently, Haitians rely heavily on oral communication and memorization and their literacy skills, in French or Creole, are not strong. As described by Rorro (1992) and others, formal Haitian education is characterized by the authoritarian role of the teacher, enforcement of strict discipline, rote memorization of facts, respect for the teacher, and obedient acceptance. These factors strongly influence the behavior and attitudes of Haitians. Although Haitians revere education, it is largely inaccessible to the masses due to the system of government, the extreme poverty of the people, and the small budget allocated to education, especially in the rural areas where the majority of the people live (R. E. Savain, personal communication, August 25, 1993).

\section{Literacy Deficiency}

The recent heavy influx of Haitian immigrants to South Florida has brought to the school system a group of students noticeably deficient in native language literacy skills. This conclusion is supported by the HRS Refugee Programs Update (Spinthourakis, 1993, February) which reports that less than thirty percent of the Haitian population, in Haiti, is literate. Stepic (1992) estimates that twenty percent are literate while according to Savain, this figure is closer to fifteen percent (R. E. Savain, personal communication, August 25, 1993). The Haitian immigrant 
population in Florida largely consists of illiterates, who lack basic reading and writing skills, and those minimally literate, who have less than six years of formal schooling (Spinthourakis, 1993; Stepick, 1992). Limited literacy and lack of prior schooling lead to a high rate of frustration, failure, and drop-out among these students. Their ability to independently function and participate in the community is, therefore, substantially jeopardized.

A tabulation of the numbers of Haitian students who registered and took the Test of Adult Basic Education (TABE) at Whiddon Adult Center during the period August 1992 through June 10, 1993 shows that forty-three percent (956 of 2,242) of the limited English proficient (LEP) students were Haitian. Ninety-seven percent (929 of 950 ) of the Haitians tested had TABE scores equal to or less than (5.9), the basic skills level. Only three percent (27 of 956) had TABE scores equal to or greater than (6.0). Approximately fifty-six percent (539 of 956) did not have enough English language skills to take the test and/or scored (0.0). These conclusions regarding adult basic skill levels are based on a hand-count of student data cards on file at Whiddon's Guidance Office since TABE scores are presently not part of the computer database for adult students.

Currently, the TABE is required by the district as an entry test for all adult students in state funded classes. However, the TABE is designed for assessment of basic skills in an English-speaking population. It does not distinguish between those lacking basic skills and those lacking English language skills. Using an instrument designed to assess basic skills in English inflates the number of illiterates in the LEP 
population and stigmatizes that population by identifying as illiterate those who may be literate in their native language (Vargas, 1986; Wiley, 1991).

According to Schilit (in Spinthourakis, 1993; Schilit \& Nimnicht, 1990) the ability of the Haitian immigrant to read and write English is a positive advantage when seeking and maintaining employment. His recent study of Haitian immigrants, prepared for the Florida Department of Health and Rehabilitative Services, links proficiency in English with higher levels of schooling and employment (1990). The report, which surveyed newly legalized Haitians and Hispanics in Florida, documents that the average educational level for farm workers and unskilled workers was 3.6 years; and for skilled workers, 7.1 years. Based on these findings, the report suggests that in order to help Haitians become productively employed, they should be encouraged to begin or continue to take English classes.

\section{Data Deficiency}

Numerous searches of clearinghouse databases revealed that the studies dealing with limited English proficient students focus primarily on the needs of children. In response to the growing concerns of educators, researchers are only now directing some attention to the needs of adults. The majority of adult studies which do exist are based on data drawn from Hispanic or Asian populations. Information specific to Haitian adults is sparse.

Details contained in this study relating to the demographics, background, and literacy of the Haitian people were corroborated by interviews with Haitian educators in South Florida, as well as one educator who currently lives and works 
in Port-au-Prince, Haiti (see Appendix A). The data reported are consistent with the beliefs of those interviewed. However, there was some concern over the statement that the Haitian population in Florida largely consists of illiterates. Although there are professionals in the Haitian community who have a high level of education, it is difficult to estimate what proportion of the total Haitian population in South Florida they represent. There is agreement that the proportion will be different according to the particular geographic area described.

\section{Florida Laws Related to Student Placement}

The Lulac, et al. v. the Florida State Board of Education, et al, generally known as the META Consent Decree (1990), refers to a court order between the set of clients in a class action represented by the Multicultural Educational Training Advocacy, Inc. (META) and the Florida State Board of Education. It requires that the educational rights of limited English proficient (LEP) students be adequately addressed through a mandated program of statewide educational standards and guidelines. The agreement specifically refers to identification and assessment, equal access to "appropriate programs" including adult education, and monitoring of student language acquisition. Citing the first section, assessment must utilize a testing instrument approved by the Florida Department of Education (Section I, subsection $\mathrm{C}$, paragraph 2e). However, the guidelines also state that a school district may use a district developed or adapted test procedure to assess a student's limited English proficiency provided that the Department of Education determines that the instrument and standards are valid and reliable measures. 
The list of state approved tests for ESOL, revised August 19, 1992, as reported by Broward County Schools Department of Multicultural Student Affairs, does not include any test appropriate for adults. Since, in the first section of the META guidelines, it is indicated that "each test shall be administered in accordance with the publisher's instructions," (Section I, subsection C, paragraph 2a) it cannot be assumed that a test intended for children would have the same validity and reliability for adults (Henning, 1987).

The following phrases in the Consent Decree refer to adults:

LEP students are entitled to equal access to other appropriate programs such as ...adult education... Programs described in this section shall be provided to LEP students in a manner appropriate to their level of English language proficiency and must provide equal access to the program's subject matter and benefits including understandable instruction... (Section III, subsection A).

The Florida Statutes incorporate the requirements addressed by the META Consent 1)ecree and stipulate that instruction must be provided to limited English proficient students in a manner which is accomplished as "rapidly as possible" (Section 233.058, Florida Statutes, 1993).

Thus far, the statewide guidelines derived from the Consent Decree have been applied to programs for children in K-12. A technical assistance paper (TAP) published by Florida's Bureau of Adult and Community Education (1993) attempts to clarify the responsibilities of the local education agencies and maintains that the guidelines do not apply to adult education except in the case of LEP students enrolled in adult education classes for high school credit. The report emphasizes that "adult LEP students must have equal access to program subject matter, content, 
and benefits; and instruction and services need to be made understandable to them" (p. 3).

At a recent meeting of Haitian educators (April, 1993), Stefan M. Rosenzweig. an attorney for Florida Rural Legal Services, Inc. and co-council for the META Consent Decree, reaffirmed that the Consent Decree has not been applied to adults. He stresses that any government funded education program must provide equal opportunity and equal access. He feels confident that state implementation of the guidelines of the decree will soon be extended to include adults. This issue continues to be debated by Florida Department of Education administrators.

At present, the state requires that one of four tests be used to determine the basic skill level of students enrolled in state funded adult education programs (Rule 6A-6.014(4), Florida Administrative Code, amended 1989). As stated in the School Board of Broward County Policy Handbook (Rule 6.7, updated 1990) either the full battery or survey form of the Test of Adult Basic Education (TABE) must be administered to all adult students in general education programs funded by the state. The TABE is a norm-referenced test which means that it evaluates ability against a standard based on the performance of a group; this implies prior test administration to a large sample of that population (Henning, 1987).

Based on the researcher's experience as an ESOL teacher, the TABE is inappropriate for use with limited English proficient students. Since the test was not intended for use with the LEP population, the validity of the test for this population is questionable. Norms reported in the TABE manual (1987) make no mention of 
LEP adults. Furthermore, according to Jackson (in Sticht, 1990), the lowest level of the TABE will be frustrating for students with below grade 3.0 skills. In addition, Jackson states that test items include content which has a middle class orientation. Still, this test is required by the state and Broward County, following state requirements, administers the TABE to its adult ESOL students. Recognizing shortcomings of the TABE, the Florida Department of Education has granted a waiver, on a case by case basis, for those ESOL students who are unable to read the test due to their lack of basic English skills. The TABE requirement is currently under review by the Florida Department of Education (J. Dodd, program specialist, personal communication, January 27,1994$)$.

The Broward County English for Speakers of Other Languages [Adult] Curriculum Guide (1991) recommends Mainstream English Language Training (MELT) Student Performance Levels (SPL) as descriptors of the four ESOL levels: preparatory, beginning, intermediate, and advanced. The ESOL Curriculum Guide suggests TABE correlations with these instructional levels as follows:

$\begin{array}{lll}\text { LEVEL } & \text { TABE } & \text { MELT } \\ \text { Preparatory } & 0-1 & 0 \text {-II } \\ \text { Beginning } & 1.0-3.9 & 0 \text {-III } \\ \text { Intermediate } & 4.0-6.9 & \text { IV-VI } \\ \text { Advanced } & 7.0-8.9 & \text { VII-IX }\end{array}$

The ESOL Curriculum Guide further recommends that placement be based on preexisting records, interviews with a guidance counselor, score on a placement 
instrument, ability to complete a teacher-made test, interview with the ESOL program coordinator, and evaluation by the classroom teacher. Although the ESOL

Curriculum Guide does not recommend any specific placement test, it suggests the following criteria for an appropriate instrument:

free from cultural bias, specifically designed for adult learners of English as an additional language, does not require implementation of a limited program whose validity is dependent upon follow-up use of intrinsic teaching-learning materials and post-test instruments, and remains compatible as a basis of comparison when subsequent instruction is delivered through an eclectic approach (1991, p. 8).

Statement of the Problem

The tremendous increase in the number of limited English proficient adults forces educators to attend to two salient problems which have not been adequately addressed. The first deals with the difficulty of placing students into programs divided into levels. At present, few tests are designed to place minimally literate limited English proficient adults into community education programs (Alderson, C., Krahnke, K., \& Stansfield, C., 1987). The available tests have drawbacks which in many cases limit their usefulness (Alderson, et al., 1987). The TABE, which is required, does not adequately reflect differences among minimally literate ESOL beginners who typically all score $(0.0)$. Furthermore, the TABE clearly does not meet any of the criteria for a placement test as described in the Guide. For these reasons, the TABE is not useful as a placement tool for students in programs where large numbers of students fall into the category of minimally literate LEP. Therefore, whereas Broward's ESOL Curriculum Guide describes four ESOL levels and suggests corresponding Mainstream English Language Training (MELT) levels 
(see Appendix B), it does not adequately describe a standardized method for placement into those levels. The Whiddon Adult Center bases its curriculum on a combination of that suggested in the district curriculum guide along with its in-house developed strands (see Appendix C).

It has been the researcher's experience that, very often, the teacher relies on informal assessment to measure students' language proficiency for placement and for advancement. Although informal, non-threatening qualitative feedback is consistent with adult education (Knowles, 1984), the results may not be accurate and may very well negatively impact a student's motivation by violating a more fundamental principle of supplying meaningful input at the correct instructional level (Krashen, $1985)$.

The second problem under consideration in this study is the effect of certain profile variables on placement of Haitian adults. Teachers who lack an awareness and understanding of the affect of these variables on placement and English language acquisition are unable to adequately address the linguistic needs of their Haitian students. The research dealing specifically with Haitian Creole-speaking adult students is scarce. A review of the literature revealed a number of studies dealing with variables related to second language acquisition in general. Such variables include age, prior schooling, length of residence, and employment. While much of the available research may be generalizable to the Haitian population, further investigation is indicated since we cannot assume this to be true. Additional research may yield results which will enable educators to better understand the 
varying linguistic needs of this population so that they may identify and apply more appropriate and effective teaching strategies.

In summary, the need exists for accurate and efficient standardized measures for initial placement of adult Haitian students into adult and community education ESOL classes. There is also a need for better understanding of the interrelationship of learner variables which may affect oral language proficiency and initial placement of Haitian adult students.

Purpose of the Study

Placement is not an end in itself, but only the beginning of the process which seeks to establish the appropriate level and starting point at which meaningful instruction may occur. A placement test is only a tool to draw one sample of a student's performance at a given moment and can be affected by factors such as anxiety and fatigue. A framework of additional profile data, for example, age, prior schooling, length of residence, and employment must also be considered if accurate and efficient placement is to be accomplished. The purpose of the present study is to determine if a standardized placement instrument (the NYS Place Test, New York State's placement test for English as a second language adult students, normed on a predominately Spanish-speaking adult population) is as accurate as, or more accurate than, subjective judgement of a department coordinator for initial placement of Haitian adult students into ESOL levels. Since the NYS Place Test is an oral assessment, the study seeks to determine if degree of accuracy is enhanced by sampling the student's writing in English (see Appendix D). This study will also 
determine if there exists a significant relationship between profile data (age, prior schooling, length of residence, or employment) and accuracy of placement method, as well as the relationship between profile data and those who withdrew or did not enter a class after registering.

The reader will note that New York State's placement test for English as a second language adult students will hereafter be referred to as the NYS Place Test or the NYS test. NYS is usually pronounced as nice. The reader will also note that the term residence, as used in this study, refers to the length of time the student has lived in the United States and is not used in any legal sense whatsoever.

The NYS Place Test has reportedly been successful in placing Spanishspeaking students in adult and community education programs (Mooney, 1991). Further investigation is needed to determine if the test is effective for Haitian adults. The NYS Place Test will be considered effective if it is at least as accurate as the subjective coordinator method of placement. Accuracy is me:- ured by classroom teacher and student responses based on the student's ability to function at the instructional level of the class. Degree of accuracy, in this study, will be numerically expressed as degree of correct placement on a scale of one to six where six indicates perfect placement. The test will be considered more efficient (cost effective) if placement can be accurately accomplished by a teacher aide, trained to administer the NYS Place Test.

In summary, this study will focus on two aspects of language learning. The first deals with accurately identifying the current skill level (Cross, 1981; Knowles, 
1984; Krashen, 1985) of Haitian LEP adults so that meaningful instruction can take place. The second deals with the interrelationship of factors affecting oral language proficiency of Haitian students and their participation in an adult literacy program. As Ellis (1985) states, "the literature suggests certain aspects of second language acquisition which are relatively stable and generalizable, if not to all learners than at least to large groups of learners" (p. 4). The results of this study may assist adult educators in the appropriate placement of Haitian students into ESOL classes. It may increase awareness as to the demographic variables, gathered upon intake, which may impact on correct placement.

\section{$\underline{\text { Research Questions }}$}

The study is concerned with a primary research question and four subsidiary questions. The primary research question is the following: Is there a significant difference in the number of correct placements of Haitian adult students into four ESOL levels based on the use of the NYS Place Test compared to subjective department coordinator assessment as measured by teacher and student responses?

The primary research question suggests four subsidiary questions:

1. Is there increased accuracy of placement of Haitian adult ESOL students by employing a writing sample, in English, in combination with the NYS Place Test as opposed to employing the NYS Place Test alone?

2. Is there increased accuracy of placement of Haitian adult ESOL students by considering profile data (age, prior schooling, length of residence, or employment) in combination with the NYS Place Test? 
3. Is there a significant relationship between the profile data (age, prior schooling, length of residence, or employment) and withdrawal from the program for Haitian adult ESOL students?

4. Is there a significant relationship between the profile data (age, prior schooling, length of residence, or employment) and DNE (did not enter, that is, those who registered but did not come to any class) for Haitian adult ESOL students?

Hypotheses

The following null hypotheses were derived from the research questions:

$\mathrm{H}_{0}$. There is no significant difference in the number of correct placements of Haitian adult students into four ESOL levels based on the use of the NYS Place Test compared to subjective department coordinator assessment as measured by teacher and student responses.

$\mathrm{H}_{1}$. There is no increased accuracy of placement of Haitian adult ESOL students by employing a writing sample, in English, in combination with the NYS Place Test as opposed to employing the NYS Place Test alone.

$\mathrm{H}_{2}$. There is no increased accuracy of placement of Haitian adult ESOL students by considering profile data (age, prior schooling, length of residence, or employment) in combination with the NYS Place Test.

$\mathrm{H}_{3}$. There is no relationship between the profile data (age, prior schooling, length of residence, or employment) and withdrawal from the program for Haitian adult ESOL students. 
$\mathrm{H}_{4}$. There is no relationship between the profile data (age, prior schooling, length of residence, or employment) and DNE (did not enter) for Haitian adult ESOL students.

\section{Assurance of Correct Test Administration}

It is assumed that the testers administer the TABE as prescribed in the test manual. Additionally, it is assumed that the department coordinator does not deviate from the way in which assessment has been accomplished in the past. Finally, it is assumed that the teacher aide who administers the NYS Place Test does so in the manner prescribed in the test instructions and video.

In order to ensure correct administration of the TABE, testers have received inservice training and have attended meetings with the guidance director. In order to ensure correct administration of the NYS Place Test, both the teacher aide and the researcher read the accompanying manual, watched the video, and discussed procedures and scoring. The researcher also discussed test administration and scoring with Mooney (personal communication, October 13, 1992; January 29, 1993) who conducted extensive research utilizing the NYS Place Test and administered the test on the video. The researcher shared this information with the teacher aide.

\section{Limitations of the Study}

This study is concerned only with initial placement of Haitian adult ESOL students into community education classes and the variables affecting second language acquisition which may impact on the accurate determination of level. The relationship of student achievement (positive gain) and successful initial placement 
is beyond the scope of this study since it would introduce too many variables. For example, factors such as motivation, health, transportation, child care, financial and/or immigration problems may contribute in varying degrees to an adult student's retention and success in an ESOL program. Therefore, it cannot be assumed those who withdraw from the program have been inaccurately placed and that those who stay have been successfully placed.

This study addresses native language literacy only in a limited sense in that it considers self-reported information on the use of native language, Creole or French, and years of prior schooling. It does not address the issues of formally assessing native language literacy and providing native language instruction for subsequent transition into ESOL classes. The effect of level of native language literacy on placement procedures and retention are recommended topics for further research. 


\section{CHAPTER II \\ REVIEW OF RELATED LITERATURE}

\section{Introduction}

"Our concern should not be with effective retention but with effective teaching," emphasized Tinto in a paper presented at the 1988 National Conference of the Advising Association in Miami, Florida. Tinto was referring to principles of effective student retention with regard to college students. Many of those principles can also be applied to students in any adult education program. Specifically, Tinto underscores the response to students' needs and interests, and a commitment to offer all students the opportunity to learn.

This is especially important in adult education programs which are voluntary, as well as open-entry/open-exit. It is the researcher's experience, and supported by the relevant literature, that adults who are improperly placed are more likely to withdraw from the program (Bean, Partanen, Wright, \& Aaronson, 1989; Brod, 1990). Providing instruction which is personally meaningful (Knowles, 1984) and at a level which is comprehensible to the student (Krashen, 1985) are essential to the student's continuation in the program.

\section{Literature Related to Placement}

Programs for literacy instruction should consider learners' characteristics, backgrounds, needs, and future goals (Fingeret, 1989; Santopietro \& Peyton, 1991). Inappropriate placement and instruction which is not relevant to students' needs contribute to learner attrition in adult literacy programs (Bean, et al., 1989; Brod, 
1990). Affective variables have been shown to influence second language attainment and are at least as important as level of knowledge (Tarone \& Yule, 1989). The differential effects of these factors on the learner's second language attainment are diverse and subjective (1989).

The student-centered approach as supported by Knowles (1984), Krashen (1985), and Savignon (1991), among others, focuses on the needs of the learner rather than on the subject matter. Knowles maintains that participation is influenced by internal and external motivation, the learner's self-concept, and the orientation to learn which is problem-centered. The implication is that presentation of material which is too difficult negatively impacts self-esteem. Material which is too easy causes the student to feel that time is being wasted. Consequently, the placement process must assess the student's current ability, as well as variables in the student's background.

\section{Literature Related to the Principles of Second Language Acquisition}

Krashen (1985) claims that all second language acquisition depends on comprehensible input and affective factors which allow the individual to receive that input. Affective factors, such as anxiety, lack of motivation, and lack of selfconfidence can effectively block second language acquisition. This, basically, is the main idea behind Krashen's Input Hypothesis. Under favorable conditions, Krashen maintains that input should be supplied just beyond the current level of competence. He refers to this level as $(i+1)$, where $\underline{i}$ is input.

In a study involving French immersion students, Swain (1985) hypothesized 
that students also need comprehensible output, that is, practice in producing language with feedback for error correction. Planned, communicative-rich activities can facilitate the process. Communicative competencies (listening, speaking, reading, and writing) develop independently (Tarone \& Yule, 1989). Language learners who do not have the opportunity for practice with attention to error correction may become relatively fluent but may lack grammatical accuracy. Errors can become fossilized, almost ingrained, and quite difficult to correct. Without feedback for error correction, students may still be able to develop effective oral communication skills which surpass their writing skills (1989).

The research now shows that second language learning is multidimensional, influenced by the interaction of a number of variables (Long, 1990). Long suggests that comprehensive second language acquisition theories need to explain the commonalities in different types of learners, as well as the variability of learner backgrounds and exposure. In addition, these theories must explain environmental factors, affective factors, and age related differences.

Literature Related to Objective Methods of Evaluation as Compared to Subjective Methods of Evaluation

The Tylerian approach (Tyler, 1969) provides a basis for educational planning and evaluation. This systematic method of pre-defining measurable objectives at the outset of instruction is also supported by Gagne and Briggs (1974), Briggs (1977), and Mager (1984). According to Mager, clearly stated instructional objectives provide the basis for assessment of the success of instruction. A primary 
characteristic of this approach is that it is material-centered.

Scriven (1972) points out that the term, subjective, does not necessarily mean unreliable, opinionated, and biased, just as the term, objective, does not always mean reliable and factual. Scriven suggests that reliability depends largely on the qualities, training, and experience of the individual evaluator.

Guba and Lincoln (1991) propose a naturalistic method of evaluation which relies on human beings as the instrument of measurement. This holistic approach is defended by Guba and Lincoln as reliable and valid. They claim that flexibility and insight contribute to the effectiveness of this type of evaluation. In agreement with Scriven, Guba and Lincoln point out that bias can be found in quantitative, as well as, qualitative methods. Both the method of inquiry and how it is accomplished, specifically, how it is utilized by the investigator, must be considered in determining validity and reliability.

In the context of the current study, the multidimensional and interrelated aspects of language proficiency may not be adequately assessed by quantitative methods alone (Johnson \& Saville-Troike, 1992). An objective test such as TABE is an example of a quantitative data collection instrument. Alternatively, a qualitative approach utilizes multiple methods in a process called triangulation (1992; Guba \& Lincoln, 1991). Degrees of credibility are achieved by comparing data from a variety of sources. Methods which are loosely defined and subjective are difficult to validate. In the placement process, purely subjective assessment, more closely aligned with qualitative methodology, may lack sufficiency of data due to time 
constraints inherent in the placement process. A placement decision which potentially impacts an individual's future may be hastily determined and inaccurate.

The option suggested here is a blend of methodologies in the form of standardized judgement along with multiple subjective indicators. In other words, a standardized process which is flexible and open-ended, yet has demonstrated validity, may provide a more comprehensive and accurate assessment of an individual's second language proficiency than either of the two previously mentioned assessment methods. Furthermore, since communicative skills have been found to develop independently (Tarone \& Yule, 1989), utilization of additional indicators may detect variability among language skill areas so that a more accurate assessment is accomplished.

\section{Tests Currently in Use for Placement of Adult ESOL Students}

In their comprehensive review of the literature on second language acquisition research methodology, Larsen-Freeman and Long (1992) concluded that the definition of language proficiency and its measurement remain unresolved. Variability in the learner's communicative skills poses numerous problems for assessment (Tarone \& Yule, 1989). Standardized tests generally capture only a limited aspect of the learner's proficiency, provide an incomplete picture of the learner's language ability, and fail to reflect the communicative approach, prevalent in current second language teaching methodology (1989; Sticht, 1990).

A review of placement tests for minimally literate adults in community education programs uncovered a limited number of tests available for that 
population. Wilcox (1991), who studied assessment of adult ESOL students, points out the need for adult ESOL placement instruments which are effective, simple to use, and inexpensive in time and cost. This need is echoed in a recent article in ESL Notes (1993, February) which further emphasizes that existing ESL tests confuse the assessment of basic skills and language proficiency. The researcher of the current study does not intend to present an exhaustive list of available adult ESOL placement instruments. However, some examples will follow. As mentioned in the Assessment of Adult Limited English Proficient Students: A Guide to Available Instruments (Texas Education Agency, 1990), no single placement or assessment instrument will be completely adequate in assessing the complex skills which make up language ability.

Examples of tests available for adult ESOL are: the Basic English Skills Test (BEST), the Delta Oral Placement Test (DOPT), The Henderson-Moriarty ESL Placement Test (HELP), the John/Fred Test, the Palm Beach School District (PBSD) Oral Proficiency Test, and the NYS Place Test. The researcher will briefly describe the advantages and disadvantages of each test considered for this study.

The BEST appears to be highly valid and reliable but expensive and time consuming (Eakin \& Ilyin, in Alderson et al., 1987). A new short form, developed while this study was in progress, has recently become available and can be considered for placement purposes. The DOPT is short but provides little guidance for the examiner and no provision for examiner training. In addition, the statistical data obtained from the test are difficult to interpret (Brown, in Alderson et al., 
1987). The HELP Test has no available technical information regarding validity or reliability (Anderson, in Alderson et al., 1987). The John/Fred Tests are short and useful for placement but sample only a limited number of survival skills (Kharde, in Alderson et al., 1987).

The Palm Beach School District (PBSD) Oral Placement Test, currently being administered in Palm Beach adult ESOL programs, is reported to successfully place incoming students into one of seven ESOL levels. A second instrument is needed to place advanced level students. Informal feedback by teachers and program coordinators who use the test seems to be favorable. The PBSD Oral Placement Test is based on state competencies and appears to be more of an achievement test than a proficiency test. According to its author, G. Strei (personal communication, June 28, 1993), rigorous standardized field testing has not been performed. Validity and reliability data have not been collected. The effectiveness of the test is based solely on subjective consensus among the educators working with the test.

Another test, the NYS Place Test, is a relatively new oral placement test which is reported to be valid and reliable in placing adult limited English proficient students into four ESOL levels in community education programs. The NYS Place Test was developed by Bodman and Kharde (1987) and the New York State Adult ESL Test Committee (see Appendix E). The test consists of three sections: oral warm-up, basic literacy screening in English, and oral assessment with pictures which tests listening and speaking skills of adult LEP students. Only the latter is scored for placement. The test is designed to be completed in fifteen minutes or less, 
depending on the oral proficiency of the student. Statistical results from field testing have been analyzed and completed for Form B. The interrater reliability (.96) appears to be quite good. Test scores were highly correlated (.83) with New York State prescribed adult ESOL levels (NYS Place Test Form B Validation Project, 1992; NYS Place Test Administrator's Manual, 1987).

Eight ethnic categories were defined in the norming group for the NYS Place Test. Nearly seventy percent were Hispanic while Southeast Asian, Western European, Eastern European, Chinese, Middle Eastern, African and Other made up the balance of the sample (New York State Education Department, 1992). Since the dominant population was Spanish-speaking in the norming sample, the data cannot be generalized to Haitians without further investigation. Mooney (1991), who claims first time use of the NYS Place Test for research purposes, also utilized a sample which was primarily Spanish-speaking. Mooney suggests further research with the NYS Place Test using other language groups such as speakers of Haitian Creole (1991; personal communication, October 13, 1992 and January 29, 1993).

A limitation of the NYS Place Test is that it only samples oral/aural skills. It is the researcher's experience that a writing sample, in English, is very helpful in making placement decisions, especially for those students whose oral proficiency far outweighs their reading and writing skills. Based on research on transfer of cognitive skills (Cummins, Swain, Nakajima, Handscombe, Green, \& Tran, 1984) and the researcher's knowledge of the Haitian culture, their level of literacy, and general preference for oral communication, it follows that one would expect the oral 
proficiency of Haitian students to be superior to their writing proficiency. Therefore, inclusion of a writing sample may help identify students who demonstrate high variability in oral and writing skills. Further investigation may show that the addition of a writing sample, in English, enhances the predictive validity of the NYS Place Test for ESOL placement.

The NYS Place Test appears to blend aspects of quantitative and qualitative philosophies. In the quantitative realm, scoring is standardized and norm-referenced. Field testing demonstrated high interrater reliability. In the qualitative realm, responses are open-ended and require a degree of subjectivity on the part of the tester. Scoring of responses on a scale of zero to two can be described, in the researcher's opinion, as standardized judgement. Although there are specific gui : lines for scoring to make it as objective as possible, a human being is processing the student's language and determining level according to the points awarded to each response. The test has other humanistic qualities in that it seems to be nonthreatening. After three incorrect responses, a fail-safe question is asked, one that the student is likely to be able to answer, ending the test on a positive note. Other favorable attributes are ease of administration and a one-on-one interview format lasting fifteen minutes or less. The interview format and open-ended oral questions reflect the intent of the communicative curriculum which is student-centered rather than material-based. The available data suggest that the NYS Place Test is effective for the norming population and may be appropriate for the population under investigation in the current study. 
Learner Differences and Second Language Acquisition

Ellis (1985) describes the following factors which provide a framework for second language acquisition research: situational, input, learner differences, learner processes, and linguistic output.

1. Situational factors include the language environment where learning occurs. They may be naturalistic (outside the classroom) or formal (inside the classroom).

2. Input refers to the nature of linguistic input; the language received by the learner.

3. Learner differences include a variety of factors which have been linked in previous research as potentially influential in second language acquisition. These factors include age, motivation, intelligence, personality, and cognitive style.

4. Learner processes refer to the learner's cognitive or linguistic strategies, the strategies utilized in language acquisition.

5. Linguistic output is the learner's use of language which appears to be somewhat predictable.

\section{Studies Focusing on the Variables Related to Second Language Acquisition}

Age. Among researchers who agree on the existence of age-related differences in second language acquisition, there remains disagreement on the reasons for the differences (Larsen-Freeman \& Long, 1992). Some data suggest that younger learners are superior to older learners in attainment of near-native proficiency in pronunciation skills of the target language (Larsen-Freeman \& Long, 
1992; Spurling \& Ilyin, 1985). Early studies reported that adults and older children may initially learn the second language faster than younger children while the ultimate attainment of the younger learner will usually be superior (Krashen, Long, \& Scarcella, 1979; Dulay, Burt, \& Krashen, 1982). Initial gains of older learners soon disappear and younger children eventually demonstrate superior language attainment, especially in near-native pronunciation (Kennedy, 1988; Krashen, et al. 1982; Krashen, et al. 1979). D'Anglejan and Renaud (1985) found that greater age was related to learning difficulties.

Tsakonas states that many studies fail to satisfactorily account for age-related differences in learner rate and eventual second language attainment (1990). McLaughlin $(1987 ; 1992)$ maintains that in controlled research studies, adult and adolescent learners outperform young children even in the area of pronunciation. McLaughlin cites numerous studies supporting the superiority of the older learner.

The literature regarding the consequence of age on second language learning is inconclusive. The question, whether or not there is an age above which second language learning is more difficult, remains unresolved (Kennedy, 1988). Nevertheless, it is clear that age should be considered as a factor in second language acquisition and was included as a variable in the current study.

Literacy/prior schooling. Cummins (1984) suggests a common underlying language proficiency such that literacy in the first language assists in the acquisition of the second language. Findings of Collier (1987) and others support positive transfer of native language literacy skills. In their study of immigrants learning 
French in Montreal, D'Anglejan and Renaud (1985) point out that poorer learners were characterized by less schooling. Those with higher levels of illiteracy experienced the greatest learning difficulties. According to Spurling and Ilyin (1985), high school graduation was the most significant overall factor related to second language learning. In a study carried out with high school LEP students, Ariza (1990) corroborates what others have found, that lack of native language literacy and academic skills represents a barrier to successful education and academic achievement. Saville-Troike (1991) also observes that students with higher levels of prior schooling are better able to make inferences and interpret new material within the context of that which was previously learned.

Based on the available research, it appears that literacy and prior schooling are related to second language acquisition. As mentioned earlier, determination of native language literacy is suggested but beyond the scope of this study. Hence, prior schooling was included as a factor in the current study. It is duly noted that problems exist quantifying self-reported data, especially in studies involving people from other cultures (Johnson \& Saville-Troike, 1992).

Length of residence. Studies which discuss length of residence as a variable appear to operationalize the definition in terms of exposure, that is, formal school acquisition versus naturalistic acquisition. Some adults are able to utilize feedback from informal exposure to the language. Those who have the ability to develop their own rules acquire language more easily. Two essential components of a formal learning environment for adults appear to be isolation of rules and feedback for 
error correction.

Krashen distinguishes between acquisition and learning. Acquisition is the result of informal exposure while learning is a conscious activity. For Krashen, language acquisition is largely an unconscious process resulting from experience using the target language (Tarone \& Yule, 1989). An opposing view is presented by McLaughlin (1987) who believes that acquisition is assisted by the formal learning of rules in the classroom setting. In agreement with the latter, Ellis (1984) suggests that learners who receive instruction outperform those who receive only exposure in the natural setting. Ellis adds that this finding may be confounded by motivation which would be different for those who voluntarily attended school as compared to those who didn't.

The literature review revealed contradictory findings regarding length of residence in the country of the target language. Oyama (1978), Spurling and Ilyin (1985), Garreton (1991), and others did not find length of residence significantly related to second language acquisition. Spurling and Ilyin note that in their study, length was measured in years, not months, which may have contributed to this outcome. They suggest that appropriate measurement would have yielded significance.

Existing research appears to be inconclusive regarding length of residence (exposure) and second language acquisition. In the context of the current study, sufficient evidence exists to warrant further investigation of oral proficiency resulting from exposure to the target language in the host country. Therefore, length of 
residence was included in the current study.

Employment. Gardner (1980) cites numerous studies linking affective variables and motivation to second language acquisition. Gardner and Lambert (1972) distinguish between integrative and instrumental motivation. The former refers to the situation in which the individual desires to identify with and become a part of the culture of the target language. The latter refers to the situation in which the individual is motivated to learn the target language as a means of obtaining something personally useful, such as employment. Based on their research, Gardner and Lambert (1972) concluded that integrative motivation would result in superior language acquisition. Larsen-Freeman and Long (1992) cite numerous studies challenging the findings of Gardner and Lambert. They also mention a reinterpretation by Gardner and Lambert, that instrumental motivation can be very effective in second language acquisition, especially for ethnic minorities (1972, p. 141-142).

In their study of students learning French, Gardner, Lalonde, and Moorcroft (1985) demonstrate that a positive affective predisposition influences the rate of second language acquisition. Students who are motivated work harder to learn material which is of interest to them. This implies that students may make more effort to learn English if they believe it will help them obtain a job or higher wages. Contradictory findings are presented by Mooney (1991) who suggests that employment is negatively correlated with second language acquisition. Mooney observes that employed students are more tired and have less available study-time 
than their unemployed counterparts.

Although debate continues regarding the differential strengths of integrative and instrumental motivation as they relate to second language acquisition, the literature clearly suggests a relationship. An extensive review of the research revealed few studies linking employment to English language proficiency of second language learners. However, since obtaining and maintaining employment can be considered as instrumental motivation, there is sufficient support in the literature for the inclusion of employment as a learner variable in the current study.

\section{Summary}

The model of learner differences, proposed by Ellis (1985) and adapted by Mooney (1991), and the review of the related literature support the selection of the learner variables, age, prior schooling, length of residence, and employment to be investigated in this study. Based on the literature, it is suggested that appropriate methods of assessing English deficiency, as well as a knowledge of a student's history, are both required for accurate placement. Although it may be possible to accurately place a student based on department coordinator judgement, in an institutional setting, it is necessary to utilize a process that accurately places students into levels without having to rely on the ability of one individual. The NYS Place Test appears to be appropriate for LEP students in community education programs. Since numerous factors influence the language acquisition process making the language experiences of each student unique, Larsen-Freeman and Long (1992) recommend that teachers consider background information of each individual student 
when making instructional decisions. Test results in the context of relevant profile data may provide a more comprehensive picture of the learner and may help the educator make judgement calls that are validated so that more meaningful instruction can be provided to better serve student needs. 


\section{CHAPTER III \\ METHODOLOGY}

\section{Introduction}

This study compared a standardized placement instrument for adult ESOL, the NYS Place Test, used alone and in conjunction with a writing sample and student profile data, to subjective judgement of a department coordinator in order to determine if the former is as effective as, or more effective than, the latter in initial placement of Haitian adult ESOL students. The study sought to determine whether there exists a significant relationship between accuracy of placement method and the student profile data variables: age, prior schooling, length of residence, or employment. The study also considered withdrawal from the program and those students who registered but did not enter a class in order to compare profile data and determine if common variables exist among students who did not complete the program.

The study comprised three parts: a pilot study and phases one and two of the basic study. The pilot study was initiated to determine the effectiveness of the NYS Place Test for the population under investigation, as well as the range of NYS Place Test scores corresponding to Whiddon's ESOL levels. Phase one considered the initial placement of Haitian adults into ESOL classes, with and without the utilization of a writing sample in English. Phase two considered profile data variables that may impact on English language acquisition of Haitian adults, withdrawal from the program, and the classification of Did Not Enter (DNE). 


\section{Site Selection and Population}

The site selected for this study was the Gene A. Whiddon Adult Center, part of the Broward County Schools, in Fort Lauderdale, Florida. The School Board of Broward County is the eighth largest fully accredited school district in the nation. The Whiddon Adult Center has one of the largest ESOL programs in Broward County. Eighteen day and evening classes draw approximately two thousand two hundred forty limited English proficient students from Broward, as well as Dade and Palm Beach Counties. The top three countries of student origin are Haiti, Colombia, and Brazil. According to information supplied by the Broward County Schools Department of Adult and Community Education, the ESOL population at Whiddon appears to be representative of the ESOL population in Broward County.

Another reason for selecting this site was an expressed need for improvement of the current placement method used at the Gene A. Whiddon Adult Center. According to the 1988 Final Report of the Visiting Committee for the Southern Association of Colleges and Schools (SACS), the committee cited deficiencies in the current placement procedures for ESOL students at Whiddon. The 1992-93 [SACS] Visiting Committee Report again recommended that provision be made for "efficient, accurate, and personalized placement." Moreover, interviews with supervisors, job incumbents, and subject matter experts, indicated a desire for a valid and efficient placement technique. Discussion with representatives from four other Broward sites as well as Broward's Adult ESOL Coordinator indicated that initial placement of adult ESOL students is a county-wide problem; each site devised its 
own in-house procedure based largely on subjective guidelines.

\section{Instruments}

NYS Place Test. The standardized instrument utilized in this study was the NYS Place Test, Form B (Appendix E). It was the researcher's judgement that the corresponding New York State prescribed adult ESOL levels, as described in the NYS Place Test manual and by Mooney who did extensive research and testing using the NYS Place Test (Mooney, 1991; personal communication, October 13, 1992; January 29, 1993), appeared to be similar to those of Whiddon (Appendices B and C). After initial comparisons, the researcher determined that Whiddon's preparatory level, beginning one (A), and beginning one (B) corresponded to NYS level one. The remaining Whiddon levels (two, three, and four) appeared to correspond to NYS levels two, three, and four respectively. However, it must be noted that although similar, these are two different curricula, and in some instances levels overlap.

In all phases of the study, data were collected separately for each section of level one. There was a problem regarding fit between the four levels of the NYS Place Test and the six levels in the field. For the purposes of this study, the subdivision of Whiddon's level one into three groups was ignored. In order to see if there exists a fit between the NYS levels and the levels in the field, data were collapsed for Whiddon's three groups of level one. It is the researcher's intent to retain the data from each of the level one classes for further analysis.

The norming population in the New York State field tests and the Whiddon target population share commonalities in the sense that both groups included adults 
with minimal basic skills enrolled in community education settings. Differences existed in the native language of the groups, since those in the field test were primarily Spanish-speaking and those at Whiddon were Haitian Creole-speaking.

The NYS Place Test is a standardized, norm referenced test comprised of three basic parts: a warm-up, a basic literacy screening in English, and an oral assessment which requires the student to respond to a series of pictures. The examiner scores responses on a scale of zero to two. A score of zero is given for no response, a non verbal response, or an inappropriate response. A score of one is given for a response that indicates comprehension but is not grammatically correct. A score of two is given for a response which indicates comprehension and correct grammatical usage. The student's score leads to placement into one of four ESOL levels. The test lasts up to fifteen minutes, depending on the oral proficiency of the student. If the student is unable to respond, the examiner concludes the test after the student scores three consecutive zeros. In order to ensure that the test ends on a positive, the final question utilizes a "fail safe" technique which elicits a correct response from the student.

Writing sample and guidelines. The writing sample, used in combination with the NYS test, was designed by the researcher in 1988, as a tool to assist the department coordinator in determining student placement. Both the researcher and the ESOL coordinator devised a list of guidelines for placement based on the writing sample in an effort to reduce subjectivity (Appendix D). Generally, students complete the task in five to fifteen minutes. Analysis of the writing sample is 
accomplished in one or two minutes and provides the coordinator with additional information on the student's ability to apply English grammar rules.

Test of Adult Basic Education (TABE). The survey form of the TABE (Locator with test $\mathrm{E}, \mathrm{M}, \mathrm{D}$ or $\mathrm{A}$ ) was administered to all incoming ESOL students who were able to take the test. Correspondence between TABE scores and Mainstream English Language Training (MELT) levels, as described in the Broward ESOL Curriculum Guide, are given on page 13 of this study. In the actual placement process, TABE scores were only considered in that they were low, moderate, or high. In general, guidelines regarding TABE scores were not useful for this population.

It is the researcher's experience that level one students usually scored zero or first grade level; level two students typically obtained a low score corresponding to first, second, or third grade level; level three students often had a score corresponding to fourth, fifth, or sixth grade level; and level four students often scored seventh through twelfth grade levels. It is the school's policy that any student who scored at the ninth grade level or above is automatically placed in level four which is part of the adult high school program. The researcher notes, based on personal experience, the correspondence of ESOL level and TABE score is highly inconsistent. It is not surprising to find level two and three ESOL students with very low TABE scores.

Profile data survey. The survey was devised by the researcher to collect selfreports on the following profile data: years of schooling, employment, length of 
residence, and ability to read the newspaper and write letters in the native language (see Appendix F). The survey instrument was based on the sociolinguistic questionnaire developed by Ramirez (in Mooney, 1991), modified and translated into Creole and English at the Whiddon Adult Center. The Creole translation was originally provided by P. Holly, a Haitian teacher aide at Whiddon. This translation was later revised by R.E. Savain, consultant in Haitian language and culture and author of Haitian-Kreol in Ten Steps (1993). The survey was administered by the multilingual Haitian teacher aide during a short, informal interview conducted in the student's native language.

Teacher-Validation-of-Placement Form (TVOP). The researcher created this form to determine the accuracy of the placement decision (see Appendix G). The form requested the classroom teacher to rate the accuracy of placement on a scale of one to six and to record student feedback, if any. The scale of six was used because Whiddon has four ESOL levels with level one divided into an additional three levels. As a cross check of information, the form also requested the teacher to write the student's correct placement level.

Teacher level refers to the placement level suggested by the classroom teacher on the TVOP. The classroom teacher made a determination as to the degree of correct placement based on the student's actual classroom performance. Since teacher level is based on actual student performance in the classroom, it was used as the measure against which the NYS test level and the department coordinator assigned level were compared. 


\section{Pilot Study}

The NYS Place Test was piloted to determine if, in fact, this test was appropriate for the study and to reveal any major concerns regarding test administration. The pilot study compared the New York State placement scores to department coordinator prescribed levels for students already placed in existing classes. The pilot phase, carried out in February and March, 1993, helped the teacher aide gain familiarity with administration of the test and supplied baseline data to determine how the NYS Place Test levels correspond to Whiddon's existing ESOL levels.

Subjects. Since the norming population for the NYS Place Test and the sample selec d in Mooney (1991) were predominantly Spanish-sł. king and Whiddon's population is predominantly Haitian Creole-speaking, both Haitian Creole and Spanish-speaking students were included in the pilot study. Whiddon's Spanishspeaking students served as a basis of comparison in the pilot study. If the test proved to be valid for other Spanish-speaking students it should be valid for Whiddon's Spanish-speaking students. Any inconsistency for Whiddon's Spanishspeaking students would cast doubt on the effectiveness of the test for the target population and impact on the continuation of the study.

Students who had been identified by their teacher as "correctly placed" were given the NYS Place Test in order to establish baseline data and compare the NYS and Whiddon ESOL levels. Stratification of the sample ensured that a sufficient number of students was selected from each of four levels. At least eight students 
were tested from each level. Level one was subdivided into three instructional levels: preparatory, beginning one (A), and beginning one (B). Student placement data were collected from each of these classes.

Instrument. The NYS Place Test was administered and scored according to the instructions provided in the manual and on the video. Scoring procedures in the test manual suggest the following: level one (0-15), level two (16-26), level three (2734), and level four (35-54). However, according to the video, if the student's score is $(16,27$, or 35$)$ placement should be adjusted to the lower level. This procedure was followed by the test administrator (teacher aide). Therefore, as suggested by the video, the following adjustments applied: level one (0-16), level two (17-27), level three (28-35), and level four (36-54). The teacher aide made every attempt to create a supportive non-threatening atmosphere.

Procedure. The NYS Place Test was administered to forty-nine students identified as correctly placed by their classroom teacher, thereby providing the data to establish a range for existing Whiddon's instructional levels: preparatory, beginning one (A) and one (B), intermediate (two and three), and advanced (four). As previously noted, data were collected separately for each section of level one preparatory, beginning one (A), and one (B) and collapsed to create a total for all of level one. Data analysis consisted of comparison of descriptive statistics, crosstabulation, and chi-square with contingency coefficient $p=.05$.

\section{Phase One (Initial Placement)}

Subjects. The sample for phase one, initial placement, consisted of all new 
incoming Haitian Creole-speaking adults who registered for day ESOL classes at Whiddon from April, 1993 through June, 1993. Only new students, not those previously enrolled, were considered. All Haitian students, except those who entered on the two days when the teacher aide was absent or during two time periods of special ESOL department events, were part of the sample. The total number of subjects tested was sixty-five. Both the interview and the test were voluntary. Students, who for any reason, did not wish to be interviewed or tested were not required to participate. No one declined.

Instruments. The instrument for this part of the study was the NYS Place Test, Form B. Data were also collected from instruments utilized in the existing placement process: the student's registration form (see Appendix $H$ ), the Test of Adult Basic Education (TABE), and the student's writing sample.

Procedure. The sample of sixty-five newly registered Haitian Creole-speaking students was assigned to the test group. Those in the test group were given a britt oral and written interview in their native language. Student background information was collected utilizing the profile data survey in the student's native language.

The interview was followed by the NYS Place Test, which took up to fifteen minutes to complete. The test was administered solely in English by a teacher aide. Documentation of the test score was recorded for later use. All students in the test group were placed as usual by the department coordinator.

The department coordinator placed the student utilizing subjective evaluation based on an informal assessment of the student's English language proficiency, the 
TABE score, and interpretation of the writing sample. This, the current method of placement, continued throughout the study. However, the coordinator did not have knowledge of the student's NYS placement score. The classroom teachers were told that both methods of placement were being used and to provide feedback as to the degree of correct placement and correct level. After three to seven days, the classroom teacher filled out the TVOP for each new student in the test group. This created the measure of correct placement. As in the pilot, data from the three sections of level one were collapsed.

Phase Two (Profile Variables)

Subjects. This part of the study attempted to determine if any of the profile variables under investigation, ages, prior schooling, residence, or employment, improved the accuracy of placement for Haitian Creole-speaking students at Whiddon. The study did not seek to generalize findings to all Haitian adult ESOL students. The second phase of the study utilized the same subjects $(\underline{N}=65)$ previously tested with the NYS Place Test at the Whiddon Adult Center.

Instruments. The instruments used to gather data for this phase were the NYS Place Test, the Teacher-Validation-of-Placement Form (TVOP), the student's registration form, and the profile data survey. Only information readily available upon intake, such as, age, prior schooling, length of residence in the United States, and employment was utilized. The student's self-reported expertise in Creole or French was noted.

Procedure. Student background information was gathered using the profile 
data survey for the following variables: native language (Creole or French), years of schooling, length of residence, and employment. The survey was given in the native language during the initial oral interview conducted by a multilingual (Haitian Creole, French, Spanish, English) teacher aide. Information regarding age was obtained from the student registration form. The independent variables were age, prior schooling, length of residence, and employment. The dependent variable was the number of correct placements based on a comparison of placement level as determined by subjective department coordinator, the NYS Place Test, and data obtained from the TVOP.

The number of withdrawals, as well as the number who did not enter the class after registering (DNE), were monitored by checking notations on class registers which used specific withdrawal codes and by tabulating test and profile data. Utilizing these data, a profile of students who withdrew was created. Profile data were also analyzed and compared for those students who were classified in the study as DNE.

For the purpose of this study, those who registered, took both the NYS Place Test and TABE, and were placed in a class but did not enter on a class roster, were considered DNE. In the school's usual recordkeeping, DNE students are those who appear on the roster but did not enter. This would typically apply to returning students, not only to new students who registered but did not enter. However, in this study which was concerned with initial placement of new students, the term DNE was used for new students who did not enter. 
Primary research question. Is there a significant difference in the number of correct placements of Haitian adult students into four ESOL levels based on the use of the NYS Place Test compared to subjective department coordinator assessment as measured by teacher and student responses?

Null hypothesis, $\mathrm{H}_{0}$. There is no significant difference in the number of correct placements of Haitian adult students into four ESOL levels based on the use of the NYS Place Test compared to subjective department coordinator assessment as measured by teacher and student responses.

Analysis of the data for the first null hypothesis included descriptive statistics, crosstabs, and chi-square with contingency coefficient, $\mathrm{p}=.05$. Analysis began with descriptive statistics to compare the number of correct placements for both the department coordinator and the NYS Place Test. Two $4 \times 4$ crosstabulations were created displaying the NYS test level (NYSLEV) by teacher level (TLEV) and department coordinator assigned level (DCLEV) by teacher level (TLEV).

The sum of the cells for each left to right diagonal was computed to determine the number of correct placements by NYS and DC respectively. The values for NYS and DC were utilized in $2 \times 2$ crosstabulations to show frequency data including the number of correct and incorrect placements for each of the two methods. The chi-square statistic was computed to further analyze the frequency data. According to Gay (1992) and Kerlinger (1986), chi-square is the appropriate test of significance for frequency data which represents mutually exclusive categories 
on the nominal scale. Statistical significance is determined by comparing observed results with expected results. The significance of the chi-square was set at the .05 level.

The contingency coefficient is one of several measures of association based on the chi-square statistic utilized to minimize the affect of sample size and further explain the nature of the association (Norusis, 1990). Since the chi-square statistic is affected by sample size its value should be interpreted cautiously (Norusis, 1988; Joreskog in Pedhazur, 1982).

Subsidiary research question one. Is there increased accuracy of placement of Haitian adult ESOL students by employing a writing sample, in English, in combination with the NYS Place Test as opposed to employing the NYS Place Test alone?

Null hypothesis, $\mathrm{H}_{1}$. There is no increased accuracy of placement of Haitian adult ESOL students by employing a writing sample, in English, in combination with the NYS Place Test as opposed to employing the NYS Place Test alone.

Analysis of the second research compared placement by the NYS Place Test alone and in combination with a writing sample. Using a table of random numbers, the sixty-five writing samples were randomly divided into three sets, two sets of twenty-two and one set of twenty-one. An instruction sheet was attached to each sample in the set indicating the student's NYS score. Three teachers were selected based on years teaching in this program and their experience teaching in more than one level. Each teacher had at least three years experience teaching ESOL at 
Whiddon including experience with more than one level. The teachers were randomly assigned to reevaluate the sets, one set per teacher, by comparing the NYS score to the writing sample and indicating agreement or disagreement as to the student's placement level. In the case of disagreement, the teacher was directed to determine and write the placement level (one to four) on the instruction sheet. Names of students and their TABE score and placement level, normally recorded on these samples, were blackened out to avoid influencing the teacher's decision.

A $4 \times 4$ crosstabulation was created to display the frequency data for the NYS plus the writing sample (NYSWRITE) by teacher level (TLEV). The number of correct placements was indicated on the left to right diagonal. Chi-square with contingency coefficient, $\mathrm{p}=.05$, were used to analyze the number of correct and incorrect placements for the NYS Place Test with and without the writing sample.

The degree of correct placement values for the variables NYS and NYSWRITE, recoded on a scale of one to four, were compared using frequency data and means. The data were further analyzed utilizing a paired t-test, $p=.05$. Since degree of correct placement values are continuous data, a paired t-test is appropriate (Norusis, 1988).

Subsidiary research question two. Is there increased accuracy of placement of Haitian adult ESOL students by considering profile data (age, prior schooling, length of residence, or employment) in combination with the NYS Place Test?

Null hypothesis, $\mathrm{H}_{2}$. There is no increased accuracy of placement of Haitian adult students by considering profile data (age, prior schooling, length of residence, 
or employment) in combination with the NYS Place Test.

Data collection included the student's performance on both the NYS Place Test and the TABE, the profile data survey, the writing sample, the registration form, and the TVOP form. Frequency data for each of the profile variables were compared to the number of correct and incorrect NYS test placements. The data were analyzed using descriptive statistics, crosstabs, and chi-square with contingency coefficient, $\mathrm{p}=.05$.

Subsidiary research question three. Is there a significant relationship between the profile data (age, prior schooling, length of residence, or employment) and withdrawal from the program for Haitian adult ESOL students?

Null hypothesis, $\mathrm{H}_{3}$. There is no relationship between the profile data (age, prior schooling, length of residence, or employment) and withdrawal from the program for Haitian adult ESOL students.

The data collection included the responses to the profile data survey, the student's registration form, and the class rosters. The data were analyzed using descriptive statistics, crosstabs, and chi-square with contingency coefficient, $p=.05$. Crosstabs displayed the frequency data for the profile variables in combination with the number of withdrawals. Chi-square with contingency coefficient were used to determine if there was a significant relationship between any of the profile variables and withdrawal.

Subsidiary research question four. Is there a significant relationship between the profile data (age, prior schooling, length of residence, or employment) and DNE 
(did not enter) for Haitian adult ESOL students?

Null hypothesis, $\mathrm{H}_{4}$. There is no relationship between the profile data (age, prior schooling, length of residence, or employment) and DNE for Haitian adult ESOL students.

The data collection included the responses to the profile data survey, the student's registration form, the class rosters, and the placement tests for those students who did not enter a class. The findings were analyzed using frequency data and percentages. Percentages were used to compare the profile variables for the DNEs to percentages in the original population sample.

\section{Summary}

The data analysis was performed to develop an increased understanding of the initial placement of Haitian adult students in four ESOL levels, as well as profile variables, age, prior schooling, length of residence, and employment, collected upon intake, which may impact on the accuracy of placement. Further analysis of the profile data in conjunction with withdrawal and DNE was initiated to suggest common variables which, if known in advance, may prompt educators to devise strategies to better serve the needs of the student. 


\section{CHAPTER IV}

\section{ANALYSIS OF THE DATA}

\section{Introduction}

The chapter is divided into two main parts: analysis of the data for the pilot and analysis of the data for phases one and two of the study. The first analysis begins with a description of the pilot sample $(\underline{N}=49)$ followed by the number of correct and incorrect placements. A comparison of the results for Haitian Creolespeaking students and Spanish-speaking students follows. Descriptive data for Whiddon are compared to NYS ranges in order to evaluate the effectiveness of the test for the population under investigation.

The second part of the chapter, resents a description of the main population under investigation $(\underline{N}=65)$ in phases one and two. The analysis for each null hypothesis tested is reported and summarized.

\section{Analysis of the Data for the Pilot Study}

Pilot sample. The pilot sample $(\underline{N}=49)$ consisted of thirty-three Haitian Creole-speaking and sixteen Spanish-speaking students identified by their teacher as correctly placed in ESOL levels as follows: eight preparatory, eight level one (A), nine level one (B), eight level two, eight level three, and eight level four. The classroom teacher indicated that four students belonged in a different level. Since pilot testing was accomplished over a period of two months, February and March, 1993, some students who may have initially been correctly placed acquired the necessary skills to advance to the next level by the end of the testing period. The 
researcher collected and compared information for department coordinator level (DCLEV) and teacher level (TLEV). TLEV was used as the measure against which both DCLEV and NYS Place Test level (NYSLEV) were compared.

Correct and incorrect placements. The crosstabulation of TLEV and NYSLEV indicated that forty of forty-nine students were correctly placed by the NYS Place Test (see Table 1 on page 57). The nine students incorrectly placed by the NYS test were placed in a level higher than that indicated by the TLEV.

Crosstabulation of TLEV and DCLEV showed that forty-five of forty-nine were correctly placed by the department coordinator (see Table 2 on page 58). It is important to keep in mind that teachers were requested to send for testing those students who were correctly placed. The data indicated that of the four who were incorrectly placed by the department coordinator, three were placed lower than the TLEV.

A chi-square comparing DCLEV and NYSLEV for the number of correct and incorrect placements, with $C=.149$, was not significant $\left(X^{2}=2.22 ; p>.05\right.$, see Table 3 on page 59). Based on the available data, it appears that there was no significant difference in the results of placement method, NYS Place Test compared to department coordinator placement, for Haitian Creole-speaking and Spanishspeaking students who were already placed in existing Whiddon levels.

Crosstabulation of the pilot sample of Haitian students $(\underline{n}=33)$ comparing TLEV and NYSLEV indicated that twenty-eight students were correctly placed by the NYS Place Test and five were incorrectly placed (see Table 4 on page 60). As 
in the total pilot sample, the NYS test placed students higher than the TLEV. Similarly, analysis comparing TLEV and DCLEV for the sample of Haitian students $(\underline{n}=33)$ showed that twenty-nine were correctly placed and four were incorrectly placed (see Table 5 on page 61). For those incorrectly placed, DCLEV was generally lower than TLEV.

Crosstabulation for the pilot sample of Spanish-speaking students $(\underline{n}=16)$ comparing TLEV and NYSLEV indicated that twelve students were correctly placed and three were incorrectly placed by the NYS test (see Table 6 on page 62). Again, those incorrectly placed by the NYS test were placed high. Crosstabulation comparing TLEV and DCLEV indicated that no Spanish-speaking students were incorrectly placed by the department coordinator (see Table 7 on page 63 ). 
Table 1

Placement Results According to Teacher Level (TLEV) and NYS Place Test Level (NYSLEV) in the Pilot Study

$$
\begin{aligned}
& \text { NYSLEV N(\%) } \\
& (\underline{N}=49)
\end{aligned}
$$

\begin{tabular}{llllll}
\cline { 2 - 5 } TLEV & 1 & 2 & 3 & 4 & Total(\%) \\
\hline 1 & 23 & 2 & & & $25(51.0)$ \\
2 & 2 & 4 & 1 & $7(14.3)$ \\
3 & & & 6 & 2 & $8(16.3)$ \\
4 & & & & 9 & $9(18.4)$ \\
Total $(\%)$ & $23(46.9)$ & $4(8.2)$ & $10(20.4)$ & $12(24.5)$ & $49(100.0)$ \\
\hline
\end{tabular}


Table 2

Placement Results According to Teacher Level (TLEV) and Department Coordinator Level (DCLEV) in the Pilot Study

$$
\begin{aligned}
& \text { DCLEV N(\%) } \\
& (\underline{N}=49)
\end{aligned}
$$

\begin{tabular}{|c|c|c|c|c|c|}
\hline 1 & 24 & 1 & & & $25(51.0)$ \\
\hline 2 & 1 & 6 & & & $7(14.3)$ \\
\hline 3 & & 1 & 7 & & $8(16.3)$ \\
\hline 4 & & & 1 & 8 & $9(18.4)$ \\
\hline Total $(\%)$ & $25(51.0)$ & $8(16.3)$ & $8(16.3)$ & $8(16.3)$ & $49(100.0)$ \\
\hline
\end{tabular}

$\begin{array}{llllll}\text { TLEV } & 1 & 2 & 3 & 4 & \text { Total( } \%)\end{array}$


Table 3

Comparison of the Number of Correct and Incorrect Placements According to NYS Place Test Level (NYSLEV) and Department Coordinator Level (DCLEV) in the Pilot Study

Method $\mathrm{N}(\%)$

Number of Placements

NYSLEV

DCLEV

$\operatorname{Total}(\%)$

\begin{tabular}{lccc}
\hline Correct & $40(40.8)$ & $45(45.9)$ & $85(86.7)$ \\
Incorrect & $9(9.2)$ & $4(4.1)$ & $13(13.3)$ \\
Total $(\%)$ & $49(50.0)$ & $49(50.0)$ & $98(100.0)$ \\
& & & \\
\hline
\end{tabular}

Note.

$$
\begin{aligned}
& X^{2}=2.22 ; p>.05 . \\
& C=.149
\end{aligned}
$$


Table 4

Placement Results According to Teacher Level (TLEV) and NYS Place Test Level (NYSLEV) for Haitian Creole-Speaking Students in the Pilot Study

NYSLEV N(\%)

$(\underline{\mathrm{n}}=33)$

TLEV

1

2

3

4

$\operatorname{Total}(\%)$

\begin{tabular}{llllll}
\hline 1 & 16 & 2 & & & $18(54.5)$ \\
2 & & 1 & 2 & & $3(9.1)$ \\
3 & & & 4 & 1 & $5(15.2)$ \\
4 & & & 7 & $7(21.2)$ \\
Total $(\%)$ & $16(48.5)$ & $3(9.1)$ & $6(18.2)$ & $8(24.2)$ & $33(100.0)$ \\
\hline
\end{tabular}


Table 5

Placement Results According to Teacher Level (TLEV) and Department Coordinator Level (DCLEV) for Haitian Creole-Speaking Students in the Pilot Study

$$
\begin{aligned}
& \text { DCLEV N }(\%) \\
& (\underline{n}=33)
\end{aligned}
$$

\begin{tabular}{llllll} 
TLEV & 1 & 2 & 3 & 4 & Total(\%) \\
\hline 1 & 17 & 1 & & & $18(54.5)$ \\
2 & 1 & 2 & & $3(9.1)$ \\
3 & & 1 & 4 & & $5(15.2)$ \\
4 & & & 1 & 6 & $7(21.2)$ \\
Total $(\%)$ & $18(54.5)$ & $4(12.1)$ & $5(15.2)$ & $6(18.2)$ & $33(100.0)$ \\
\end{tabular}


Table 6

Placement Results According to Teacher Level (TLEV) and NYS Place Test Level (NYSLEV) for Spanish-Speaking Students in the Pilot Study

\begin{tabular}{|c|c|c|c|c|c|}
\hline \multirow[b]{2}{*}{ TLEV } & \multicolumn{5}{|c|}{$\begin{array}{l}\text { NYSLEV N(\%) } \\
(\underline{n}=16)\end{array}$} \\
\hline & 1 & 2 & 3 & 4 & Total $(\%)$ \\
\hline 1 & 7 & & & & $7(43.8)$ \\
\hline 2 & & 1 & 2 & 1 & $4(25.0)$ \\
\hline 3 & & & 2 & 1 & $3(18.7)$ \\
\hline 4 & & & & 2 & $2(12.5)$ \\
\hline Total $(\%)$ & $7(43.8)$ & $1(6.2)$ & $4(25.0)$ & $4(25.0)$ & $16(100.0)$ \\
\hline
\end{tabular}


Table 7

Placement Results According to Teacher Level (TLEV) and Department Coordinator Level (DCLEV) for Spanish-Speaking Students in the Pilot Study

$$
\begin{aligned}
& \text { DCLEV N(\%) } \\
& (\underline{\mathrm{n}}=16)
\end{aligned}
$$

\begin{tabular}{llllll}
\cline { 2 - 5 } TLEV & 1 & 2 & 3 & 4 & Total(\%) \\
\hline 1 & 7 & & & $7(43.8)$ \\
2 & 4 & 3 & & $4(25.0)$ \\
3 & & & & 2 & $3(18.7)$ \\
4 & & & & $2(12.5)$ \\
Total $(\%)$ & $7(43.8)$ & $4(25.0)$ & $3(18.7)$ & $2(12.5)$ & $16(100.0)$ \\
\hline
\end{tabular}


Summary of correct and incorrect placement data in the pilot study. Data from the pilot sample, show that students placed incorrectly by the NYS test were placed at a level higher than that indicated by the teacher. NYS Place Test data appear to be consistent for both Haitian Creole-speaking and Spanish-speaking students. Chi-square comparing the two language groups was not computed due to unequal number in each language group and the small size of the Spanish-speaking group. The department coordinator placed Spanish-speaking students more accurately than Haitian Creole-speaking students. It should be noted that the department coordinator is also Spanish-speaking.

Comparison of descriptive data for Whiddon levels (department coordinator and teacher level) and NYS Place Test levels in the pilot study. Descriptive data obtained in the pilot study were compared to determine if the ranges suggested by the NYS Place Test were similar to those at Whiddon. Descriptive data for level one are displayed in Table 8 on page 66. The adjusted range for the NYS test level one (0-16) was lower than the ranges indicated by both DCLEV (1-28) and TLEV (1-26). Outliers refer to values beyond the range in either direction. Outliers for DCLEV and TLEV were three and two respectively, showing that three students according to DCLEV and two according to TLEV were beyond the NYS Place Test range. The means, medians, and modes for both DCLEV and TLEV of the sample seemed to be appropriate compared to the NYS range. Students in Whiddon's level one appeared to have a higher oral proficiency than that indicated by the NYS range. The TLEV was slightly more similar to the NYS range for level one. 
Data for level two students are displayed in Table 9 on page 67. Again, the adjusted range for NYS level two (17-27) was lower than that of Whiddon's level two DCLEV (11-42) and TLEV (24-42). There were six outliers for DCLEV, one low and five high, showing that six students in existing level two classes scored outside the NYS range and five had a higher oral proficiency than the range indicated by the NYS test. There were four high outliers for TLEV indicating that according to the level suggested by the classroom teacher, four students scored outside the NYS range. All four were higher than the NYS level. The mean and median for the sample were high and not appropriate when compared to the NYS range. The modes for DCLEV and TLEV were not similar and appeared not to be appropriate for the NYS range. However, the range for TLEV was more similar to the NYS range. Of all the levels, level two had the most outliers and the most inconsistency.

Data for level three indicate that range for DCLEV (29-42) and TLEV (2942) were similar to each other and similar to the adjusted NYS range (see Table 10 on page 68). Means, medians, and modes for DCLEV and TLEV were similar and slightly higher in comparison to the NYS range. There were two high outliers for both DCLEV and TLEV.

Data for level four ranges were equal for DCLEV (37-50) and TLEV (37-50) and similar to the adjusted NYS level four range (36-54). Means, medians, and modes appeared to be similar and appropriate when compared to the NYS range (see Table 11 on page 69). Data for level four seemed to demonstrate the most consistency. 
Table 8

Descriptive Data for Department Coordinator Level (DCLEV) and Teacher Level (TLEV) for Level One in the Pilot Study

Descriptor

DCLEV TLEV

$\underline{\mathrm{n}}$

25

25

range $(\min / \max )$

$1 / 28$

$1 / 26$

$\underline{\mathrm{M}}$

9.7

9.0

median

7.0

7.0

mode

4.0

4.0

$\underline{\mathrm{SD}}$

7.1

6.0

outliers (low)

0

0

outliers (high)

3

2

outliers (total)

3

2

Note.

$\underline{N}=49$.

Outliers are based on the adjusted NYS Test range for level one, 0-16. 
Table 9

Descriptive Data for Department Coordinator Level (DCLEV) and Teacher Level (TLEV) for Level Two in the Pilot Study

\begin{tabular}{lll}
\hline Descriptor & DCLEV & TLEV \\
\hline$\underline{\mathrm{n}}$ & 8 & 7 \\
range (min/max) & $11 / 42$ & $24 / 42$ \\
$\underline{\mathrm{M}}$ & 28.9 & 30.0 \\
median & 29.0 & 28.0 \\
mode & 11.0 & 28.0 \\
SD & 9.5 & 6.1 \\
outliers (low) & 1 & 0 \\
outliers (high) & 5 & 4 \\
outliers (total) & 6 & 4 \\
\end{tabular}

Note.

$\underline{\mathrm{N}}=49$.

Outliers are based on the adjusted NYS Test range for level two, 17-27. 
Table 10

Descriptive Data for Department Coordinator Level (DCLEV) and Teacher Level (TLEV) for Level Three in the Pilot Study

\begin{tabular}{lll}
\hline Descriptor & DCLEV & TLEV \\
\hline$\underline{\mathrm{n}}$ & 8 & 8 \\
range (min/max) & $29 / 42$ & $29 / 42$ \\
$\underline{\mathrm{M}}$ & 33.8 & 33.9 \\
median & 33.5 & 33.5 \\
mode & 30.0 & 30.0 \\
$\underline{\text { SD }}$ & 4.4 & 4.4 \\
outliers (low) & 0 & 0 \\
outliers (high) & 2 & 2 \\
outliers (total) & 2 & 2
\end{tabular}

Note.

$\underline{N}=49$.

Outliers ar based on the adjusted NYS Test range for level three, 28-35. 
Table 11

Descriptive Data for Department Coordinator Level (DCLEV) and Teacher Level (TLEV) for Level Four in the Pilot Study

\begin{tabular}{lll}
\hline Descriptor & DCLEV & TLEV \\
\hline$\underline{\mathrm{n}}$ & 8 & 9 \\
range (min/max) & $37 / 50$ & $37 / 50$ \\
$\underline{\mathrm{M}}$ & 42.0 & 41.4 \\
median & 40.0 & 40.0 \\
mode & 40.0 & 40.0 \\
$\underline{\text { SD }}$ & 4.3 & 4.4 \\
outliers (low) & 0 & 0 \\
outliers (high) & 0 & 0 \\
outliers (total) & 0 & 0
\end{tabular}

Note.

$\underline{N}=49$.

Outliers are based on the adjusted NYS Test range for level four, 36-54. 
Summary of descriptive data for Whiddon levels and NYS Place Test levels

in the pilot study. In summary, a comparison of descriptive data revealed that the ranges for the NYS Place Test were similar to Whiddon's four ESOL levels when outliers were considered. The ranges seemed to be more similar for levels three and four than for levels one and two. The most inconsistency appeared in level two. Ranges determined from data based on TLEV were closer to the NYS ranges than data based on DCLEV. Supported by the available data from the pilot study, it appeared that the NYS Place Test was a viable test for this population. However, oral proficiency of Whiddon's ESOL students seemed to be higher than levels indicated by the NYS Place Test. Another indicator, such as a writing sample, was considered to enhance the accuracy of the NYS Place Test.

An. the Sample for Phases One and Two

Analysis of the population under investigation $(\underline{\mathrm{N}}=65)$ showed a range in age of participants from nineteen to forty-one, with the majority (fifty-two) between the ages of twenty and thirty. The median age was twenty-five. The range of TABE scores was 0.0 to 5.1 with fifty-three receiving 0.0 .

Years of schooling of participants ranged from one year or less to nineteen. Those who reported one year or less were grouped together for the purpose of data analysis. The data for one student were incomplete. Based on the student's interview, the researcher determined that the student should be grouped in the category of one year or less. The median for years of schooling was ten. The selfreported levels of schooling appear to be higher than expected based on the 
researcher's experience with this population, the review of relevant statistics regarding Haitian literacy, and interviews with Haitian educators. It is important to note that years of schooling and not grade level were reported. At present, official documentation of prior schooling is generally not required for registration in adult ESOL classes.

Residence, or length of stay in the United States, ranged from one month or less to one hundred ten months. Those who reported one month or less were grouped together for the purpose of data analysis. The data for one student, a different student than the one described above, were incomplete. Based on information from the student's interview, the researcher determined that the student should be grouped in the category of one month or less. The median for length of residence was six months.

The majority of the students, fifty $(76.9 \%)$, were unemployed. Since the sample of employed students was small, five part-time and ten full-time, these two categories were grouped together for the purpose of data analysis.

Information gathered from rosters indicated that twenty-five withdrew from the program. After six consecutive absences, the seventh constitutes a withdrawal. Although some of these students re-entered the program during the time period under investigation, for the purposes of this study, information on cause of withdrawal was not examined; only the evidence that they withdrew at least once was factored in. 
Analysis of the Data for Null Hypothesis, $\mathrm{H}_{n}$

$\mathrm{H}_{0}$ : There is no significant difference in the number of correct placements of Haitian adult students into four ESOL levels based on the use of the NYS Place Test compared to subjective department coordinator assessment as measured by teacher and student responses.

Crosstabulation comparing the number of correct placements resulting from the NYS Place Test and department coordinator placement $(\underline{N}=65)$ showed fiftytwo $(80 \%)$ correct and thirteen $(20 \%)$ incorrect placements for the NYS test (see Table 12 on page 73 ); fifty-nine $(91 \%)$ correct and six $(9 \%)$ incorrect for the department coordinator (see Table 13 on page 74). Analysis of the data yielded the chi-square $\left(\mathrm{X}^{2}=3.02 ; \mathrm{p}>.05\right.$, see Table 14 on page 75$)$. The value of the statistic was not significant, indicating that there appears to be no difference between the proportions of observed and expected frequencies between the two methods of placement. The contingency coefficient, $\mathrm{C}=.15$, does not indicate a strong association (Kerlinger, 1986).

Summary of the data analysis for $\mathrm{H}_{0}$. It appeared that there was no significant difference between placement results attained through the NYS Place Test or department coordinator. Therefore, the primary null hypothesis could not be rejected. The data suggested that the NYS Place Test was at least as accurate as department coordinator placement. 
Table 12

Placement Results According to Teacher Level (TLEV) and NYS Place Test Level (NYSLEV) for Null Hypothesis, $\mathrm{H}_{0}$

\begin{tabular}{|c|c|c|c|c|c|}
\hline \multirow[b]{2}{*}{ TLEV } & \multicolumn{5}{|c|}{$\begin{array}{l}\text { NYSLEV N(\%) } \\
(\underline{N}=65)\end{array}$} \\
\hline & 1 & 2 & 3 & 4 & Total $(\%)$ \\
\hline 1 & 45 & 2 & 5 & & $52(80.0)$ \\
\hline 2 & 1 & 4 & 5 & & $10(15.4)$ \\
\hline 3 & & & 1 & & $1(1.5)$ \\
\hline 4 & & & & 2 & $2(3.1)$ \\
\hline Total $(\%)$ & $46(70.8)$ & $6(9.2)$ & $11(16.9)$ & $2(3.1)$ & $65(100.0)$ \\
\hline
\end{tabular}


Table 13

Placement Results According to Teacher Level (TLEV) and Department Coordinator (DCLEV) for Null Hypothesis, $\mathrm{H}_{0}$

$$
\begin{aligned}
& \text { DCLEV N }(\%) \\
& (\underline{N}=65)
\end{aligned}
$$

\begin{tabular}{llllll} 
TLEV & 1 & 2 & 3 & 4 & Total(\%) \\
\hline 1 & 49 & 3 & & & $52(80.0)$ \\
2 & 2 & 8 & 1 & $10(15.4)$ \\
3 & & & 1 & 1 & $1(1.5)$ \\
4 & & & & & $2(3.1)$ \\
Total(\%) & $51(78.5)$ & $11(16.9)$ & $2(3.1)$ & $1(1.5)$ & $65(100.0)$ \\
\hline
\end{tabular}


Table 14

Number of Correct and Incorrect Placements According to NYS Place Test Level (NYSLEV) and Department Coordinator Level (DCLEV) for Null Hypothesis, $\mathrm{H}_{n}$

Method $\mathrm{N}(\%)$

Number of Placements

NYSLEV DCLEV

Total $(\%)$

\begin{tabular}{lccc}
\hline Correct & $52(40.0)$ & $59(45.4)$ & $111(85.4)$ \\
Incorrect & $13(9.5)$ & $6(9.5)$ & $19(14.6)$ \\
Total $(\%)$ & $65(50.0)$ & $65(50.0)$ & $130(100.0)$ \\
\hline
\end{tabular}

Note.

$X^{2}=3.02 ; p>.05$.

$\mathrm{C}=.15$ 
Analysis of the Data for Null Hypothesis, $\mathrm{H}_{1}$

$\mathrm{H}_{1}$ : There is no increased accuracy of placement of Haitian adult ESOL students by employing a writing sample, in English, in combination with the NYS Place Test as opposed to employing the NYS Place Test alone (previously shown in Tables 12 and 14 on pages 73 and 75 ).

Crosstabulation comparing the number of correct placements resulting from the NYS Place Test plus the writing sample (NYSWRITE) and teacher level (TLEV) $(\underline{N}=65)$ showed that there were fifty-five correct placements and ten incorrect placements (see Tables 15 and 16 on pages 78-79). The addition of the writing sample enhanced the number of correct placements by three. However, the value of chi-square $\left(X^{2}=.476 ; p>.05\right)$ suggested no significant difference between the proportions of observe and expected frequencies for placement by the NYS test alone and in combination with the writing sample. Although the writing sample appeared to improve the accuracy of the test, the improvement was not statistically significant. The contingency coefficient, $\mathrm{C}=.006$ was small, indicating a small discrepancy between expected and observed frequencies as related to the expected (McNemar, 1969).

Degree of correct placement according to the NYS (DOCPNYS) was compared to degree of correct placement according to the NYS plus the writing sample (DOCPNW) (see Table 17 on page 80 ). On a scale of one to six, the means, 5.723 and 5.815 , were very close in value. The higher degree of accuracy of the NYS plus the writing sample is indicated by the higher mean value. A paired t-test 
resulted in the 2-tail probability of $.277, \mathrm{p}>.05$, again indicating the statistic was not significant.

Summary of the data analysis for $\mathrm{H}_{1}$. In summary, the available data suggested no significant difference between the NYS Place Test used alone and in combination with a writing sample. Although the writing sample appeared to enhance the NYS by three correct placements, the increase attributed to the writing sample was not statistically significant. Therefore, the null hypothesis, $\mathrm{H}_{1}$, could not be rejected. The NYS Place Test alone was at least as accurate as the NYS Place Test plus the writing sample. 
Table 15

Placement Results According to Teacher Level (TLEV) and NYS Place Test Level plus Writing Sample (NYSWRITE) for Null Hypothesis, $\mathrm{H}_{1}$

NYSWRITE N(\%)

$$
(\underline{N}=65)
$$

TLEV

12

3

4

Total $(\%)$

\begin{tabular}{llllll}
\hline 1 & 48 & 3 & & 1 & $52(80.0)$ \\
2 & 5 & 4 & 1 & & $10(15.4)$ \\
3 & & & 1 & & $1(1.5)$ \\
4 & & & 2 & $2(3.1)$ \\
Total $(\%)$ & $53(81.5)$ & $7(10.8)$ & $2(3.1)$ & $3(4.6)$ & $65(100.0)$ \\
\hline
\end{tabular}


Table 16

Number of Correct and Incorrect Placements According to NYS Place Test Level (NYSLEV) and NYS Place Test Level plus Writing Sample (NYSWRITE) for Null Hypothesis, $\mathrm{H}_{1}$

Method $\mathrm{N}(\%)$

Number of Placements

NYSLEV NYSWRITE Total $(\%)$

\begin{tabular}{lccc}
\hline Correct & $52(40.0)$ & $55(42.3)$ & $107(82.3)$ \\
Incorrect & $13(11.5)$ & $10(11.5)$ & $23(17.7)$ \\
Total $(\%)$ & $65(50.0)$ & $65(50.0)$ & $130(100.0)$ \\
\hline
\end{tabular}

Note.

$\mathrm{X}^{2}=.476 ; \mathrm{p}>.05$.

$\mathrm{C}=.006$ 
Table 17

Summary of Data for Paired T-Test Comparing Degree of Correct Placement According to the NYS Place Test (DOCPNYS) and Degree of Correct Placement According to the NYS Place Test plus Writing Sample (DOCPNW) for Null Hypothesis, $\mathrm{H}_{1}$

Method

Descriptor

DOCPNYS DOCPNW

$\underline{\mathrm{N}}$

65

65

$\underline{\mathrm{M}}$

5.723

5.815

$\underline{\mathrm{SD}}$

.600

.497

$\underline{\mathrm{SE}}$

.074

.062

Note.

$\underline{\mathrm{t}}(64)=.277, \mathrm{p}>.05$, two-tailed. 


\section{Analysis of the Data for Null Hypothesis $\mathrm{H}_{2}$}

$\mathrm{H}_{2}$ : There is no increased accuracy of placement of Haitian adult students by considering profile data (age, prior schooling, length of residence, or employment) in combination with the NYS Place Test.

Frequency data for each profile variable were compared to the number of correct and incorrect placements by the NYS Place Test. The data for the profile variables were recoded based on descriptive statistics, which in most cases, was the median.

Age. Data collected for the profile variable, age, were recoded into two groups based on the median value for age which was twenty-five. Group one included data for students aged nineteen through twenty-five years; group two included data for those aged twenty-six through forty-one. A crosstabulation comparing number of correct placements and age is displayed in Table 18 on page 85. Chi-square was not significant $\left(\mathrm{X}^{2}=.097 ; \mathrm{p}>.05\right.$, see Table 18). The contingency coefficient, $\mathrm{C}=.077$, was expectedly small based on the size of chisquare. The null hypothesis could not be rejected. The model worked equally well for older and younger students.

Prior schooling. Data collected for the profile variable, prior schooling, were recoded into two groups, low and high, based on the median value for prior schooling which was ten years. The reader should note that the value for prior schooling refers to the self-reported number of years of prior schooling and not grade level. Group one included data for those with one through ten years of prior 
schooling; group two included data for those with eleven through nineteen years of prior schooling. A crosstabulation comparing number of correct placements and prior schooling is displayed in Table 19 on page 86 . Chi-square $\left(X^{2}=1.125 ; p>.05\right)$ was not significant. The contingency coefficient, $C=.168$, was appropriate for the size of chi-square. The null hypothesis could not be rejected. The model worked equally well for those with low levels and high levels of schooling.

Length of residence. Data collected for the profile variable, length of residence, showed that the median for length of residence was six months. Group one included those residing in the United States for one through six months; group two included those in the category of seven through twelve months; group three, thirteen through twenty-four months; and group four, twenty-five through one hundred ten months. A crosstabulation comparing number of correct placements and length of residence is displayed in Table 20 on page 87 . Investigation of the crosstabulation shows the following relationship between incorrect placements and length of residence: the number of incorrect placements appears to increase for those in category four. Chi-square was significant $\left(X^{2}=13.09 ; p<.05\right.$, see Table 20$)$. The contingency coefficient, $\mathrm{C}=.409$, was appropriately large based on the chisquare. The null hypothesis could be rejected. It appears that there is significant increased accuracy of placement of Haitian adult ESOL students by employing the profile variable, length of residence. For residence, group four, the percentage of incorrect placements was significantly higher than the other percentages. The model seems not to work equally well for those in residency group four. Since four of eight 
cells had less than five cases each, these data should be interpreted cautiously (Norusis, 1988).

A post hoc crosstabulation comparing raw scores on the NYS Place Test, adjusted and recoded by level, was performed to examine the relationship of NYS placement level and accuracy of placement. The post hoc analysis was initiated to reveal the existence of any relationship between fluency, reflected by a higher NYS test score, and accuracy of placement. The post hoc crosstabulation and chi-square with contingency coefficient are shown in Table 21 on page 88 . The chi-square was significant $\left(X^{2}=44.871 ; \mathrm{p}<.05\right.$, see Table 21$)$. These data show that those who placed in NYS level three had a significantly higher incidence of incorrect placements. The model appears not to work as well for those who placed in NYS level three. The contingency coefficient, $\mathrm{C}=.639$, was very high indicating a strong association. Six of eight cells had less than five cases each and should be interpreted cautiously (1988).

This finding is consistent with that of Tarone and Yule (1989) who suggest that oral proficiency may increase with length of residence in the host country while other skills may not improve at the same rate. Consequently, strength in oral proficiency may give a false indication of the student's overall skills.

Employment. Data collected for the profile variable, employment, were divided into two groups based on descriptive statistics. Since relatively few students were employed, both categories of employment, part or full-time, were collapsed into one. Group one included participants who were unemployed; group two included 
those who were employed either part-time or full-time. ' Crosstabulation for number of correct placements and employment is displayed in Table 22 on page 89 . Chisquare was not significant $\left(X^{2}=.000 ; \mathrm{p}>.05\right.$, see Table 22). The contingency coefficient, $\mathrm{C}=.000$, was expected. The null hypothesis could not be rejected. There was no significant increase in accuracy of placement by using the profile variable, employment.

Summary of the data analysis for $\mathrm{H}_{2}$. Based on the available data, there appeared to be no difference in accuracy of placement according to the profile variables: age, prior schooling, and employment. However, there seemed to be significant increased accuracy for placement of Haitian adult ESOL students according to the profile variable, length of residence. It appeared that there was a higher number of incorrect placements for students who lived in the host country from twenty-five to one hundred ten months. A post hoc analysis of NYS test score by level and number of correct and incorrect placements was significant and suggested that those learners with placement scores in NYS level three had a higher incidence of incorrect placements. 
Table 18

Comparison of Age and Number of Correct and Incorrect Placements According to the NYS Place Test for Null Hypothesis, $\mathrm{H}_{2}$

Age by Group N(\%)

$$
(\underline{N}=65)
$$

Number of Placements

$1 \quad 2 \quad \operatorname{Total}(\%)$

Correct

27

25

$52(80.0)$

Incorrect

8

5

$13(20.0)$

$\operatorname{Total}(\%)$

$35(53.8) \quad 30(46.2) \quad 65(100.0)$

Note.

$X^{2}=.097 ; \underline{p}>.05$.

$\mathrm{C}=.077$

Group one: nineteen through twenty-five years old.

Group two: twenty-six through forty-one years old. 
Table 19

Comparison of Prior Schooling and Number of Correct and Incorrect Placements According to the NYS Place Test for Null Hypothesis, $\mathrm{H}_{2}$

Prior Schooling by Group N(\%)

$$
(\underline{N}=65)
$$

Number of Placements

$1 \quad 2 \quad$ Total( $\%)$

Correct

31

21

$52(80.0)$

Incorrect

5

8

$13(20.0)$

$\operatorname{Total}(\%)$

$36(55.4)$

29(44.6)

$65(100.0)$

Note.

$X^{2}=1.125 ; p>.05$.

$\mathrm{C}=.168$

Group one: one through ten years.

Group two: eleven through nineteen years. 
Table 20

Comparison of Length of Residence and Number of Correct and Incorrect Placements According to the NYS Place Test for Null Hypothesis, $\mathrm{H}_{2}$

Length of Residence by Group N(\%)

$$
\underline{N}=65)
$$

Number of

Placements

12

3

$4 \quad$ Total $(\%)$

Correct

33

7

8

4

$52(80.0)$

Incorrect

3

2

2

6

13(20.0)

Total $(\%)$

$36(55.4)$

9(13.8)

10(15.4)

$10(15.4) \quad 65(100.0)$

Note.

$X^{2}=13.09 ; \mathrm{p}<.05$.

$\mathrm{C}=.409$

Group one: one through six months.

Group two: seven through twelve months.

Group three: thirteen through twenty-four months.

Group four: twenty-five through one hundred ten months. 
Table 21

Post Hoc Comparison of Score by Level on the NYS Place Test and Number of Correct and Incorrect Placements for Null Hypothesis. $\mathrm{H}_{2}$

Score by NYS Level N(\%)

$$
(\underline{N}=65)
$$

Number of

Placements

12

3

4

Total $(\%)$

\begin{tabular}{llllll}
\hline Correct & 45 & 4 & 1 & 2 & $52(80.0)$ \\
Incorrect & 1 & 2 & 10 & 0 & $13(20.0)$ \\
Total(\%) & $46(70.8)$ & $6(9.2)$ & $11(16.9)$ & $2(3.1)$ & $65(100.0)$ \\
& & & & & \\
\hline
\end{tabular}

Note.

$\mathrm{X}^{2}=44.871 ; \mathrm{p}<.05$.

$C=.639$ 
Table 22

Comparison of Employment and Number of Correct and Incorrect Placements According to the NYS Place Test for Null Hypothesis, $\mathrm{H}_{2}$

$$
\begin{aligned}
& \text { Employment by Group } N(\%) \\
& (\underline{N}=65)
\end{aligned}
$$

Number of

Placements

1

$2 \quad \operatorname{Total}(\%)$

Correct

40

12

$52(80.0)$

Incorrect

10

3

13(20.0)

Total(\%)

$50(76.9)$

$15(23.1)$

$65(100.0)$

Note.

$X^{2}=.000 ; p>.05$.

$\mathrm{C}=.000$

Group one: unemployed.

Group two: employed full-time or part-time. 
Analysis of the Data for Null Hypothesis, $\mathrm{H}_{3}$

$\mathrm{H}_{3}$ : There is no relationship between the profile data (age, prior schooling, length of residence, or employment) and withdrawal from the program for Haitian adult ESOL students.

Frequency data for each profile variable were compared to the number of withdrawals from the program. The same recoding of variables used in Hypothesis $\mathrm{H}_{2}$ applied. Analysis of the findings indicated that none of the profile variables were significantly related to withdrawal.

Age. The crosstabulation comparing age and attendance is displayed in Table 23 on page 92 . Chi-square was not significant $\left(X^{2}=.0004 ; p>.05\right.$, see Table 23$)$. The contingency coefficient, $\mathrm{C}=.034$, was appropriately small. The null hypothesis could not be rejected. The data suggested there was no significant relationship between age and withdrawal from the program for Haitian adult ESOL students.

Prior schooling. The crosstabulation comparing prior schooling and attendance appears in Table 24 on page 93 . Chi-square was not significant $\left(X^{2}=\right.$ $.032 ; \mathrm{p}>.05)$. Again, the contingency coefficient, $\mathrm{C}=.054$, was appropriately small. The null hypothesis could not be rejected. The data suggested there was no significant relationship between prior schooling and withdrawal from the program for Haitian adult ESOL students.

Length of residence. The crosstabulation comparing length of residence and attendance is shown in Table 25 on page 94 . Chi-square was not significant $\left(X^{2}=\right.$ $.452 ; \mathrm{p}>.05)$. The contingency coefficient, $\mathrm{C}=.083$, was appropriate for the chi- 
square. The null hypothesis could not be rejected. The data suggested there was no significant relationship between length of residence and withdrawal from the program for Haitian adult ESOL students.

Employment. The crosstabulation comparing employment and attendance appears in Table 26 on page 95 . The number of employed Haitian students who stayed was almost equal to the number of employed Haitians who withdrew. Chisquare was not significant $\left(\mathrm{X}^{2}=.196 ; \mathrm{p}>.05\right)$. The contingency coefficient, $\mathrm{C}=$ .092 , was expected. The null hypothesis could not be rejected. The data suggested there was no significant relationship between employment status and withdrawal from the program for Haitian adult ESOL students.

Summary of the data analysis for $\mathrm{H}_{3}$. The available data revealed no significant relationship between any of the profile variables, age, prior schooling, length of residence, or employment and withdrawal from the program for Haitian adult ESOL students. Although these findings are initially surprising, as Cross (1981) points out, for some groups of learners, especially ethnic minorities, participation or non participation in adult education may be for reasons other than those represented by the external variables investigated here. 
Table 23

Comparison of Age and Attendance for Null Hypothesis, $\mathrm{H}_{3}$

$$
\begin{aligned}
& \text { Age by Group } \mathrm{N}(\%) \\
& (\underline{\mathrm{N}}=65)
\end{aligned}
$$

Attendance

$1 \quad 2 \quad \operatorname{Total}(\%)$

Stayed

21

19

$40(61.5)$

Withdrew

14

11

25(38.5)

$\operatorname{Total}(\%)$

$35(53.8) \quad 30(46.2) \quad 65(100.0)$

Note.

$\mathrm{X}^{2}=.0004 ; \mathrm{p}>.05$

$\mathrm{C}=.034$

Group one: nineteen through twenty-five years old.

Group two: twenty-six through forty years old. 
Table 24

Comparison of Prior Schooling and Attendance for Null Hypothesis, $\mathrm{H}_{3}$

\section{Prior Schooling by Group N(\%)}

$$
(\underline{N}=65)
$$

Attendance

1

2

Total $(\%)$

Stayed

23

17

$40(61.5)$

Withdrew

13

12

$25(38.5)$

Total $(\%)$

$36(55.4)$

29(44.6)

$65(100.0)$

Note.

$\mathrm{X}^{2}=.032 ; \mathrm{p}>.05$.

$\mathrm{C}=.054$

Group one: one through ten years.

Group two: eleven through nineteen years. 
Table 25

Comparison of Length of Residence and Attendance for Null Hypothesis, $\mathrm{H}_{3}$

Length of Residence by Group $\mathrm{N}(\%)$

$(\underline{N}=65)$

Attendance

1

2

3

4

Total $(\%)$

\begin{tabular}{lllccr}
\hline Stayed & 22 & 5 & 7 & 6 & $40(61.5)$ \\
Withdrew & 14 & 4 & 3 & 4 & $25(38.5)$ \\
Total $(\%)$ & $36(55.4)$ & $9(13.8)$ & $10(15.4)$ & $10(15.4)$ & $65(100.0)$ \\
\hline
\end{tabular}

Note.

$X^{2}=.451 ; p>.05$.

$\mathrm{C}=.083$

Group one: one through six months.

Group two: seven through twelve months.

Group three: thirteen through twenty-four months.

Group four: twenty-five through one hundred ten months. 
Table 26

Comparison of Employment and Attendance for Null Hypothesis, $\mathrm{H}_{3}$

$$
\begin{aligned}
& \text { Employment by Group N(\%) } \\
& (\underline{\mathrm{N}}=65)
\end{aligned}
$$

Attendance

1

2

Total $(\%)$

Stayed

32

8

$40(61.5)$

Withdrew

18

7

25(38.5)

Total $(\%)$

$50(76.9) \quad 15(23.1)$

$65(100.0)$

$\mathrm{X}^{2}=.196 ; \mathrm{p}>.05$

$\mathrm{C}=.092$

Group one: unemployed.

Group two: employed full-time or part-time. 


\section{Analysis of the Data for Null Hypothesis, $\mathrm{H}_{4}$}

$\mathrm{H}_{4}$ : There is no relationship between the profile data (age, prior schooling, length of residence, or employment) and DNE for Haitian adult ESOL students.

The data analysis indicated that during the period under investigation, only seventeen Haitian Creole-speaking and Spanish-speaking students did not enter (DNE) a class after registering and testing. The sample of DNEs was almost evenly divided between both language groups, eight and nine respectively. The researcher determined that the number of DNEs was too small to test for significance. However, a table was prepared displaying the percentages of Haitian Creolespeaking DNEs $(\underline{N}=8)$ to the population under investigation in phases one and two $(\underline{N}=65)$ for each profile variable (see Table 27 on page 98$)$.

Age. The most striking difference appeared for the variable, age. Seventyfive percent of the DNEs were over twenty-five years old as compared to forty-six percent in the phases one and two of the study.

Prior schooling. A larger percentage of DNEs (62.5\%) had ten years or less schooling than those in phases one and two (55.4\%).

Length of residence. A larger percentage of DNEs (62.5\% compared to $55.4 \%$ ) were in the category of six months or less. None were in the category of twenty-five plus months, whereas phases one and two had more than fifteen percent.

Employment. More than eighty-seven percent of those who did not enter were unemployed as compared to almost seventy-seven percent in phases one and two. 
Summary of the data analysis for $\mathrm{H}_{4}$. Surprisingly, there was almost an equal number of Haitian Creole-speaking and Spanish-speaking DNEs. The comparison of DNEs to the population under investigation in phases one and two was largely unremarkable except for age. Although significance could not be determined, the majority of DNEs were older than twenty-five, thirty-one percentage points higher than in phases one and two. This was the largest difference found in the comparison. 
Table 27

Percentages of Haitian Creole-Speaking Students Who Did Not Enter (DNE)

Compared to Percentages of Haitian Creole-Speaking Students in Phases One and Two

Haitian Creole-Speaking Students N(\%)

Profile Variable

DNE

Phase One/Phase Two
$(\underline{\mathrm{N}}=8)$
$(\underline{N}=65)$

Age

25 years or less

$2(25)$

$35(54)$

26 years or more

$6(75)$

$30(46)$

Prior Schooling (years)

10 years or less

$5(62.5)$

$35(55.4)$

11 years or greater

$3(36.5)$

$35(44.6)$

Length of Residence (months)

$1-6$

$7-12$

13-24

$25+$
$5(62.5)$

$1(12.5)$

$2(25.0)$

$0(00.0)$
$36(55.4)$

9(13.8)

$10(15.4)$

$10(15.4)$

(table continued) 
(Table 27 continued)

Employment

unemployed

$7(87.5)$

$50(76.9)$

employed

$1(12.5)$

$15(23.1)$ 
CONCLUSIONS, DISCUSSION, IMPLICATIONS, AND RECOMMENDATIONS Introduction

This study was designed to find ways to improve the placement of ESOL students and to determine if the NYS Place Test should be used for initial placement of Haitian adult ESOL students in a community education program. The study compared placement by the NYS Place Test and placement by department coordinator. The study included three parts: a pilot, phase one, and phase two. The pilot was conducted to determine if the NYS Place Test was appropriate for the target population by testing students already placed in existing classes and comparing ranges for NYS Place Test levels to those in the field. Phase one compared accuracy of placement using the NYS Place Test, alone and in combination with a writing sample, and the current method, subjective judgement of a department coordinator. Phase two was devised to reveal if consideration of any of the profile variables (age, prior schooling, length of residence in the United States, or employment) improved accuracy of placement by the NYS test. Additionally, the study sought to determine if there existed a significant relationship between any of the profile variables and program withdrawal among the Haitian students who left the program or DNE (did not enter) among the Haitian students who registered but did not enter a class. Pilot Study: Conclusions and Discussion

The data from the pilot suggested no significant difference existed between the NYS Place Test and the department coordinator placement methods for those 
students previously placed in existing classes. The data supported the conclusion that the NYS Place Test could be used for the target population. It became apparent that there was a problem regarding fit between the four level instrument and the six level practice in the field. For purposes of this study, the subdivision of level one into three groups was ignored in order to assess the fit between the test instrument and the field.

Frequency data generated from the pilot comparing the range of scores for correctly placed students in existing levels showed more similarities in ranges between the two placement methods for levels three and four than for levels one and two (Tables $8,9,10$, and 11 on pages 66-69). The greatest differences in frequency data appeared in level two. Data utilizing adjusted NYS ranges incorporated more of the students in existing levels than non adjusted ranges. It was decided to use adjusted ranges throughout the study. For those students whose scores fell outside the range, more were above the range than below, suggesting that some students' oral proficiency may be higher than their overall language skills. Based on test score alone, students could be placed in a level reflecting their oral proficiency but beyond their writing capability. Review of data derived from the pilot study leads to the conclusion that use of a writing sample in combination with oral assessment may be justified to help detect unequal skill development.

Phase One and Phase Two: Conclusions and Discussion

1. The results of the chi-square test in phase one revealed no significant differences between the two methods of placement for Haitian adult ESOL students. 
The data supported the conclusion that the NYS Place Test was an effective substitute for subjective department coordinator placement (Table 14, page 75), especially in an institutional setting where standardized placement is preferable to the subjective decision of a single individual.

2. The results of the chi-square test (Table 16, page 79) showed no significant difference between the NYS Place Test used alone or in combination with a writing sample. The number of correct placements improved by employing a writing sample, but the degree of improvement was not significant. Although data derived in the pilot study suggested inclusion of a writing sample, the findings in phase one revealed that the addition of a writing sample did not significantly improve the accuracy of the NYS Place Test.

However, a knowledge of Haitian traditions and culture supports the idea that Haitians prefer oral expression to written. One would naturally expect Haitians to be more proficient in oral skills than writing skills. Evidence is provided in the literature (Tarone \& Yule, 1989) that second language learners, in general, acquire skills at different rates. An oral placement test, such as the NYS, may place a highly fluent student in a level beyond his/her overall ability. It would be helpful to detect a large discrepancy between oral and writing ability. Since the data gathered in this study showed that, for the most part, incorrect NYS placements were high, further investigation of a short writing sample to improve accuracy of placement is warranted. This presumes a class curriculum which combines skills rather than addressing them separately. Alternatively, curriculum restructuring may be 
warranted so that assessment of oral skills leads to placement in oral communication and assessment of writing skills leads to placement in reading and writing.

In a post hoc investigation conducted at the Whiddon Adult Center in October through November, 1993, the teacher aide utilized the NYS Place Test in combination with the writing sample and placed all incoming students. Data for the Haitian Creole-speaking students indicated that of eighteen students, seventeen were correctly placed. The one incorrect placement occurred as a result of human error. In the case of the incorrectly placed student, both the NYS score and the writing sample suggested placement in level one (B). For unknown reasons, the teacher aide placed the student in level one (A). The Teacher-Validation-of-Placement Form (TVOP) confirmed appropriate placement in level one (B). Collapsing the three subdivisions of level one, as in phases one and two of the study, this placement would have been considered correct. Additionally, all nine Spanish-speaking students placed during this time period were correct, making a total of twenty-seven consecutive placements utilizing the NYS Place Test in combination with the writing sample. Placement was accurately accomplished by the teacher aide and not the department coordinator, demonstrating an additional advantage of cost effectiveness.

3. Accuracy of placement of Haitian adult ESOL students was not significantly increased by considering the following profile variables: age, prior schooling, or employment. However, the chi-square test comparing accuracy of placement and residence (Table 20, page 87) was significant. There were significantly more incorrect placements among those students who lived in the 
United States between twenty-five and one hundred ten months. The data supported the conclusion that accuracy of the NYS Place Test for Haitian adult ESOL students could be increased by considering the profile variable residence. This study did not investigate the relationship between length of residence and oral proficiency. It was not determined if those who were incorrectly placed because of length of residence were the same as those who were highly fluent.

4. There appeared to be no significant relationship between any of the profile variables (age, prior schooling, length of residence, or employment) and withdrawal from the program. Although the data did not suggest any commonalities between any of the profile variables and withdrawal, further investigation may reveal other factors which may influence a student's decision to leave the program.

5. The sample of Haitian students who registered and did not enter (DNE) was too small to determine significance. Therefore, the profile variables (age, prior schooling, length of residence, or employment) and DNE for Haitian adult ESOL students could not be tested. Frequency data for the profile variables and DNE were compared and seemed to be unremarkable except for age, which was noticeably different from the original population sample. Percentages suggested that the majority of those who were classified as DNE were older compared to the original data sample. Further investigation is indicated.

Implications and Recommendations

The findings of this study lead to the following implications and recommendations for future research: 
1. The data collected in this study suggest that the NYS Place Test worked well for Haitian students regardless of the students' backgrounds, except for length of residence. This finding is seen as a strength of the test when used for initial placement of a population of Haitian adult ESOL students.

2. Although the writing sample was not shown to significantly improve accuracy of the NYS test, teachers repeatedly mentioned writing as evidence of correct placement. The literature reports research findings that indicate individuals acquire language skills at different rates. Continued usage of the writing sample may be justified in the placement process as an additional indicator to detect a discrepancy between the student's oral and writing proficiency.

3. It would be helpful to utilize the NYS Place Test to assign students to the preparatory level, one (A), and one (B) classes especially since a large proportion of students at the Adult Center are beginners. The researcher proposes that it may be possible to adapt the test with assignment to level one as follows: 0-6 (preparatory), 7-11 (A), and 12-16(B). Although the data collected for ranges in this study did not exhibit clear divisions for level one, the researcher suggests that after utilizing the NYS test over a period of several months, placement into classes already formed by the department coordinator would switch to classes formed by the NYS Place Test. At that point, the subdivisions for level one may become more apparent. At the present time, however, the researcher notes that the results of the TVOP, as to who belongs in their class and what constitutes the definition of their level, are affected by the mindset of the teachers. This was a limitation preventing finer 
distinction of level one in this study.

4. More attention should be paid to native language literacy in future studies. The current study relied on self-report of the variables gathered upon intake. The researcher felt the mandatory TABE test and the addition of the NYS test already burdened the student. Therefore, the researcher chose not to require additional testing in the native language. Although the NYS Place Test has an accompanying screening instrument in several languages, the Adult Center does not presently offer literacy classes in any language other than English. Consequently, this screening was not utilized. The researcher notes that reliance on self-reported data is cautioned against (Johnson \& Saville-Troike, 1992) and further assessment in the native language would provide a more comprehensive profile of the learner's literacy level.

5. The researcher suggests the following alternative to the current placement procedure for ESOL students at the Adult Center: Registration and interview, initial assessment utilizing the NYS Place Test, and a waiver of the TABE requirement from the Florida Department of Education for all ESOL students who place at level one on the NYS. Until such time that the state changes its requirement regarding TABE for ESOL students, it would continue to be used only for those ESOL students who place at levels two, three, or four on the NYS. Reassessment, which is required annually by the state, would follow the same procedure, namely, waiver of the TABE requirement for all ESOL students who place at level one on the NYS.

6. A possible disadvantage of the NYS Place Test is that proper administration requires up to fifteen minutes per student. An appropriate number 
of personnel should be assigned for placement of new students. In times of high student registration, such as beginning of terms, the institution should adequately accommodate the number of students, providing the necessary attention to complete the testing process in an unhurried manner without keeping students waiting. This possible disadvantage can be considered an advantage since the one-on-one interview feature of the NYS Place Test ensures personalization in the institutional setting. The school setting appears intimidating for some adult learners and a warm, supportive initial contact with the institution may make the difference between participation and non participation (Cross, 1981).

7. The researcher notes that NYS Place Test pictures number one and ten may need to be revised. Regarding picture number one, at least eight Haitian students commented that it was raining. The students mistakenly thought the grass in the foreground was rain. Picture number ten raises concern about stereotype and cultural bias since it presents a man, who appears to be Hispanic, wearing a large medallion; there is also a bullfighter in the background.

8. The researcher suggests recognition of the importance of adequate initial assessment and placement procedures for Haitian adult students as the foundation of a sound, well-designed ESOL program. The growing number of Haitian adult limited English proficient (LEP) students in community education programs demands that they be afforded the opportunity to acquire English skills in the most efficient and effective manner possible so that they may function and participate more easily and independently within the community. 


\section{EPILOGUE}

This epilogue was requested by the dissertation committee during the defense in response to a question raised regarding the changes made or in process as a result of this study.

The following actions have been taken:

1. The NYS Place Test plus writing sample has successfully been used for placement at the Whiddon Adult Center since October, 1993.

2. The 1988 and 1993 Southern Association of Colleges and Schools (SACS) recommendations have been met by implementing an effective, accountable, and personalized method of initial placement for Whiddon's adult ESOL students.

3. The researcher has written a waiver request to the Florida Department of Education and to the School Board of Broward County through Whiddon's School Improvement Team for permission to utilize the NYS Place Test in lieu of the TABE for Whiddon's level one ESOL students.

4. The researcher is currently training a cadre of testers at Whiddon to administer the NYS Place Test.

5. The researcher has written a letter to the New York State Education Department outlining the results of the study and expressing concern about possible bias for pictures one and ten in the NYS Place Test as described in chapter five of this study.

The following, while not a direct consequence of the study, are linked by the researcher's participation: 
1. The researcher is on the committee suggesting revisions of the Broward ESOL Curriculum Guide. Assessment for initial placement is being addressed.

2. The researcher created a transition class at Whiddon, focusing on improvement of writing skills facilitating students' entry into mainstream academic and business classes. The researcher is also on a writing team developing a precollege writing class as part of a joint effort between Broward County Schools and Broward Community College. These two programs respond to the unequal skill development of ESOL students through an alternative to the current curriculum where placement is based on a composite of skills. A writing sample will be required for entry and exit in the pre-college program, while both standardized assessment and a writing sample will be required for entry into Broward Community College, demonstrating recognition that language assessment procedures for placement should consider the multidimensional aspects of language development.

The following action is in progress at the state level:

1. The Florida Department of Education is currently considering alternatives to the TABE requirement. A draft of a technical assistance paper outlining the proposed new requirements has been completed but is not yet available. 


\section{REFERENCES}

Adult literacy and learning. (1993, February). ESL Notes. Washington DC: U.S.

Department of Adult Education, Division of Adult Education and Literacy.

Alderson, C. J., Krahnke, K. K., \& Stansfield, C. W. (Eds.). (1987). Reviews of English language proficiency tests. Washington DC: Teachers of English to Speakers of Other Languages.

Ariza, M. J. (1990, April). A new beginning for LEP students? Paper presented at the Annual Meeting of the American Educational Research Association, Boston, MA.

Assessment of adult limited English proficient students: A guide to available instruments. (1990). Austin, TX: Texas Education Agency, Division of Adult and Community Education. (ERIC Document Reproduction Service No. ED 322790 )

Bean, R. M., Partanen, J., Wright, F., \& Aaronson, J. (1989). Attrition in urban basic literacy programs and strategies to increase retention. Pittsburgh, PA: University of Pittsburgh. (ERIC Document Reproduction Service No. ED 317 797)

Briggs, L. J. (Ed.). (1977). Instructional design: Principles and application. Engelwood Cliffs, NJ: Educational Technology Publications.

Brod, S. (1990). Recruiting and retaining language minority students in adult literacy programs. ERIC Digest. Washington DC: Center for Applied Linguistics. (ERIC Document Reproduction Service No. ED 321 621) 
Bureau of Adult and Community Education. (1993). Application of limited English proficient (LEP) requirements to adult education. (Technical Assistance Paper). Tallahassee, FL: Department of Education.

Carnevale, A. P., Gainer, L. J., \& Meltzer, A. S. (1990). Workplace basics: The essential skills employers want. San Francisco, CA: Jossey-Bass.

Cicchella, T. (1988, April). Final report of the visiting committee, Southern Association of Colleges and Schools, the Florida committee: Commission on secondary schools. Paper presented at a meeting at the conclusion of the ten year study for the Downtown Adult Center, now the Gene A. Whiddon Adult Center, Fort Lauderdale, FL.

Collier, V. P. (1987). Age and rate of acquisition of second language for academic purposes. TESOL Quarterly, 21(4), 617-641.

Council, C. T. (1993, May). Southern Association of Colleges and Schools: Five-year visiting committee report. Paper presented at a meeting at the conclusion of the five year interim study for the Gene A. Whiddon Adult Center, Fort Lauderdale, FL.

Cross, P. (1981). Adults as learners. San Francisco, CA: Jossey-Bass.

Cummins, J., Swain, M., Nakajima, K., Handscombe, J., Green, D., \& Tran, C. (1984). Linguistic interdependence among Japanese and Vietnamese immigrant students. In C. Rivera (Ed.), Communicative competence approaches to language proficiency assessment: Research and application (pp. 60-81). Clevedon, England: Multilingual Matters. 
D’Anglejan, A. \& Renaud, C. (1985). Learner characteristics and second language acquisition: A multivariate study of adult immigrants and some thoughts on methodology. Language Learning. 35(1), 1-19.

Departement De L'Education Nationale. (1982). La reforme educative. Elements d'information [Educational reform. Elements of information.] Haiti: Comite De Curriculum - Institut Pedagogique National.

Dibble, S. (1990, January). Census asks: How many Haitians? Miami Herald, p. 3BR.

Dulay, H., Burt, M. \& Krashen, S. (1982). Language two. NY: Oxford University Press.

Ellis, R. (1984, September). The role of instruction in second language acquisition. Paper presented at the IRAAL-BAAL Seminar on the Formal and Informal Contexts of Language Learning. In Singleton, D. \& Little, D. (Eds.), Language learning in formal and informal contexts (pp. 19-37). Dublin: IRAAL.

Ellis, R. (1985). Understanding second language acquisition. NY: Oxford University Press.

English for speakers of other languages curriculum guide. (1990). Fort Lauderdale, FL: School Board of Broward County, Adult and Community Education Department.

Fingeret, A. (1989). The social and historical context of participatory literacy education. In Fingeret, A. \& Jurmo, P. (Eds.), New directions for continuing 
education. Participatory education, 42, 5-15. San Francisco. CA: Jossey-Bass. Florida Administrative Code Annotated. (1990). Tallahassee: Florida Department of State.

Florida DOE/META (8/09/90) ESOL Agreement. (1990). Tallahassee: Florida Department of Education.

Foreign/PEP Student Impact, July 1992 - June 1993. (1993). Fort Lauderdale, FL: School Board of Broward County, Multicultural Education Department.

Gagne, R. M. \& Briggs, L. J. (1974). Principles of instructional design. NY: Holt, Rinehart, \& Winston.

Gardner, D. (1992). Florida's adult education programs. Challenges and accomplishments. A report for fiscal year 1991. Miami, FL: Florida Training Center for Adult Literacy Educators, Miami-Dade Community College.

Gardner, R. C. (1980). On the validity of affective variables in second language acquisition: Conceptual, contextual, and statistical considerations. Language Learning, $\underline{30}(2)$, 255-270.

Gardner, R. C., Lalonde, R. N., \& Moorcroft, R. (1985). The role of attitudes and motivation in second language learning: Correlational and experimental considerations. Language Learning, $35(1), 207-227$.

Gardner, R. \& Lambert, W. (1972). Attitudes and motivation in second language learning. Rowley, MA: Newbury House.

Garreton, R. and Terdy, D. (1991). Correlation study of adult English as a second language (ESL) and adult basic education ( $\mathrm{ABE}$ ) reading tests. Final report. 
Il: Adult Learning Resource Center. (ERIC Document Reproduction Service No. ED 352 849)

Gay, L. R. (1992). Educational research competencies for analysis and application. (4th ed.). Columbus, OH: Merrill.

Guba, E. G. \& Lincoln, Y. S. (1991). Effective evaluation. San Francisco, CA: Jossey-Bass.

Henning, G. (1987). A guide to language testing. Cambridge, MA: Newbury House.

Johnson, D.M. \& Saville-Troike, M. (1992). Validity and reliability in qualitative research on second language acquisition and teaching. Two researchers comment. TESOL Quarterly 26(3), 602-605.

Kennedy, B. (1988). Adult v. child L2 acquisition: An information-processing approach. Language Learning, $\underline{38(4), ~ 477-96 . ~}$

Kerlinger, F. N. (1986). Foundations of behavioral research (3rd ed.). NY: Holt, Rinehart, \& Winston.

Knowles, M. (1984). The adult learner: A neglected species (3rd ed.). Houston, TX: Gulf Publishing Company.

Kolberg, W. \& Smith, F. (1992). Rebuilding America's workforce. Business strategies to close the competitive gap. Homewood, IL: Business One Irwin. Krashen, S. (1985). The input hypothesis: Issues and implications. NY: Longman. Krashen, S., Long, M. \& Scarcella, R. (1979). Age, rate, and eventual attainment in second language acquisition. TESOL Ouarterly 13(4), 573-82. 
Larsen-Freeman, D. \& Long, M. (1992). An introduction to second language acquisition research. NY: Longman.

Long, M. H. (1990). The least a second language acquisition theory needs to explain. TESOL Quarterly, 24(4), 649-666.

Mager, R. (1984). Preparing instructional objectives (2nd ed.). Belmont, CA: David S. Lake, Publ.

McLaughlin, B. (1987). Theories in second language acquisition. London: Edward Arnold.

McLaughlin, B. (1992). Myths and misconceptions about second language learning: What every teacher needs to unlearn. Educational Practice Report: 5. CA: National Center for Research on Cultural Diversity and Second Language Learning.

McNemar, Q. (1969). Psychological Statistics (4th ed.). NY: John Wiley \& Sons, Inc.

Mooney, P. M. (1991). Variables affecting oral language proficiency among Spanish-speaking adults learning English as a second language. (Doctoral dissertation, State University of New York at Albany, 1991). Dissertation Abstracts International, 53, 1986A. (University Microfilms No. 9133328)

Multicultural education in Florida. Multicultural education review task force. (1991). Tallahassee, FL: Florida Department of Education.

NYS Place Test: New York State's Placement Test for English as a Second Language Adult Students - Form B. (1987). Albany, NY: State Education Department, 
Division of Continuing Education Planning and Development.

New York State Education Department/The University of the State of New York. (1992). [NYS Place Test Form B Validation Project]. Unpublished raw data. Norusis, M. J. (1988). SPSS/PC+ studentware. Chicago, IL: SPSS.

Norusis, M. J. (1990). SPSS introductory statistics student guide. Chicago, IL: SPSS.

Ocker, L. (1992, December). More smuggling of Haitians suspected. Sun-Sentinel, p. 1 A.

Ocker, L. \& Pierre-Pierre, G. (1992, December). Refugees see signs of hope with Clinton. Miami Herald. pp. 1A, 20A.

Official Florida Statutes. (1993). Tallahassee: State of Florida.

Olsen, R. E. W-B. (1991). Report of the 1991 limited English proficient (LEP) student enrollment survey. Alexandria, Virginia: TESOL Field Services.

Oyama, S. (1978). The sensitive period and comprehension of speech. Working papers on bilingualism. No. 16. Canada: Bilingual Education Project, The Ontario Institute for Studies in Education. (ERIC Document Reproduction Service No. ED 165 474)

Pedhazur, E. (1982). Multiple regression in behavioral research (2nd ed.). NY: Holt, Rinehart \& Winston.

Pierre-Pierre, G. (1992, December). Haitian refugee thankful her days of hiding are over. Sun-Sentinel, p. 6A.

Rorro, G. (1988). Academic achievement of Haitian limited English proficient students in New Jersey public high schools. (Doctoral dissertation, Rutgers, 
The State University of New Jersey, 1988.) Dissertation Abstracts International, 49, 3292A. (University Microfilms No. 8827362)

Rorro, G. (1992). Haitian voices: Considerations for the classroom teacher. Trenton, NJ: New Jersey State Department of Education.

Santopietro, K. and Peyton, J. K. (1991). Assessing the literacy needs of adult learners of ESL. ERIC Digest. Washington, DC: National Clearinghouse on Literacy Education.

Savain, R. E. (1993). Haitian-Kreol in ten steps (rev. 4th ed.). VT: Schenkman Books, Inc.

Saville-Troike, M. (1991, Spring). Teaching and testing for academic achievement:

The role of language development. Focus, Occasional Papers in Bilingual

Education (No. 4). Washington, DC: National Clearinghouse for Bilingual Education.

Savignon, S. J. (1991). Communicative language teaching: State of the art. TESOL Quarterly, 25(2), 261-274.

Schilit, J. \& Nimnicht, G. (1990). The Florida survey of newly legalized persons. (Contract No. MF-123). Tallahassee, FL: Department of Health and Rehabilitative Services.

School Board of Broward County, Florida Policy Handbook. (1992). Fort Lauderdale, FL: School Board of Broward County.

Scriven, M. (1972). Objectivity and subjectivity in educational research. In L. G. Thomas (Ed.), Philosophical redirection of educational research (pp. 94-142). 
Chicago, IL: University of Chicago Press.

Shermyen, A. H. (Ed.). (1992). Florida statistical abstract. Gainesville, FL: University Press of Florida.

Sorenson, E. \& Enchautegui, M. (1992). Immigrant male earnings in the 1980s: Divergent patterns by race and ethnicity. Washington, DC: The Urban Institute.

Spinthourakis, J. A. (Ed.). (1993, February). HRS Refugee Programs Update, 4(1), 28.

Spurling, S. \& Ilyin, D. (1985). The impact of learner variables on language test performance. TESOL Quarterly, 19(2), 283-299.

Stepick III, A. (1992). The refugees nobody wants: Haitians in Miami. In G. J. Grenier \& A. Stepick III (Eds.), Miami now! Immigration, ethnicity, and social change (pp. 57-82). Gainesville, FL: University of Florida Press.

Sticht, T. G. (1990). Testing and assessment in adult basic education and English as a second language programs. San Diego, CA: Applied Behavioral and Cognitive Sciences, Inc.

Swain, M. (1985). Communicative competence: Some roles of comprehensible input and comprehensible output in its development. In S. Gass \& C. Madden (Eds.), Input in second language acquisition. Rowley, MA: Newbury House. Tarone, E. \& Yule, G. (1989). Focus on the language learner. NY: Oxford University Press.

Test of adult basic education forms 5 and 6 norms book. (1987). CA: 


\section{CTB/McGraw-Hill.}

Tinto, V. (1988, October). The educational principles of effective student retention. Presented at the National Conference of the National Academic Advising Association, Miami, FL.

Tsakonas, F. (1990, April). Optimal age revisited--A Piagetian perspective. Paper presented at the Meeting of the World Congress of Applied Linguistics, Thessaloniki, Greece. (ERIC Document Reproduction Service No. ED 329 126)

Tyler, R. W. (1969). Basic principles of curriculum and instruction. Chicago, IL: University of Chicago Press.

Waggoner, D. (Ed.). (1993). Census issues information on countries of birth of foreign-born population. Numbers and needs. Ethnic and linguistic minorities in the United States, $3(3), 2-3$.

Wallace, R. (1992, May). Haitians vie to be state's 2nd-largest immigrant group. Miami Herald, p. 13A.

Wilcox, W. B. (1991). The predictive validity of the Wide Range Achievement Test and achievement scores of ESOL adults. Master's thesis, University of Kansas. (ERIC Document Reproduction Service No. ED 341 294)

Wiley, T. (1991). Measuring the nation's literacy: Important considerations. ERIC Digest. Washington, DC: National Clearinghouse on Literacy Education.

Wingerd, J. (1990). Urban Haitians: Documented/undocumented in a mixed neighborhood. Ethnographic evaluation of the 1990 decennial census 
(Report No. 7). Washington, DC: Bureau of the Census, Center for Survey Methods Research.

Vargas, A. (1986). Illiteracy in the Hispanic community. Washington, DC: National Council of La Raza. 
APPENDIX A 
DOCUMENTATION OF COLLABORATION

WITH HAITIAN EDUCATORS

Name

Père Lamy

Anonymous

R. E. Savain

M. P. Fontis
Area of Expertise or Affiliation

Haitian Catholic Center,

Fort Lauderdale

Haitian Educator,

Broward County Schools

Bilingual Education Consultant

for Haitian Language and Culture

Assistant Director of FONHEP

$9 / 4 / 93$
$7 / 20 / 93$

$8 / 18 / 93$

$8 / 25 / 93$

(Fondation Haitienne de l'Education Privée)

Executive Secretary FEPH

(Fédération des Ecoles Protestantes d'Haiti) 
APPENDIX B 


\section{STUDENT PERFORMANCE LEVELS - ABBREVIATED VERSION}

\begin{tabular}{|c|c|c|c|}
\hline & No abllity whetcosver. & & \\
\hline$I$ & $\begin{array}{l}\text { - Functions minimally. } \\
\text { If al all, in English. }\end{array}$ & $\begin{array}{l}\text { - Can hendie onty } \\
\text { very routline entry. } \\
\text { level lobs that do not } \\
\text { requile orel commu. } \\
\text { nicallon. and in which } \\
\text { all lasks can be easily } \\
\text { demonatrated. }\end{array}$ & $\begin{array}{l}\text { - A natwe English } \\
\text { epoaker used to deal. } \\
\text { ing wilh imiled Engligh } \\
\text { speohers can rerely } \\
\text { communtcele with } \\
\text { person at lhis level } \\
\text { encept imrough } \\
\text { eestures. }\end{array}$ \\
\hline & $\begin{array}{l}\text { - Funclions in a } \\
\text { very limited wey in } \\
\text { silualions related to } \\
\text { Immediate moede. }\end{array}$ & $\begin{array}{l}\text { - Can handle only } \\
\text { roullne eniry-level } \\
\text { fobs inat do not re. } \\
\text { quire oral communica. } \\
\text { llon. and in which all } \\
\text { lasks can be eedly } \\
\text { demonatrated. }\end{array}$ & 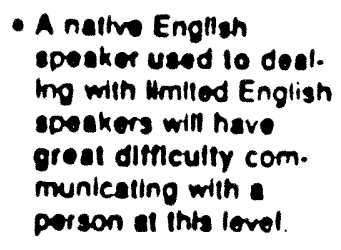 \\
\hline & $\begin{array}{l}\text { - Functions with some } \\
\text { ditticully in elluellons } \\
\text { coleted to Immediate } \\
\text { neede. }\end{array}$ & $\begin{array}{l}\text { - Can handle routlne } \\
\text { entry-tevet fobs inat } \\
\text { Involve onty the moot } \\
\text { bede oral communl. } \\
\text { cetlon, and in which } \\
\text { ell laske cen be } \\
\text { cemometrated. }\end{array}$ & 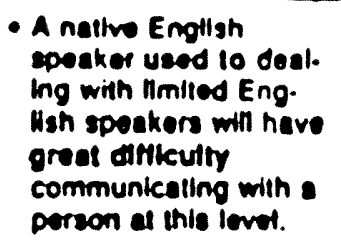 \\
\hline & $\begin{array}{l}\text { - Cen cailsty besle } \\
\text { survivel noeds and a } \\
\text { lew very routine } \\
\text { social demands. }\end{array}$ & $\begin{array}{l}\text { - Can handle entry. } \\
\text { levet jobe indit involve } \\
\text { come elmple orel } \\
\text { communication, but } \\
\text { in which taske cen } \\
\text { atwo bo demonetreled. }\end{array}$ & 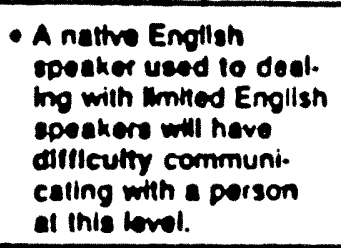 \\
\hline$V$ & $\begin{array}{l}\text { - Can ealisly baske sur. } \\
\text { vival neods and come } \\
\text { llmited eoclel } \\
\text { demande. }\end{array}$ & 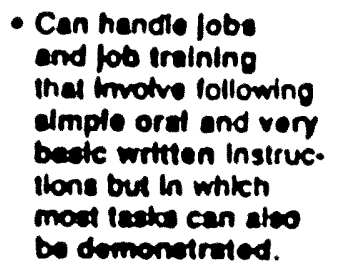 & 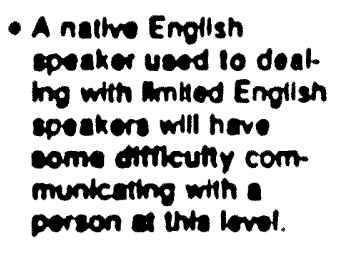 \\
\hline
\end{tabular}




\begin{tabular}{|c|c|c|c|}
\hline$V$ & $\begin{array}{l}\text { Can eatisty moet } \\
\text { eurvival moede and } \\
\text { limited coclat } \\
\text { demends. }\end{array}$ & 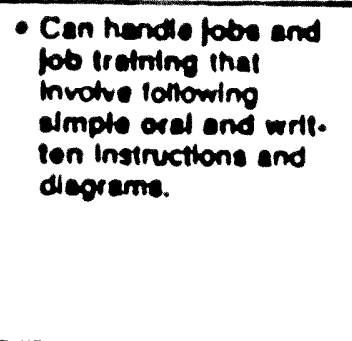 & 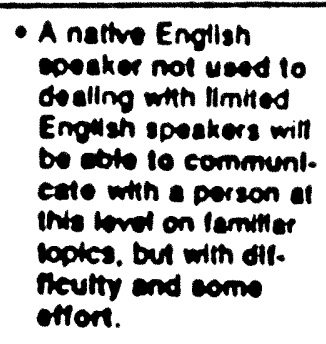 \\
\hline & $\begin{array}{l}\text { - Can ealisty curvtivel } \\
\text { neods and routine } \\
\text { work and coctel } \\
\text { demends. }\end{array}$ & 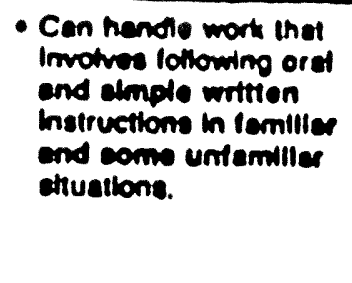 & 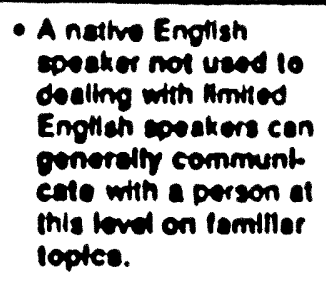 \\
\hline & $\begin{array}{l}\text { Cen particlpete oflec. } \\
\text { lively in sociel and } \\
\text { lamillef work stus. } \\
\text { llons. }\end{array}$ & & $\begin{array}{l}\text { - A nathe English } \\
\text { speaker not ueed to } \\
\text { dealling with Hmited } \\
\text { English sposkers cen } \\
\text { communteate with } \\
\text { person at inis level on } \\
\text { almost afl toples. }\end{array}$ \\
\hline & $\begin{array}{l}\text { - Can perticlpate } \\
\text { fluenily and accurately } \\
\text { In prectleal, eoclal. } \\
\text { end work iltuations. }\end{array}$ & & 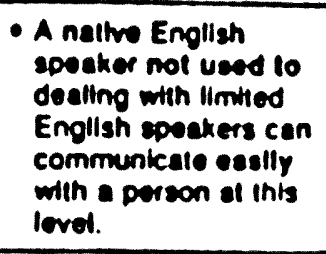 \\
\hline $\mathbf{X}$ & $\begin{array}{l}\text { - Ability oquel to that } \\
\text { of a nalive epoeker } \\
\text { of the eame coclo- } \\
\text { cconomic lovol. }\end{array}$ & & \\
\hline
\end{tabular}


APPENDIX C 


\section{STRAND 1 - DEMONSTRATING BASIC SURVIVAL SKILLS}

\section{IDENTIFICATION AND COMMUNICATION}

1. Give orally upon request self-identification and personal information including name, address, phone number, place of birth, age.

2. Rote count numbers $0-10$.

3. Identify numbers $0-10$.

4. Respond to simple greetings.

5. Initiate simple greetings.

6. Respond to simple good-byes.

7. Initiate simple good-byes.

8. Respond to simple introductions.

9. Initiate simple introductions.

10. Express feelings and states of being orally.

11. Recognize members of immediate and extended family.

12. Tell time in minutes and hours.

13. Identify periods of time in days, months, and years.

14. Say and dial given telephone numbers.

15. Identify simple weather conditions.

\section{MONEY}

16. Recognize American money.

17. Recognize simple identification.

18. Ability to endorse a check.

\section{HEALTHCARE}

19. Identify simple body parts.

20. Identify common health problems.

21. Know what information to include when making an emergency phone call.

\section{IRANSPORTATION}

22. Name means of transportation.

23. Know traffic and information signs.

\section{HOUSNG}

24. State housing needs to potential landlord.

25. Name rooms in house or apartment.

26. Name common household furniture.

27. Name most common tools.

\section{CLOTHING AND FABRICS}

28. Identify most common articles of clothing.

29. Identify basic colors.

\section{COMMUNTYY RESOURCES}

30. Know how to locate agencies and institutions in the community.

31. Understand services available from agencies and institutions, (health, social security, schools, and libraries). 


\section{STRAND 2 - DEMONSTRATING KNOWLEDGE OF BASIC VOCABULARY}

1. Identify the meanings of words that give directions: circle, check, put an $\mathrm{x}$, and underline.

2. Understand basic signs (Wilson's List).

3. Identify easy opposites (list included).

\section{STRAND 3-DEMONSTRATING APPROPRIATE GRAMMAR AND USAGE}

\section{CAPITALIZATION}

1. Recognize capital letters $A$ through $Z$.

2. Write capital letters $A$ through $Z$.

3. PUNCTUATION

\section{SPELLING}

4. Spell own first and last name.

5. Say own complete address, spelling street names if necessary.

\section{RECOGNIZING AND USING GRAMMATICALIY CORRECT SENTENCES}

6. Identify singular and plural forms of regular nouns (add "s") and child-children, man-men, woman-women.

7. Respond to yes-no questions in the present time (affirmative).

8. Respond in the negative to yes-no questions in the present time.

9. Initiate questions using appropriate grammatical English.

10. Respond to information questions.

\section{STRAND 4 - DEMONSTRATING A KNOWLEDGE OF PHONICS}

1. Identify letter forms that are the same.

2. Identify letter forms that are different.

3. Identify letter forms using visual memory.

4. Identify letter symbols for initial consonant sound and vowel sounds.

5. Write initial consonant sounds.

6. Identify letter symbols for final consonant and vowel sounds.

\section{STRAND 5 - ORGANIZING OBJECTS AND INFORMATION INTO LOGICAL GROUPINGANDORDERS}

1. Organize pictures in sequential order.

2. Classify pictures naming objects with similar characteristics under appropriate headings.

\section{STRAND 6 - DEMONSTRATING LITERAL COMPREHENSION SKILLS}

1. Follow one-step oral directions.

2. Write letters of the alphabet in order dictated.

3. Write numbers $0-10$ in the order dictated. 


\section{STRAND 7 - WRITING}

1. Write on the lines not in the space.

2. Copy 3 sentences that are visually shown.

3. Complete form requesting name and age.

\section{STRAND 8 - DEMONSTRATING JOB SEARCH AND INTERVIEW SKILLS}

\section{(PRE-VOCATIONALESOL)}

1. Identify various occupations.

2. Know how to present a positive image.

3. Answer questions concerning background education and experience.

4. Read and complete job application form.

5. Use correct markings on an application form (dash, slash, " $\mathrm{x"}$ ", parentheses).

6. Know how and where to look for a job.

\section{STRAND 9 - UNDERSTANDING UNITED STATES CULTURE}

1. Understand format of reading materials (left to right, top to bottom).

2. Understand common forms of greeting and accepted spatiality.

3. Write dates in correct order.

4. Name the months of the year.

5. Ordering at a fast food restaurant.

6. Identify how to dress appropriately for the weather.

7. Recognize signals of non-verbal communication.

8. Identify major American holidays.

\section{STRAND 10-DEMONSTRATING CORRECT PRONUNCIATION}

1. Pronounce vowel contrasts (long and short).

2. Compare and contrast consonants using minimal pairs.

3. Compare and contrast vowels using minimal pairs.

4. Speak with American stress and intonation. 


\section{LEVEL 1 - EEGINNINGA \\ STRAND 1-DEMONSTRATING BASIC SURVIVAL SKILLS}

1. (Identification and communication) Give orally, upon request, self identification and personal information including: name, address, telephone number, place of birth, age, social security number, nationality, education, marital status, and occupation.

2. Rote count numbers 0 to 100 .

3. Identify numbers 0 to 100 .

4. Respond to simple greetings.

5. Initiate simple greetings.

6. Respond to simple good-byes.

7. Initiate simple good-byes.

8. Respond to simple introductions.

9. Initiate simple introductions.

10. Express feelings and states of being, orally.

11. Identify members of immediate and extended family.

12. Tell time in minutes and hours.

13. Identify periods of time in days, months, years, and seasons.

14. Say and dial telephone numbers.

15. Identify different weather conditions.

\section{MONEY}

16. Recognize and count American money.

17. Ask for and make change.

18. Understand when identification may be required and what is acceptable.

19. Know how to endorse checks.

\section{HEALTHCARE}

20. Identify and write correctly the body parts.

21. Identify common health problems.

22. Know what information to include when making emergency calls.

\section{IBANSPORTATION}

23. Know how to use local transportation.

24. Identify traffic and information signs.

25. Identify means of transportation.

\section{HOUSNG}

26. State housing needs to potential landlords.

27. Identify and write the rooms of a house or apartment.

28. Identify and write common household furniture.

\section{Togs}

29. Identify common tools.

\section{CLOTHING AND FABRIC}

30. Identify and write most common articles of clothing.

31. Identify most common sewing equipment. 


\section{(STRAND 1, continued)}

\section{COMMUNTY RESOURCES}

33. Know how to locate agencies and institutions in the community.

34. Understand services available from agencies and institutions (health, employment, social security, schools, and libraries).

\section{STRAND 2-DEMONSTRATING KNOWLEDGE OF BASIC VOCABULARY}

1. Identify the meanings of words that give directions: circle, check, put an $x$, or underline.

2. Recognize and understand basic signs and labels.

3. Identify Easy Opposites (list included in references).

\section{STRAND 3 - DEMONSTRATING APPROPRIATE GRAMMAR AND USAGE}

\section{CAPITALIZATION}

1. Recognize appropriate use of capital letters A-Z.

\section{PUNCTUATION}

2. Identify correct punctuation (period, question mark).

\section{SPELING}

3. Say, spell, and write own first and last name.

4. Say and write own complete address, spelling street name if necessary.

\section{RECOGNIZING AND USING GRAMMATICALIY CORRECT SENTENCES}

5. Write singular and plural forms of nouns including adding es and irregulars (mouse/mice, foot/feet, tooth/teeth).

6. Respond affirmatively to yes/no questions in the present time.

7. Respond negatively to yes/no questions in the present time.

8. Initiate questions in the present time.

9. Respond appropriately to information questions.

10. Identify the meaning of contractions in positive and negative, present time with the verb to be and to do.

11. Respond to questions using there is/there are.

12. Identify appropriate use of possessive adjectives (my, your, his, her, its, our, their).

13. Identify location of objects by using the correct preposition.

\section{STRAND 4-DEMONSTRATING A KNOWLEDGE OF PHONICS}

1. Identify letter symbols for initial consonant and vowel sounds.

2. Write initial consonant and vowel sounds.

3. Identify letter symbols for final consonant and vowel sounds. 


\section{STRAND 5 - ORGANIZING OBUECTS AND INFORMATION INTO}

\section{LOGICAL GROUPINGS AND ORDERS}

1. Arrange and describe pictures in sequential order.

2. Classify words naming objects with similar characteristics

under appropriate headings.

\section{STRAND 6-DEMONSTRATING LITERAL COMPREHENSION SKILLS}

1. Follow one-step and two-step oral directions.

2. Write 4 dictated sentences concentrating on spelling.

3. Read and respond to questions based on written material.

\section{STRAND 7- WRITING}

1. Copy 5 sentences that are visually shown.

2. Address an envelope.

3. Complete forms requesting name and personal information.

4. Complete forms for registering a child in school or day care center.

\section{STRAND 8 - DEMONSTRATING JOB SEABCH AND INTERVIEW SKILLS}

(PRE-VOCATIONALESOL)

1. Identify various occupations.

2. Know how to present a positive image.

3. Answer questions concerning personal background education and experience.

4. Read and complete simple job application form.

5. Use correct markings on an application form (dash, slash, " $\mathrm{X}$ ", parentheses).

6. Understand abbreviations on an application.

7. Know how and where to look for a job.

\section{STRAND 9 - UNDERSTANDING UNITED STATES CULTURE}

1. Understand common forms of greeting and accepted spatiality.

2. Define nuclear versus extended family.

3. Understand the importance of being on time.

4. Simulate ordering at a fast food restaurant.

5. Understand the practice of tipping.

6. Recognize signals of non-verbal communication.

7. Identify visually major American holidays.

\section{STRAND 10 - DEMONSTRATING CORRECT PRONUNCIATION}

1. Compare and contrast consonants using minimal pairs.

2. Compare and contrast vowels using minimal pairs.

3. Speak with American stress and intonation. 
IDENTIFICATION AND COMMUNICATION

1. Rote count numbers 0 to 1000 .

2. Identify numbers 0 to 1000 .

3. Answer incoming phone calls.

4. Take simple phone messages.

5. Identify different weather conditions.

\section{MONEY}

6. Identify various means of payment.

7. Know banking vocabulary.

\section{HEALTHCARE}

8. Identify uses of body parts.

9. Describe common health problems.

10. Demonstrate how to make medical and dental appointments.

\section{IBANSPOBTATION}

11. Communicate simple needs to gas station attendant.

\section{HOUSING}

12. Understand abbreviations used in classified ads.

13. Understand security deposit arrangements.

14. Understand rules of apartment living.

\section{CLOTHING AND FABRICS}

15. Describe clothing in terms of color, size, and price.

\section{POSTAL SERVCES}

16. Know procedures for mailing a package or letter (inside or outside the United States), buying a postal money order, and registering or insuring mail.

\section{STRAND 2 - DEMONSTRATING KNOMLEDGE OF BASIC VOCABULARY}

1. Recognize and identify survival words (Wilson's List).

2. Identify Easy Opposites (from given list). 


\section{STRAND 3 - DEMONSTRATING APPROPRIATE GRAMMAR AND USAGE}

1. Read and write using appropriate punctuation (period, question mark, comma, apostrophe).

2. Say name, address, telephone number.

3. Write name, address, telephone number.

\section{USING GRAMMATICALIY CORRECT SENTENCES}

4. Write singular and plural forms of nouns (" $y$ " change to " $i "$ ", $f$ " change to " $v "$, before "-es", final "o", identical singular and plural).

5. Respond affirmatively to yes/no questions in the past time using short three word answers.

6. Respond negatively to yes/no questions in the past time using short three-word answers.

7. Initiate questions in the past time.

8. Respond to information questions in the past time.

9. Recognize appropriate use of this, that, these, and those with nouns.

10. Respond to questions using object pronouns (me, you, him, her, it, us, them).

\section{STRAND 4-DEMONSTRATING A KNOMLEDGE OF PHONICS}

1. Identify final silent " $e$ ".

2. Identify silent consonants.

3. Distinguish between long and short vowel sounds.

\section{STRAND 5 - ORGANIZING OBJECT AND INFORMATION INTO LOGICAL GROUPINGS AND ORDERS}

1. Arrange sentences in sequential order.

2. Classify words naming objects with similar characteristics under appropriate headings.

\section{STRAND 6 - DEMONSTRATING LITERAL COMPREHENSION SKILLS}

1. Follow 2 and 3-step oral directions.

2. Demonstrate comprehension of dictated story.

3. Write 10 dictated sentences.

4. Read and respond to questions based on written material.

\section{STRAND 7 - WRITING}

1. Write a short thank you note (3-5 sentences). 


\section{STRAND 8 - DEMONSTRATING JOB SEARCH AND INTERVIEW SKILLS} (PRE-VOCATIONALESOL)

1. Know how to present a positive image.

2. Know the importance of asking questions regarding duties, hours, salary, qualifications, and fringe benefits.

3. Answer questions concerning background, education, and experience.

4. Read and complete a simple job application form.

5. Know how and where to look for a job.

\section{STRAND 9 - UNDERSTANDING UNITED STATES CULTURE}

1. Compare popular American foods to native foods.

2. Name and use common weights and measures.

3. Identify common types of food stores.

4. Understand the practice of "tipping".

5. Understand how to wash certain fabrics.

6. Know vocabulary related to major American holidays.

\section{STRAND 10 - DEMONSTRATING CORRECT PRONUNCIATION}

1. Compare and contrast consonants using minimal pairs.

2. Compare and contrast vowels using minimal pairs.

3. Speak with American stress, intonation, and rhythm. 


\section{IDENTIFICATION AND COMMUNICATION}

1. Use and respond to polite expressions such as, please, excuse me, etc.

2. Identify and define members of the extended family (in-laws, godparents, greatgrandparents).

3. Answer incoming calls and take messages.

\section{FOOD ANDMONEY}

4. Identify items in a grocery store.

5. Determine best product price through comparison shopping.

6. Identify common packaging of foods.

7. Read an order from a menu.

8. Count correct change for bill.

\section{HEALTHCARE}

9. Describe medical problems over the phone and in person.

10. Demonstrate skill of communicating emergency situations using " 911. "

11. Demonstrate recognition of prescription and non-prescription drugs.

12. Determine safety procedures involved in medicines and poisons including poison control center.

13. Recognize the importance of proper personal hygiene.

14. Describe dental health problems.

\section{IRANSPOBTATION}

15. Ask for and give directions locally.

16 Use schedules for travel information.

17. Recognize and identify common road signs.

18. Identify outside parts of a car.

19. Fill out driver's license application.

20. Respond to police officer when being stopped for a violation.

\section{HOUSNG}

21. Identify different means of locating a rented apartment (agencies, signs, ads, or ask friends).

22. Identify vocabulary for installations of phone service and electrical service.

23. Identify vocabulary for rooms and furnishings in detail.

24. Compare different types of housing.

25. Define types of materials (cotton, silk, linen, permanent press, polyester).

26. Describe material designs (solid, floral).

27. Know how to use washer and dryer.

\section{BANKING}

28. Demonstrate ability to open a bank account (savings and checking).

29. Define terms used in a payroll check.

30. Complete deposit and withdrawal slips. 
31. COMMUNITY RESOURCESAND

32. Identify spectator sports.

33. Identify the role of the following agencies (hospital and library).

\section{STRAND 2 - DEMONSTRATING APPROPRIATE GRAMMAR AND USAGE}

1. Write past tense sentences using regular verbs (affirmative and negative).

2. Ask questions in writing using question words (present, past).

3. Write past tense sentences using irregular verbs (affirmative and negative).

4. Change sentences from present to past, orally.

5. Initiate and follow direct and indirect commands (affirmative and negative).

6. Respond to questions in future orally (will, going to) (affirmative and negative).

7. Ask questions in writing using question word (future).

8. Formulate questions orally using tag endings (affirmative and negative).

9. Utilize possessive pronouns appropriately orally in sentences.

10. Demonstrate proper use in writing of count mass adjectives (much/many, a few/a little, and some/any).

11. Identify nouns of quantity.

12. Respond to questions orally using appropriate object pronouns (me, you, him, her, us, them).

13. Formulate sentences using past continuous (affirmative and negative).

14. Distinguish in writing the difference between the past continuous and the simple past tense.

15. Differentiate in writing among who, whom, which, and that in sentences.

16. Identify appropriate usage of reflexive pronouns (myself, herself, themselves).

17. Demonstrate correct usage of possessive forms of nouns in writing.

18. Recognize in writing the appropriate use of the future continuous and the present tense.

19. Use prepositions of time in writing.

\section{STRAND 3 - DEMONSTRATE KNOWLEDGE OF PRONUNCIATION OF AMERICAN ENGLISH}

1. Reproduce short a sound in a series of words.

2. Reproduce short e sound in a series of words.

3. Reproduce short $i$ sound in a series of words.

4. Reproduce short o sound in a series of words.

5. Reproduce short $u$ sound in a series of words.

6. Demonstrate auditory discrimination of short words.

7. Reproduce long a sound in a series of words.

8. Reproduce long e sound in a series of words.

9. Reproduce long $i$ sound in a series of words.

10. Reproduce long o sound in a series of words.

11. Reproduce long u sound in a series of words.

12. Demonstrate auditory discrimination of long vowels.

13. Reproduce special vowel sounds (oo - foot, o- dog, ou - cow, oi - boy).

14. Demonstrate auditory discrimination of special vowel sound. 
(STRAND 3, continued)

15. Reproduce the $d$ sound in a series of words.

16. Reproduce the $t$ sound in a series of words.

17. Reproduce the ed sound in a series of words.

18. Demonstrate auditory discrimination of $\mathrm{d}, \mathrm{t}$, and ed sounds of regular past tense verbs.

\section{STRAND 4 - ORGANIZING OBJECTS AND INFORMATION INTO LOGICAL GROUPINGS AND ORDERS}

1. Organize series of pictures in sequential order, and orally state reasons for sequence.

2. Classify words naming objects with similar characteristics under appropriate headings.

\section{STRAND 5 - DEMONSTRATING LITERAL COMPREHENSION SKILLS}

1. Demonstrate comprehension of a dictated story.

2. Identify the order of events in an oral story.

3. Read and respond to questions based on written material.

STRAND 6 - DEMONSTRATING APPROPRIATE SKILLS FOR OBTAINING INFORMATION

1. Obtain appropriate information from a dictionary.

\section{STRAND 7 - DEMONSTRATE WRITING ABILITY}

1. Identify the parts of a friendly letter.

2. Write a friendly letter.

3. Properly punctuate a paragraph (period, comma, question mark, and exclamation point).

4. Write a creative paragraph.

\section{STRAND 8 - DEMONSTRATING JOB SEARCH AND INTERVIEW SKILLS} (PRE-VOCATIONALESOL)

1. Identify abbreviations used in want ads.

2. Demonstrate ability to read want ads.

3. Complete a job application form (complex).

4. Use acceptable language in a job interview.

5. Follow acceptable procedure in being laid off from a job.

6. Demonstrate ability to use time cards and time sheets.

\section{STRAND 9 - UNDERSTANDING UNITED STATES CULTURE}

1. Compare social class structure of United States and other countries.

2. Differentiate among the various components of education (elementary, middle school, etc.). 
STRAND 10 - DEMONSTRATE ABILITY TO SPEAK BEFORE A GROUP

1. Demonstrate and explain a favorite hobby or skill.

2. React to a picture in a spontaneous 3 minute speech.

3. Role play teacher in front of the class and teach or recount something.

\section{STRAND 11 - DEMONSTRATING AN EXPANDED VOCABULARY}

1. Identify appropriate synonyms.

2. Identify appropriate antonyms.

3. Distinguish orally between homograph pairs.

4. Distinguish in writing between homophones.

5. Determine analogous relationship between words.

6. Define two-word verbs in context.

7. Recognize idiomatic expressions.

8. Identify commonly used symbols, abbreviations and acronyms.

9. Increase vocabulary by building on word families (buy-buyer, act-actor, happy-happiness, slow-slowly, pay-payment). 


\section{STRAND 1 - DEMONSTRATING BASIC SURVIVAL SKILLS}

\section{IDENTIFICATION AND COMMUNICATION}

1. Use time expressions correctly such as: weekend, day after tomorrow, in two weeks, yearly, daily, quarterly, bi-monthly, semi-annually, ago, since, for.

2. Utilize telephone or directory for local and long-distance calls.

3. Answer incoming calls and take messages.

\section{FOOD AND MONEY}

4. Follow directions from a recipe.

5. Recognize and explain mistakes in change.

\section{HEALTHCARE}

6. Maintain medical records.

7. Obtain, identify, and be able to follow proper dosages of medicine.

8. Determine safety procedures involved in medicines and poisons including Poison Control Center.

9. Identify medical specialists.

10. Respond to emergencies using 911.

11. Ask for and give directions for long distance traveling.

12. Identify parts of a car (inside and outside).

13. Identify different types of cars (sedan, convertible, coupe, station wagon).

\section{HQUSING}

14. Define terms used in a rental lease.

15. Communicate apartment maintenance problems.

\section{CLOTHINGAND FABBICS}

16. Identify various types of clothing and fashion.

17 Communicate needs to a salesperson in a clothing store.

\section{BANKING}

18. Compare services offered at banks.

\section{COMMUNITY RESOURCES AND RECREATIONAL FACILITIES}

19. Identify various forms of recreation (sports, picnics, theater, etc.).

20. Explain hobbies.

21. Identify the role of Health Department, Immigration Services, and health clinics.

\section{MEDIA}

22. Demonstrate ability to read newspaper headlines.

23. Interpret TV/radio newspaper headlines.

24. Recount favorite TV program. 


\section{STRAND 2 -DEMONSTRATING APPROPRIATE GRAMMAR AND USAGE}

1. Respond to questions orally in present perfect tense (negative, affirmative, and short answer).

2. Differentiate in writing between the present perfect tense and the past.

3. Use time expressions appropriately (for, since, ago, yet, already, adverbs of time and frequency).

4. Utilize prepositions of place, time, and manner correctly.

5. Differentiate among modals: can, could. may, might, shall, will, should, would, must, ought to, have to, able to, supposed to, had better, would rather.

6. Demonstrate ability to use comparative adjectives correctly.

7. Demonstrate ability to use superlative adjectives correctly.

8. Formulate grammatically correct sentences using adjectives in expressions of equality.

9. Formulate grammatically correct sentences using adjectives in expressions of inequality.

10. Recognize the difference between adjectives and adverbs.

11. Demonstrate ability to use comparative adverbs correctly.

12. Demonstrate ability to use superlative adverbs correctly.

13. Formulate grammatically correct sentences using adverbs in expressions of equality.

14. Formulate grammatically correct sentences using adverbs in expressions of inequality.

15. Distinguish between good and well to formulate grammatically correct sentences.

16. Distinguish in writing the difference between the past perfect and the present perfect.

17. Properly place indirect objects in complete sentences.

18. Formulate plurals of words with foreign derivatives.

19. Demonstrate the ability to utilize conjunctions correctly (either, neither, so, too, but, and nor).

20. Use the "used to" past in grammatically correct sentences.

\section{STRAND 3}

\section{DEMONSTRATE A KNOWLEDGE OF PRONUNCIATION OF AMERICAN ENGUSH}

1. Reproduce one letter consonant sound in a series of words.

2. Reproduce two letter consonant sounds in a series of words.

3. Demonstrate auditory discrimination between one and two letter consonant sounds.

4. Reproduce the " $j$ " sound in a series of words (" $j "$ and " $g$ ").

5. Reproduce the "k" sound in a series of words. ("k" and "c").

6. Reproduce the " $s$ " sound in series of words (" $s$ " and " $c$ ").

7. Reproduce the " $z$ " sound in a series of words (" $z$ " and " $s$ ").

8. Demonstrate auditory discrimination between the " $s$ " and " $z$ " sound. 
STRAND 4

ORGANIZING OBJECTS AND INFORMATION INTO LOGICAL GROUPING AND ORDERS

1. Organize series of pictures in sequential order and orally related events prior to the situation and the events following the situation.

2. Classify words naming objects with similar characteristics under appropriate headings.

\section{STRAND 5 -DEMONSTRATING LITERAL COMPREHENSION SKILLS}

1. Demonstrate comprehension of a dictated story.

2. Identify order of events in an oral story.

3. Read and respond to questions based on written material.

STRAND 6

DEMONSTRATING APPROPRIATE SKILS FOR OBTAINING FACTUALINFORMATION

1. Obtain appropriate information from maps.

2. Obtain appropriate information from table of contents.

\section{STRAND 7-DEMONSTRATE WRITING ABILITY}

1. Identify the parts of business letter.

2. Write a business letter.

3. Properly punctuate a business letter.

4. Properly punctuate and capitalize a paragraph (period, comma, colon, question mark, and exclamation point).

5. Write a creative two-paragraph composition.

\section{STRAND 8 - DEMONSTRATE JOB SEARCH AND INTERVIEW SKILLS} (PRE-VOCATIONAL SKILLS)

1. Complete job application form (complex).

2. Arrange a job interview by phone.

3. Use acceptable language in a job interview.

4. Use appropriate modes of behavior and strategies (eye contact, hand shake, and coffee break).

\section{STRAND 9 - UNDERSTANDING UNITED STATES CULTURE}

1. Recognize proper attire to fit the occasion.

2. Recognize the changing role of each member of the family.

3. Recognize the changing role of the American woman.

4. Recognize the procedures in planning a wedding. 
1. Present a speech about native country.

2. React to a picture in a spontaneous 3-5 minute speech.

3. Role play teacher in front of the class and teach or recount something.

\section{STRAND 11 - DEMONSTRATING AN EXPANDED VOCABULARY}

1. Identify appropriate synonym.

2. Identify appropriate antonym.

3. Distinguish orally between homograph pairs.

4. Distinguish in writing between homophones.

5. Determine analogous relationships between words.

6 . Define two-word verbs in contexts.

7. Recognize idiomatic expressions. 


\section{STRAND 1 - DEMONSTRATING BASIC SURVIVAL SKILLS}

\section{IDENTIFICATION AND COMMUNICATION}

1. Request information on the telephone.

\section{FOOD AND MONEY}

2. Compare restaurants for type of food, quality of service, and price.

3. Compare the buying power of American currency with foreign currency (i.e., what $\$ 10.00$ will buy here vs. in a foreign country).

\section{HEALTHCARE}

4. Identify terms needed for health insurance.

5. Identify different types of health care services available.

6. Compare the role of the pharmacist and the pharmacy in the U.S. with other countries

7. Determine safety procedures involved in medicines and poisons, including poison control.

8. Respond to emergencies using 911.

9. Recognize terms dealing with hospital procedures.

10. Read and explain maps.

11. Explain malfunctions of an automobile.

12. Recognize proper car maintenance.

13. Identify terms needed for auto insurance.

14. Identify terms needed for purchasing a car (new and used).

\section{HOUSING}

15. Demonstrate ability to read a lease.

16. Demonstrate procedure for breaking a lease.

17. Define terms needed to purchase real estate (house, condo, time-sharing, land).

18. Demonstrate ability to compare insurance, maintenance contracts, and taxes.

\section{EMERGENCIES}

19. Define terms involving natural disasters (hurricane, tornado, twister).

20. Demonstrate ability to communicate information regarding assault, theft, and rape.

\section{CLOTHING AND FABRICS}

21. Ordering from a catalogue.

22. Compare various purchasing methods.

23. Communicate displeasure in exchanging and returning merchandise.

\section{BANKING}

24. Demonstrate ability to obtain a bank loan.

25. Follow directions for using an automatic teller. 


\section{COMMUNITY RESOURCES AND RECREATIONAL FACILITIES}

26. Identify the role of the following community resources: Legal Aid, Social Services, and Social Security.

MEDIA

27. Demonstrate ability to read an interpret a newspaper article.

28. Interpret TV news bulletins.

\section{STRAND 2 - DEMONSTRATING APPROPRIATE GRAMMAR AN USAGE}

1. Change sentences from active voice to passive voice.

2. Initiate sentences using the future-possible condition in response to questions.

3. Initiate sentences using the present-unreal condition in response to questions.

4. Initiate sentences using the past-unreal condition in response to questions.

5. Differentiate among various conditional phrases to express proper usage.

6. Change sentences from the present to the perfect form of modals (example: present form-must go; perfect form + must have gone).

7. Recount previous conversations or tell a story by using indirect speech.

\section{STRAND 3}

\section{DEMONSTRATE KNOWLEDGE OF PRONUNCIATION OF AMERICAN ENGLISH}

1. Reproduce "f" sound in a series of "ph" and "gh" words (phase, tough).

2. Reproduce "sh" and " $k$ " sounds in a series of "ch" words (chaise, mechanic).

3. Reproduce words used in American English that are foreign in origin (patio, hors d'oeuvres).

\section{STRAND 4 - ORGANIZING OBUECTS AND INFORMATION INTO LOGICAL GROUPINGSAND ORDER}

1. Organize a series of pictures in sequential order and write a short story of 150 words.

2. Classify words naming objects with similar characteristics under appropriate headings.

\section{STRAND 5 - DEMONSTRATING LITERAL COMPREHENSION SKILLS}

1. Demonstrate comprehension of an oral story.

2. Identify the order of events in a oral story.

3. Read and respond to questions based on written material.

\section{STRAND 6 - DEMONSTRATE WRITING ABILITY}

1. Properly punctuate a paragraph (capital, period, comma, semi-colon, colon, question mark, exclamation point, quotation marks, and hyphen).

2. Write a creative composition of approximately 200 words.

3. Write a job resume. 


\section{STRAND 7 - DEMONSTRATING JOB SEARCH AND INTERVIEW SKILLS (PRE-VOCATIONAL ESOL)}

1. Obtain information on benefits and rights (insurance, vacation, raises, sick leave, holidays).

2. Demonstrate acceptable behavior.

3. Use acceptable procedure in following up a job interview.

\section{STRAND 8 - UNDERSTANDING UNITED STATES CULTURE}

1. Develop short range and long range goals.

2. Identify animals which are considered pets.

3. Recognize alternative family lifestyles.

4. Realize the role of the aged in the United States.

5. Communicate the role of religion in a secular society.

6. Communicate accepted behavior involved in reacting to death and dying (include proper time for sending a sympathy card).

7. Recognize acceptable behavior.

8. Recognize the necessary terminology for pregnancy and childbirth.

\section{STRAND 9 - DEMONSTRATE ABILITY TO SPEAK BEFOREA GROUP}

1. Present a topic for discussion based on reference list.

2. Present a television commercial.

3. Role play "teacher" in front of the class and teach or recount something.

\section{STRAND 10 - DEMONSTRATING AN EXPANDED VOCABULARY}

1. Identify appropriate synonym.

2. Identify appropriate antonym.

3. Distinguish orally between homograph pairs.

4. Distinguish in writing between homophones.

5. Determine analogous relationship between words.

6. Define three-word verbs in context.

7. Recognize idiomatic expressions.

8. Communicate properly using troublesome verbs (sit/set, raise/rise, lay/lie).

9. Identify commonly used abbreviations and acronyms.

10. Increase vocabulary by building on word families (buy/buyer, act/actor, happy/happiness, slow/slowly, pay/payment).

11. Identify foreign words used in American English. 
APPENDIX D 
NAME:

1. Look at the actures. Wrtte the correct name below each picture.

CAR BLS HAND LED TELEHONE

II. Answer the questions in a complete sentence.

EXAMPLE: What class is this? This is an English class.

What is your name?

What country are you from?

What language do you speak?

Are you married or single?

Where do you live?

How long have you been here?

III. DIRECTIONS: Write these sentences in negative and question form.

1. John goes there twice a week.

negative.

question:

2. The nurse is watching the baby.

negative:

question:

3. You were here last week.

negative:

question:

4. I an from the school.

negative:

question:

IV. Write a few sentences about yourself--for example: why you are here, how long you will be in this country, what do you like to do, etc. 
* A maximum of 15-20 minutes should be allowed for the student to complete the test.

I. If the student cannot complete any of the four parts of the test or makes mistakes in PART I, picture indentification, he/she should be placed in the Level I Pre-Lit class.

II. If the student completes PART I but makes mistakes in PART II, example: does not use complete sentences or does not use the correct verbs, he/she should be placed in Level Ia or Ib depending on his proficiency in the oral interview.

III. Students who complete PART I and II correctly but have difficulty with questions or negatives should be placed in Level II. Students who have problems with verbs in the past tense should also be placed in Level II.

IV. Students who answer PART II using the present perfect, example: "I have lived in Florida for 2 years," or those who make only a few mistakes in using the past tense, and with questions, should be placed in Level III. These students should have been able to write a 2-3 sentence paragraph in PART IV of the placement test. They should also demonstrate oral proficiency in the interview with the guidance counselor and/or department head.

\section{ORAL PROFICIENCY INTERVIEW}

Suggested questions for ESOL students' placement interview.

1. Where do you come from?

2. How long have you been in Florida? (Rephrase to "time in Florida" if they don't understand)

3. Have you studied English before? Where?

4. Do you work?

5. Can you come to school every day until $2: 00 \mathrm{p} . \mathrm{m}$. or 10:00 p.m.?

6. What is you difficulty or problem with the English language?

7. Are you on vacation or do you live in Florida?

Student placement will be based both on oral proficiency and written work done on the placement test. 
APPENDIX E 


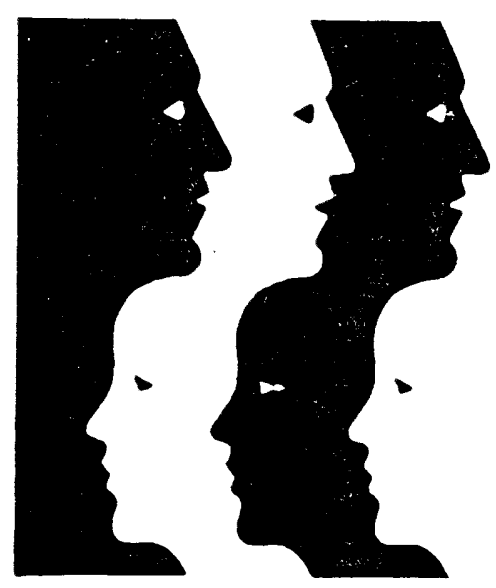

The NYS Place Tes?

New York State's Placement Test for English as a Second Language Adult Students

ADMINISTRATOR'S MANUAL

TEST BOOKLET - FORM B

PICTURE CUE BOOKLET - FORM B

ESL CURRICULUM

SUGGESTIONS FOR USING THE VIDEOTAPE

Yew Youk

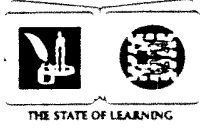

The University of the State of New York

The State Education Department

Division of Continuing Education Planning and Development

Albany, New York 12230

(Reprinted with permission from the New York State Education Department.) 


\section{THE UNIVERSITY OF THE STATE OF NEW YORK}

\section{Regents of The University}

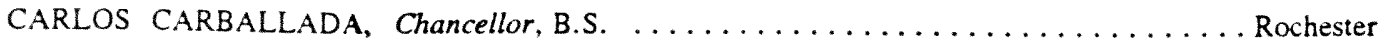

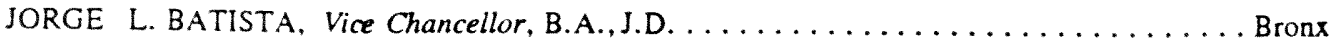

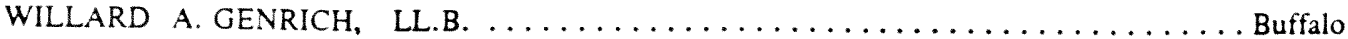

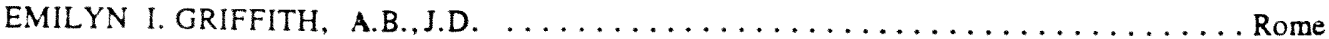

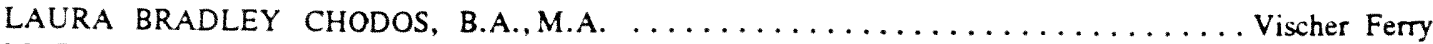

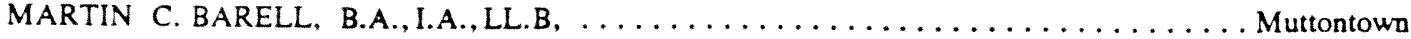

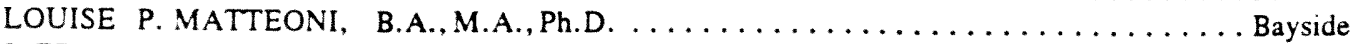

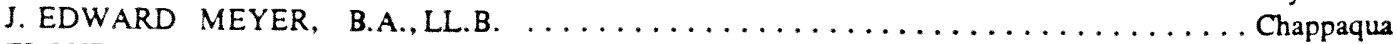

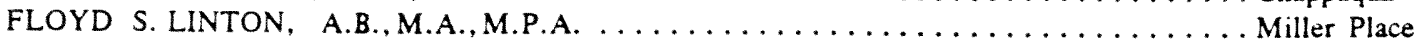

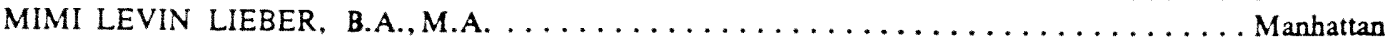

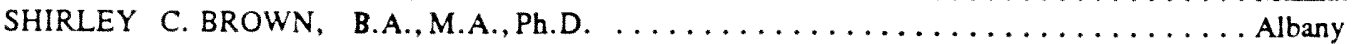

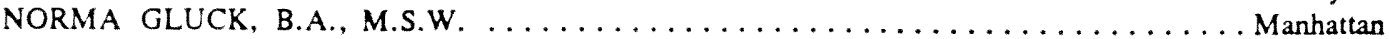

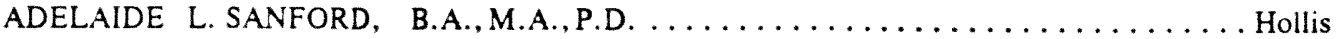

WALTER COOPER, B.A., Ph.D. $\ldots \ldots \ldots \ldots \ldots \ldots \ldots \ldots \ldots \ldots \ldots \ldots \ldots \ldots \ldots$ Rochester

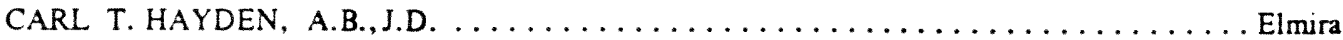

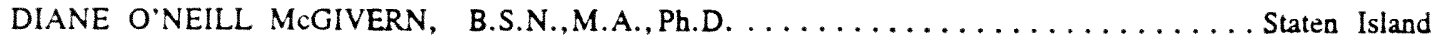

President of The University and Commissioner of Education

Thomas Sobol

Executive Deputy Commissioner of Education

Thomas E. Sheldon

Deputy Commissioner for Elementary, Middle and Secondary Education

Arthur L. Walton

Assistant Commissioner for Office of Workforce Preparation and Continuing Education

James A. Kadamus

The State Education Department does not discriminate on the basis of age, color, religion, creed, disability, marital status, veteran status, national origin, race, gender or sexual orientation in the educational programs and activities which it operates. Portions of this publication can be made available in a variety of formats, including braille, large print or audio tape, upon request. Inquiries concerning this policy of equal opportunity and affirmative action should be referred to the Department's Affirmative Action Officer, NYS Education Department, 89 Washington Avenue, Albany, NY 12234 
Eric Rosenbaum, McBurney YMCA, New York City

Julie Spinthourakis, Florida Department of Education

Lily Din Woo, New York state Education Department

Principal consultants to the Committee were Jean Bodman and Linda Smith Kharde, both internationally known authorities in the field of English as a second Language program design and evaluation. Jean D'ArCy Maculaitis, of MAC Testing and Consulting, Inc., and Philip Merrifield of New York University advised the committee in the early stages regarding theories of language acquisition and the difficulties of properly assessing English language competencies. For their help we are deeply grateful.

Too numerous to mention are the scores of ESOL instructors from New York, New Jersey, and Florida, who cooperated in the field test by administering the NYS Place Test to over 1100 students. For the hours they devoted to this task and for their subsequent evaluations we are especially appreciative.

Dr. George K. Tregaskis, chaired the ESOL Test Committee, Dr. Camille Fareri, office of Workforce Preparation and continuing Education serves as the project's program manager. Dorothy Houde, Albany City Schools and Dr. Patricia Mooney Gonzalez, office of Workforce Preparation and Continuing Education have provided invaluable assistance as project coordinators.

The art work was provided by the Department's Center for Art and Design. 


\section{ADMINISTRATOR'S MANUAL}

\section{NYS PLACE TEST DEVELOPMENT}

In 1983 the New York state Education Department published a manual, Managing Programs for Adults, which contained, among other guidelines, an English as a second language curriculum. The instruments being used for assessment in the state's Adult ESOL program at the time bore little relationship to this curriculum. In addition, they were criticized for the amount of time required to administer them, for being too expensive, for containing pictures and scoring systems that were ambiguous, for lacking validity and reliability, and for being offensive to adults.

It became apparent that a new test was needed. Indeed an entire battery of tests consisting of a quick assessment instrument for initial placement, an achievement test to mark progress and a tool for diagnosing an individual's strengths and weaknesses (and each available in several forms) -- would comprise a most ideal testing program.

Late in 1983 a committee of state Education Department staff plus representatives from various New York City, Long Island and upstate adult ESOL programs began to convene monthly to consider the alternatives. Bordering states of New Jersey, Connecticut, and Massachusetts, also sensing the need for a good adult EsOL test, joined the endeavor by sending representatives to the committee's meetings. A later participant joining the committee was florida.

This committee reviewed numerous testing instruments available to the adult ESOL field, and even met with some of the test developers. The committee concluded that a majority of the specifications that they had established for the test they envisioned could be met only by an instrument specifically developed to those specifications - - a task the committee agreed to undertake.

It was further determined that no single instrument could be expected to function as an indicator for placement, an achievement marker, and a diagnostic tool. Thus, the committee decided to first develop two forms of a placement test and schedule the development of achievement and diagnostic instruments for a later date.

\section{B. TEST SPECIFICATIONS}

The committee established and met a series of specifications for the placement test. Its curricular validity is based on the New York State's English to Speakers of other Languages curriculum found in Managing Programs for Adults.

The committee members themselves, representing an impressive array of experience and training in adult ESOL instruction, along with the guidance of several nationally recognized authorities in 
the field of ESOL program design and evaluation, developed test items that were subject to peer review. Thus, they also served as the panel of experts that further established validity. The items which were developed test principally for the listening and speaking objectives of each of the four levels of the ESOL curriculum.

The test has three sections: oral Warm-up, Basic English Literacy Screening, and oral Assessment with Pictures.

1. The oral Warm-up consists of some simple greetings and brief commands.

2. The Basic English Literacy Screening consists of reading numbers, letters, words, and a single sentence or question.

3. In the oral Assessment with pictures, the main part of the test, the student examines several two to four picture scenarios depicting adults in everyday life situations and responds to questions about the pictures.

Maximum testing time is approximately 10-15 minutes.

\section{FIELD TEST/VALIDATION INFORMATION}

Two forms of the NYS Place Test, Forms $A$ and $B$, were developed and field tested. Field testing results based on test scores from 1,118 students from New York, New Jersey and Florida indicate that the scoring system is objective and that interrater reliability is high $(.96)$.

Form $B$ went on to the validation phase. Validation study results based on test scores of 1,751 students in New York state indicate that student placement in a recommended ESOL level was appropriate in $96.5 \%$ of the cases. The validation data also provided convincing evidence of the appropriateness of the cut scores that were developed on the basis of the original field test. In addition, the item difficulties appear appropriate for the purpose of the test.

\section{CURRENT STATUS}

The NYS Place Test, Form B has undergone more rigorous evaluation than any other test currently available for use in adult ESOL programs and surpassed projections regarding its reliability and validity. New York State's Committee for Adult ESOL Program Improvement has recommended use of the NYS Place Test exclusively for assessing the oral English language proficiency of adults. Based on the Committee's recommendations, the NYS Place Test, Form $B$, has been mandated as of July 1, 1992, for all New York State Education Department office of Workforce Preparation and Continuing 
Education funded ESOL programs.

At this time, only Form $B$ is available for general use. Form A has been revised and subsequently re-field tested. Form A will also be available for general use once the field test data analysis and the ensuing validation study have been completed.

\section{E. TEST ADMINISTRATOR TRAINING}

A test administrator must be trained to give and score the NYS Place Test. Training is available via two routes:

1. Attending a NYS Place Test Implementation Training Workshop ( 3 hours) offered by the NYS Education Department.

2. Using the NYS Place Test Training Video (approximately 30 minutes) in conjunction with the Administrator's Manual.

Training can be provided conveniently on-site for individuals or small groups by using the NYS Place Test Training Video and reviewing the Administrator's Manual, the NYS Place Test itself, and the Videotape Training Notes. Copies of the training video, additional copies of the NYS Place Test and looseleaf easel binder, and Student Information and Answer Sheets (SIAS) are available for purchase from:

\section{Albany Educational Television}

27 Western Avenue

Albany, New York 12203

Phone: (518) 465-4741 Fax:(518) 462-7104

For answers to questions concerning the state Education Department's training or the substance, field testing, validation and use of the NYS Place Test, contact:

NYS Place Test Information Center

NYS Education Department

office of Workforce Preparation and Continuing Education

Cultural Education Center - Room 5D28

Albany, New York 12230

Phone:(518) 474-8701 Fax: (518) 474-2801

\section{F. TEST ADMINISTRATION}

To administer the test, the following materials are needed:

- Student Information and Answer Sheet - one per student. This is a white and pink NCR (no carbon required) sheet and is used to record scores as well as other pertinent information. 
Test Booklet - one per test administrator. (blue pages) This booklet contains the procedural notes and questions for the test. The Test Booklet may be separated from this binder and placed in a separate binder or folder for use by the test administrator.

- Picture Cue Booklet - one per test administrator. This section contains the stimulus cues (letters, numbers, words or pictures) for the Basic English Literacy Screening section and the oral Assessment with Pictures scenarios. The NYS Place Test loose leaf binder has a presentation easel feature which may be used to display the pictures for the student. An entire set of pictures for one scenario may be presented without having to turn pages.

- A sheet of paper and either a paper bag and four pencils (option I) or three pencils (option II)one set per administrator.

- Clipboard to hold the student Information and Answer Sheet (SIAS) - (optional).

\section{Test Administration Protocol}

The test is administered orally to one student at a time. Choose a quiet room and have the student sit so that he/she may see the Picture cue Booklet as you point to the pictures. You may use a clipboard to hold the SIAS so you can record scores without distracting the student.

The following conventions are used in the Test Booklet:

- Procedural notes for the test administrator are in italic type.

\section{"Point to numbers" \\ - oral cues are in regular type. \\ "Please read these numbers."}

Follow the procedural notes (in italics) as you give the test. Be sure to point to the pictures when the procedural notes instruct you to do so. Read the oral cues (regular type) exactly as they are written. Do not make any changes, since this will affect the standardization of the test. Look at the student while asking the questions. 
If a student asks for a repetition of an oral cue, you may repeat the cue once. There is no penalty for the student. If after one repetition, the student still does not understand the cue, go on to the next item. Also, if you do not understand what a student has said, you may ask the student to repeat, without penalty to the student. If the student responds with a gesture or gives a non-English response, ask him/her to repeat the answer in English.

\section{G. SCORING}

(A1l examples and references relate to Form B of the NYS Place Test)

\section{Introduction to scoring}

NYS Place Test scoring is designed to be objective, provide accurate placement of students and be convenient for the test administrator to learn and use. Practice is essential to make the scoring of each response easy and almost "automatic" for the test administrator.

There are only three possible scores for each response: 0,1 , and 2. Responses must be verbal and must be in English. Pronunciation and accent do not affect scores unless they make the response unintelligible.

The following sections explain how to score each of the three components of the NYS Place Test, followed by specific examples to illustrate and explain correct scoring.

There is a "fail safe" question at the end of each series of questions in the oral Assessment with Pictures section. Use this question to conclude the testing if the student scores three consecutive zeros $\left(0^{\prime} \mathrm{s}\right)$. This question is designed to be easy to answer, and enables the student to conclude with a correct response and a positive feeling. The "fail safe" question is not scored. The fail safe questions are found in section II on pages 22, 23 , 24 , and 25. Once the fail safe question has been given, conclude the testing session appropriately.

\section{Scoring for the oral warm-up}

Score
$0=\begin{aligned} & \text { Student Response } \\ & \text { student did not understand the question. } \\ & \text { stumse, the response is inappropriate, or }\end{aligned}$
$\begin{aligned} & \text { Response is communicative: } \\ & \text { a) The student understands the question. } \\ & \text { b) There is a problem with grammar or } \\ & \text { vocabulary. }\end{aligned}$




$$
\begin{aligned}
& \text { c) It is not something a native English } \\
& \text { speaker would say. } \\
& 2= \\
& \text { Response is communicative: } \\
& \text { a) The student understands the question. } \\
& \text { b) It is grammatically accurate. } \\
& \text { c) It is something a native English speaker } \\
& \text { would say. }
\end{aligned}
$$

\section{Score Rationale}

\section{Scoring the Basic English Literacy screening}

Scoring for the Basic English Literacy Screening may not bear on the student's ESOL placement level. It only provides the most general information on the student's basic English literacy skills.

Score 1 point for each correct response. For example, item number 1 asks, "Please read these numbers." $(5,9,28,743)$ If the student reads all four numbers correctly, score 4 ; if three are read correctly, score 3 ; etc.

Note: 743 may be read as "seven hundred forty three" or "seven forty three" (as in a street address) but not as single digit numbers: "seven, four, three." 
$0=$ The student did not understand the question. No response, or the response is inappropriate.

$1=$ The response is communicative:

a) The student understands the question.

b) There is a problem with grammar or vocabulary.

c) It is not something a native English speaker would say.

$2=$ The response is communicative:

a) The student understands the question.

b) It is grammatically accurate.

c) It is something a native English speaker would say.

Scoring Examples for the oral Assessment with Pictures

Question number 9 (second set of pictures) asks, "What's the woman trying to do?"

Possible Responses

No response

"Kitchen"

0

"She try to got a

dish."

"To buy a dish."

"To get a plato."

1

1

"She try to, (student hesitates makes motion of reaching) to, the dish."

"She is trying to reach a dish."

"She's trying to reach a dish."

0

1
Score Rationale

The student does not understand the question.

The response is inappropriate.

The response is communicative but grammatically inaccurate.

The response is communicative.

The response is communicative but incorrect vocabulary is used. (Only English responses are correct.)

The response indicates the student understood the question; lack of vocabulary.

The response is communicative and grammatically accurate.

The response is communicative and grammatically accurate. (Contractions are acceptable.) 
"Get a dish."

"Prepare dinner." or

"Show the girl how

to reach high up." or

"Collect insurance."
All plausible responses.

Remain open to divergent responses.

If a student answers "I don't know" to any item, you must decide if he/she is saying "I don't know" in response to what you just asked or if he/she doesn't know what may be going on in the pictures. In some cases, "I don't know" may be a plausible response. If you are unsure, prompt the student by saying "What do you think?" or "Try to think of something." If the student's answer is still "I don't know" and the student appears confused, score 0 .

Note that item 20 of the oral Assessment with Pictures is a two-part question requiring either a yes or no response and an explanation.

For item 25 of the oral Assessment with Pictures, ("What could Joe say to his boss now? "Anything else?") the student must respond with a minimum of two answers, to score 1 or 2 . If the student only gives one answer, score 0 , regardless of the correctness of the response.

Listen carefully in order to rate the accuracy of student responses. Only standard English, as spoken by a native English speaker is acceptable for a score of 2 .

Remain open to divergent responses. ESOL students come to class with a wide range of abilities, backgrounds and life experiences. Students from various sociolinguistic and cultural backgrounds may view the pictures differently from you. It is not your job as test administrator to determine what may be going on in the picture scenarios; rather, you are to determine how well the students are able to respond to your test questions.

\section{H. PLACEMENT}

If a student scores three consecutive $0^{\prime} s$ on the oral Warm-up, terminate testing and place the student in ESOL level 1. You may then wish to administer the Basic English Literacy screening section of the NYS Place Test to gain additional information regarding the student's reading ability. 
If the student completes the oral Warm-up successfully (without scoring three consecutive $0^{\prime} S$ ), proceed by administering the Basic English Literacy Screening section. Regardless of the student's performance on the Basic Literacy Screening section of the test, proceed by administering the oral Assessment with Pictures.

Stop testing when the student scores three consecutive o's in any part of the oral Assessment with Pictures. Finish the testing session by asking the fail safe question at the end of the scenario in which the student scored three consecutive o's. This "fail safe" question is not scored and has been included to end the testing situation with the student feeling successful.

Tally the total value of the scores the student obtained on the Oral Assessment with Pictures only. Note: "Total value" means the sum of all scores for this section of the test, not the number of items answered correctly. Refer to section VI of the student Information and Answer sheet (SIAS). Check (X) the proper placement for the student according to the range in which his/her score fell.

Additional comments regarding circumstances that effect the student's scoring or placement may be added on the back of the SIAS. Be sure to note "over" on the front of the SIAS.

Performance on the oral Warm-up ar. whe Basic Literacy Screening are not used for placement. The range of scores provided on the student Information and Answer sheet reflects proper placement based on the student's performance on only the oral Assessment with Pictures.

Administering the first two sections of the test is necessary to: (1) reach a quick placement of the student (failure on the oral Warm-up), (2) gather cursory information on the student's literacy skills in English, and (3) establish a standardized prelude to the administration of the oral Assessment with Pictures.

\section{STUDENT PERFORMANCE LEVELS}

The performance levels used in the NYS Place Test to place entering ESOL students at the correct level of instruction are geared to the majority of programs in New York state which offer four levels of instruction. However, the English language competencies expected of students at the four levels may vary from program to program. Therefore, the following descriptions of student performance Levels (SPL'S) are provided as a general indicator of the skills which would be the focus of instruction at the respective levels. The performance levels are described as part of a Continuum of competencies which may not have absolutely clear distinctions between one performance level and another. 
The range of scores for placement (e.g., 0-15 for Level 1) is based on this standard. If a program's student Performance Levels vary considerably from this standard, then adjustments in the range of scores may be warranted to achieve more precise placement. 


\section{English for speakers of other Languages student Performance Levels \\ Level 1 of the competency Continuum}

\section{Listening Comprehension}

No ability whatsoever.

Unable to understand spoken English except for a few isolated words and extremely simple, previously-learned phrases.

Able to understand a very restricted range of simple, previously-learned phrases spoken extremely slowly with frequent repetitions in familiar situations.

Able to understand simple, previously-learned phrases spoken slowly with frequent repetitions in familiar situations.

\section{oral comprehension}

\section{Vocabulary}

No ability whatsoever.

Limited to a few isolated words.

Adequate only to express a very restricted range of immediate needs using short, previously-learned phrases. Can respond to direct questions on familiar subjects using one or two words.

Adequate only to express immediate survival needs using previously-learned, short phrases. Can respond to direct questions on familiar subjects, using short, previously-learned phrases.

Grammar

No ability whatsoever.

No control.

Almost no control over basic grammar.

\section{Pronunciation}

No ability whatsoever.

Frequently unintelligible. 


\section{English for speakers of other Languages \\ student Performance Levels \\ Level 2 of the Competency Continuum}

\section{Listening comprehension}

Able to understand previouslylearned phrases with ease and very simple new phrases which contain familiar vocabulary and are spoken slowly with frequent repetitions in familiar situations. Can partially understand new phrases spoken in contexts which help convey the meaning.

Able to understand short phrases which contain familiar vocabulary and are spoken slowly, with repetition in both familiar and unfamiliar situations.

\section{oral comprehension}

vocabulary

Adequate to express basic survival needs using previously-learned phrases as well as some new phrases. Can ask and respond to direct questions on familiar subjects. Can engage in basic conversations on familiar subjects but lacks the ability to participate in most social situations. Speaks with obvious effort and frequent pauses.

\section{Grammar}

Very little control of basic grammar.

\section{Pronunciation}

often unintelligible. 


\section{English for speakers of other Languages \\ student performance Levels \\ Level 3 of the competency continuum}

\section{Listening comprehension}

Able to understand

conversations on a variety of everyday subjects which

contain some unfamiliar vocabulary and are spoken somewhat slowly with some need for repetition. Limited ability to function without face-to-face contact.

\section{Oral Comprehension}

\section{Vocabulary}

Adequate to function independently in most face-toface basic survival situations but needs help occasionally. Can ask and respond to direct questions on familiar subjects and a limited number of unfamiliar subjects. Can participate with difficulty in some social situations when addressed directly. Has limited ability to convey general meaning by repeating and re-wording but is usually unable to convey exact meaning or intentions. Shows some signs of spontaneity and creativity, speaks with obvious effort and frequent pauses.

\section{Grammar}

Increasing control of basic grammar is evident but errors persist.

\section{Pronunciation}

Occasionally unintelligible. 


\section{English for 8peakers of Other Languages student Performance Levels \\ Level 4 of the Competency Continuum}

\section{Listening Comprehension}

Able to understand most conversations on non-technical subjects spoken at normal speed when addressed directly, although may sometimes need repetition or re-wording. Has ability to understand routine conversations in own field.

Less dependent on face-to-face contact. Cannot usually follow rapid conversation between native speakers.

Able to understand most conversations on non-technical subjects and has some ability to understand routine conversations in own field of specialization. Can function easily when not in face-toface contact, though may have difficulty understanding rapid speech. Can understand most conversations between native speakers, though may miss some details if the subject is unfamiliar.

\section{oral Comprehension}

\section{Vocabulary}

Adequate to function

independently in most survival situations but will

occasionally need help. Can give simple explanations and ask for clarification. can participate with some confidence in social situations when addressed directly. Can communicate with some difficulty on the phone on familiar subjects. Is usually able to convey general meaning by repeating and re-wording but will have difficulty conveying exact meaning. spontaneity and creativity are evident but speaks with effort and hesitation.

Adequate to function independently in survival and most social situations but may need some help. Generally able, though reluctant, to communicate by phone on familiar subjects. Increasing ability but still speaks with hesitation.

\section{Grammar}

Control of basic grammar is evident but inconsistent. Good control of basic grammar.

\section{Pronunciation}

Usually intelligible but mispronunciations lead to occasional misunderstandings. Usually intelligible. 


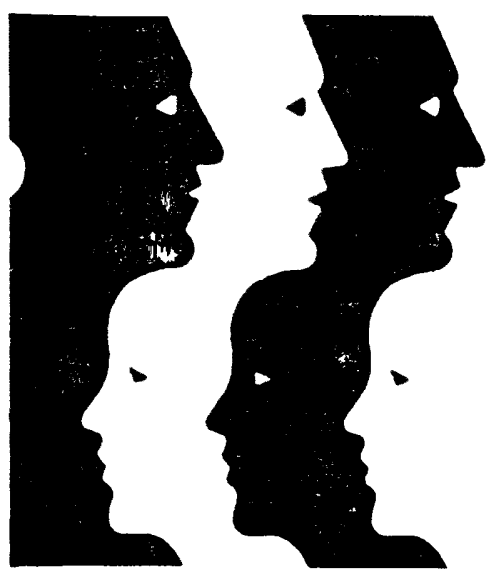

Now York State's Placement Test
New for English as a Second Language Adult Students

Picture Cue Booklet

Form B 

5
9
28
743

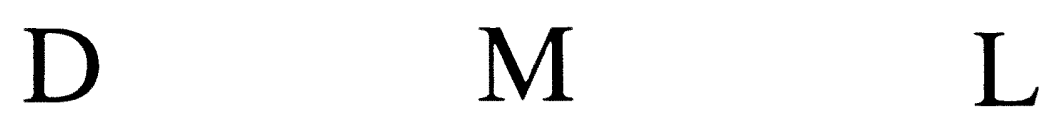

$\begin{array}{lll}\mathrm{F} & \mathrm{H} & \mathrm{T}\end{array}$

in pull stop

phone danger

Do you like to read English? 

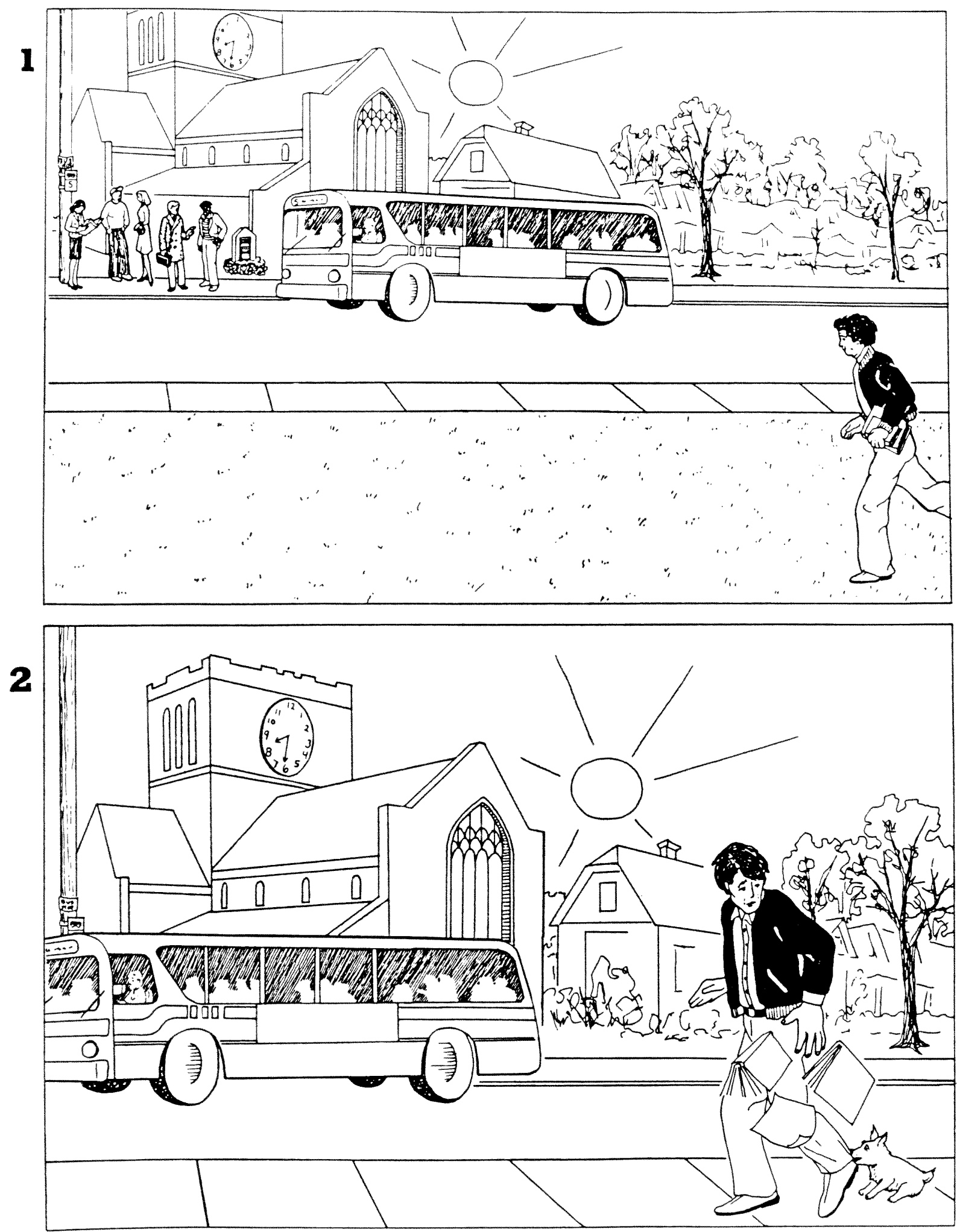


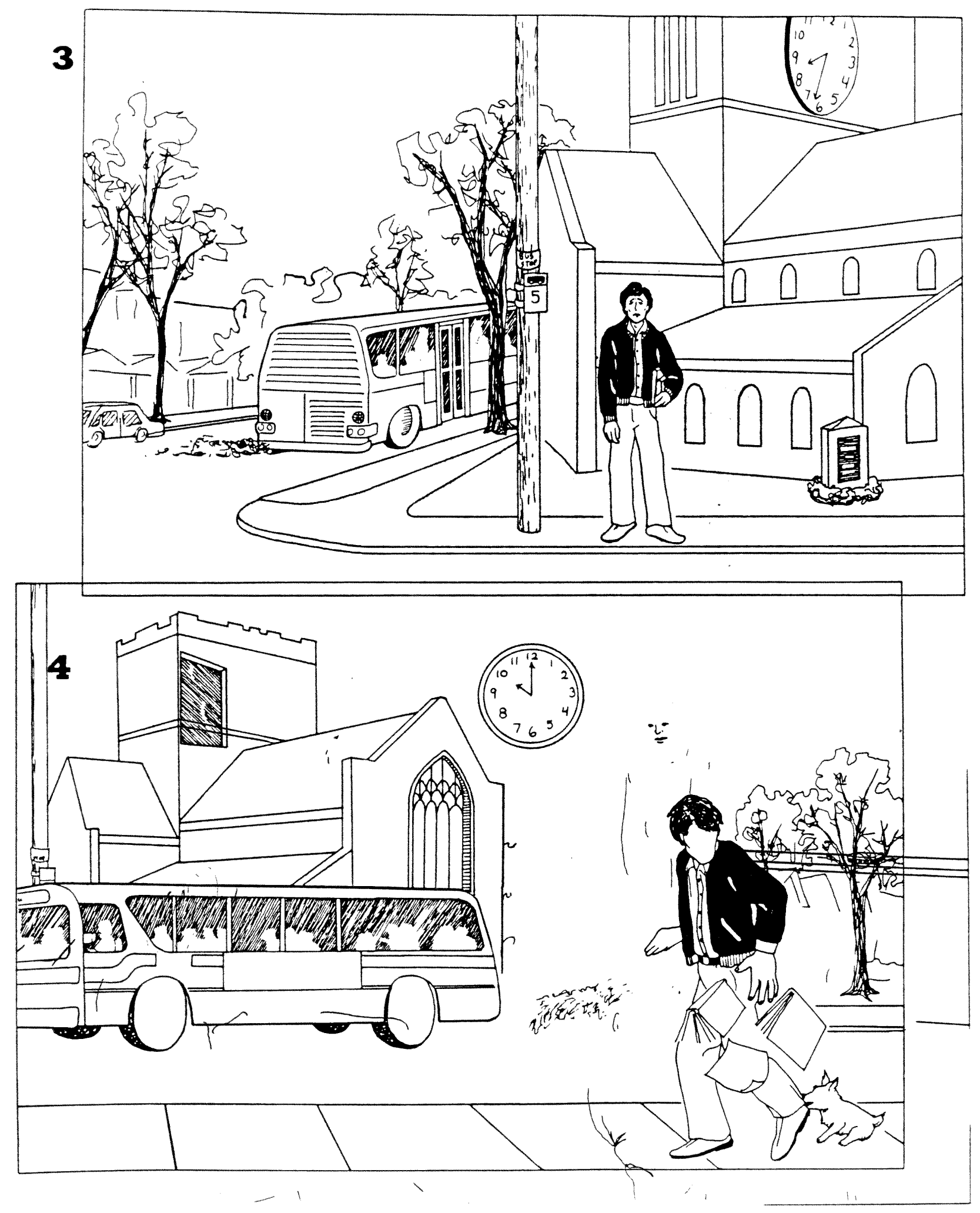



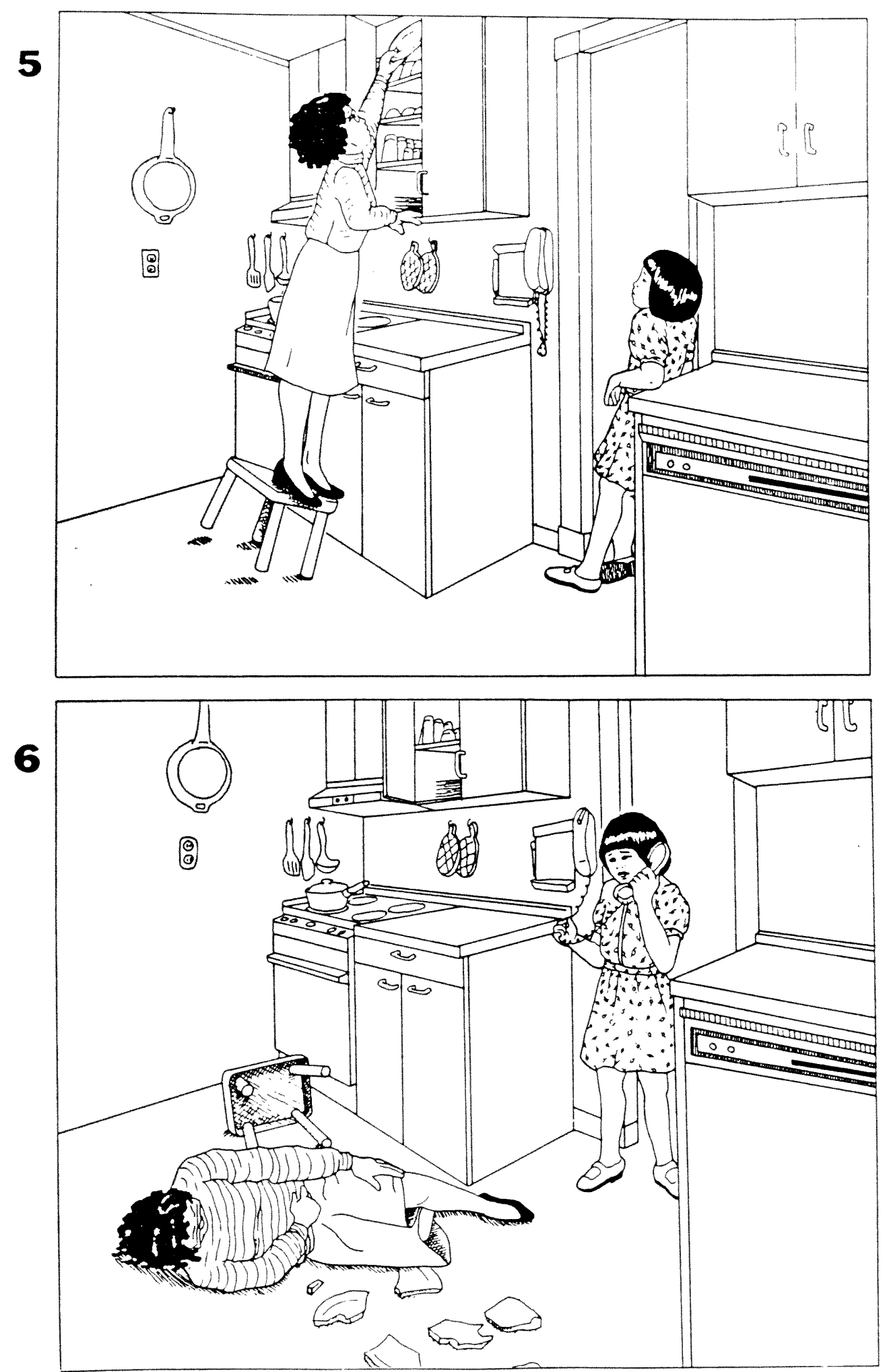


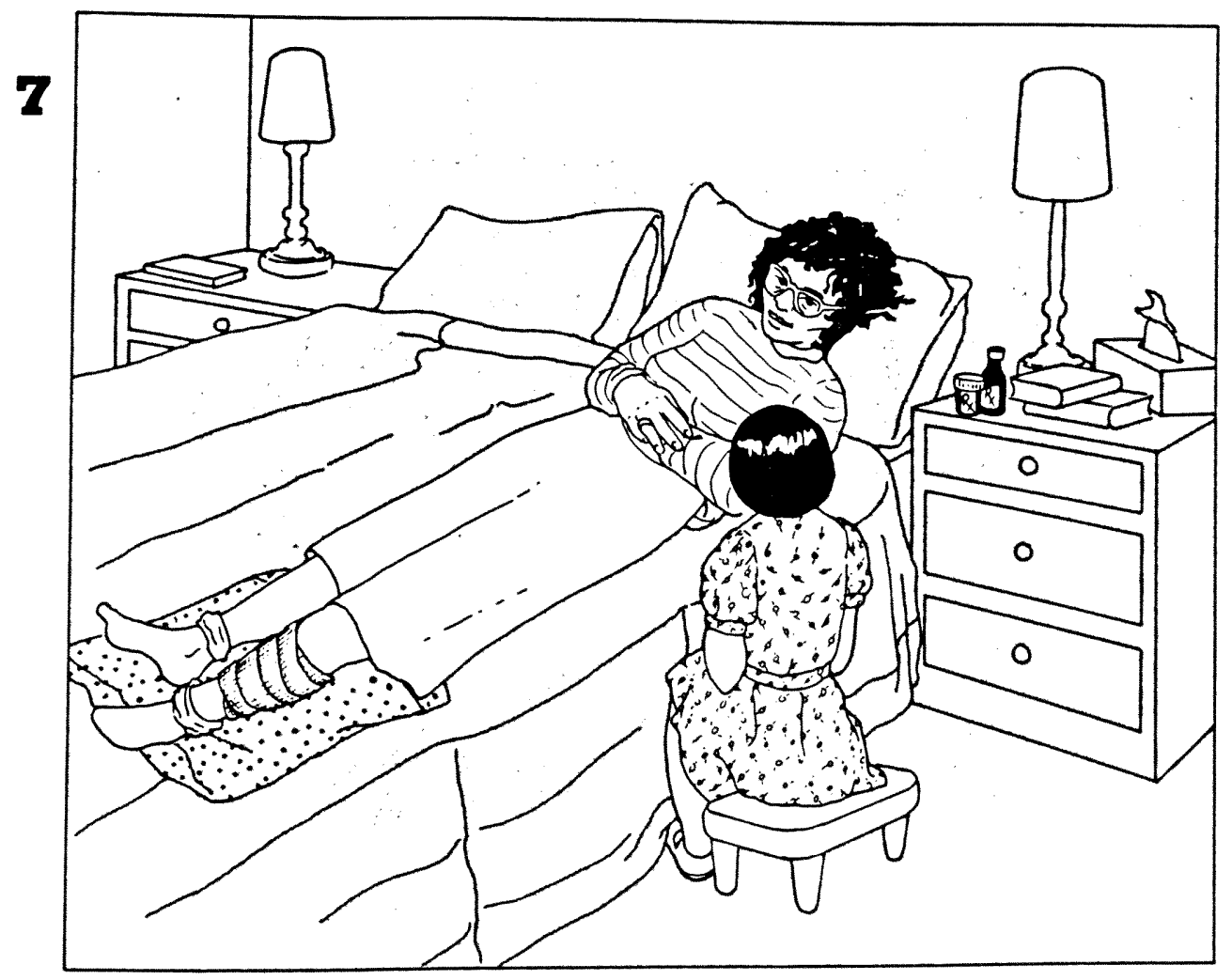



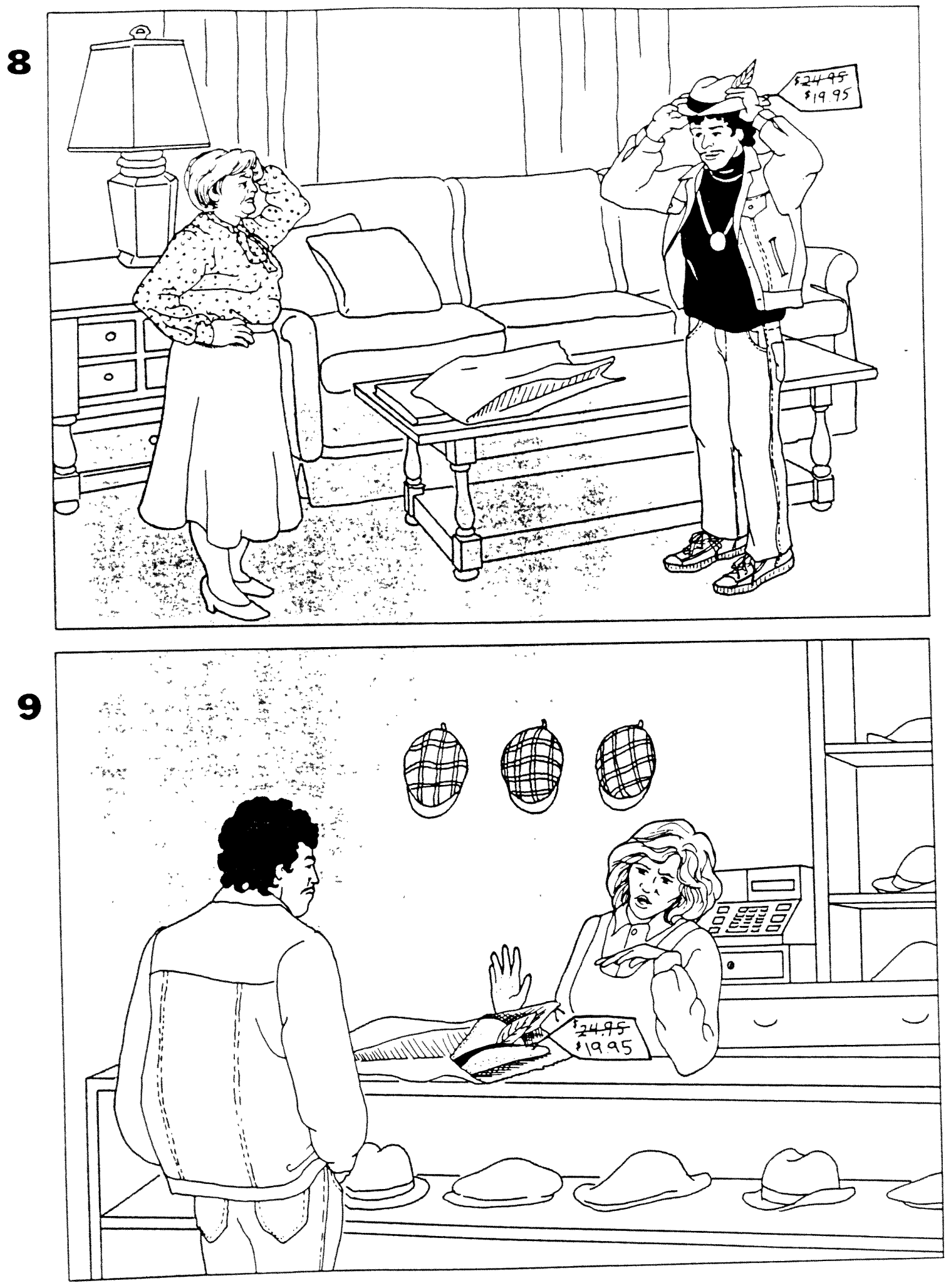

173 


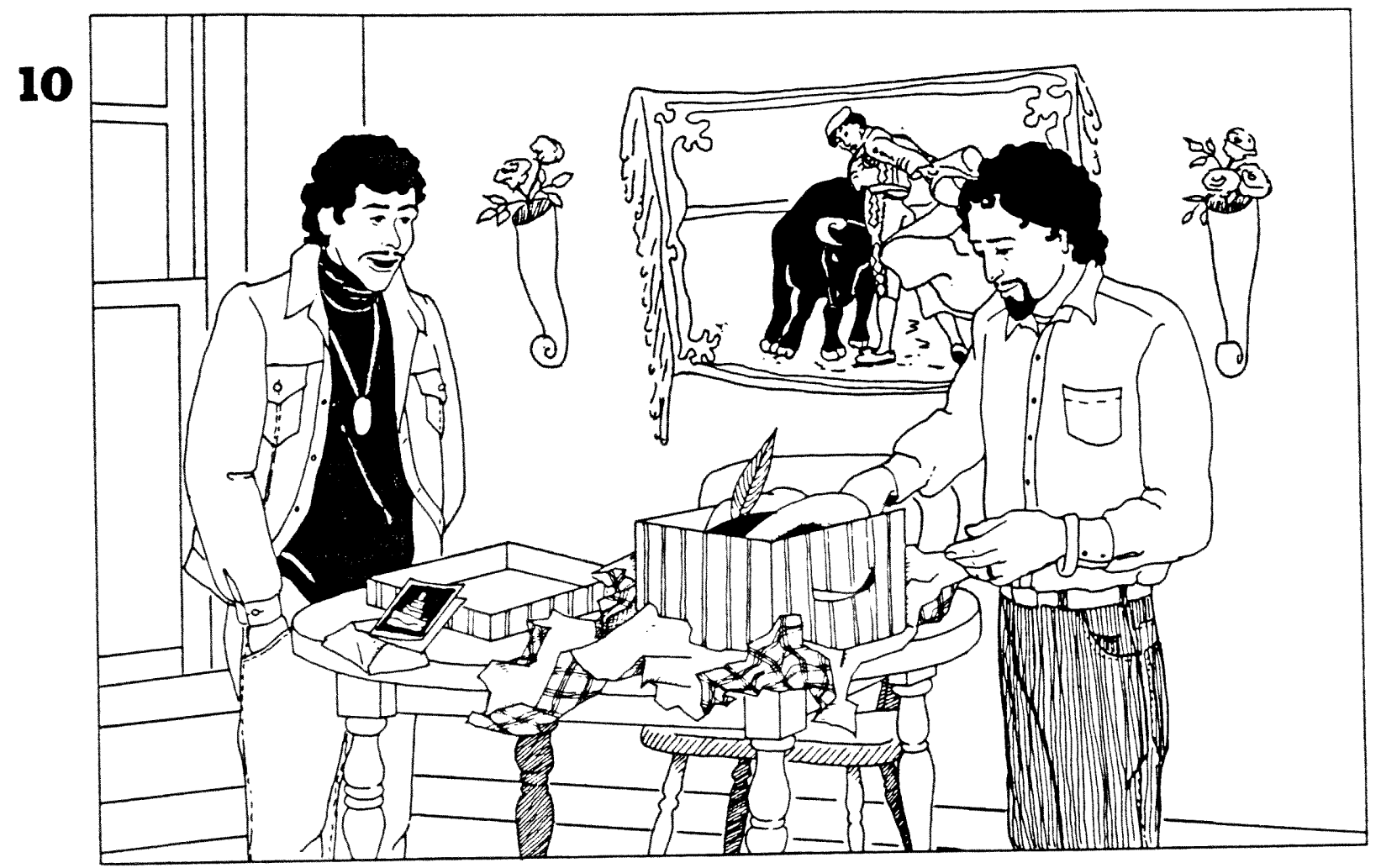



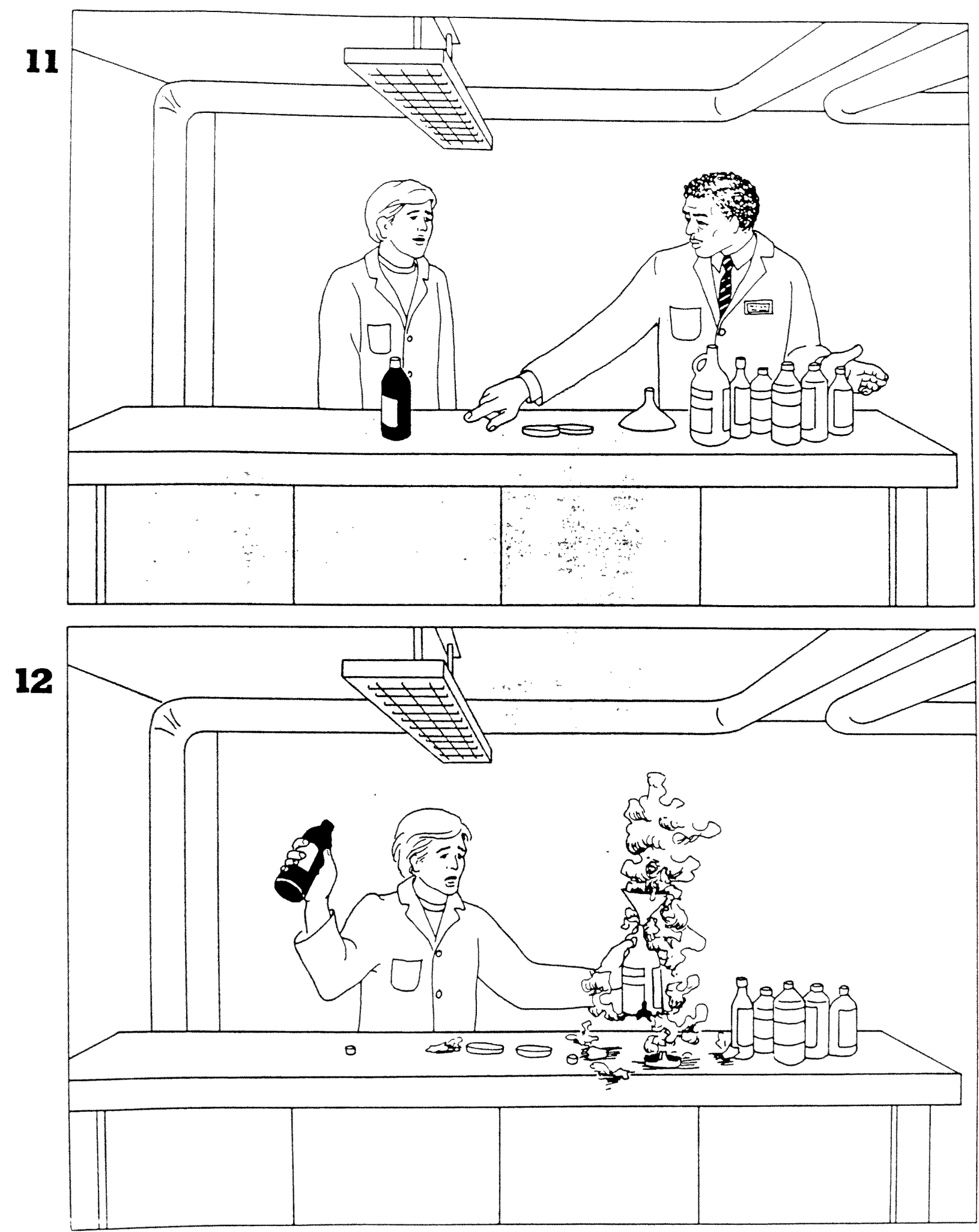


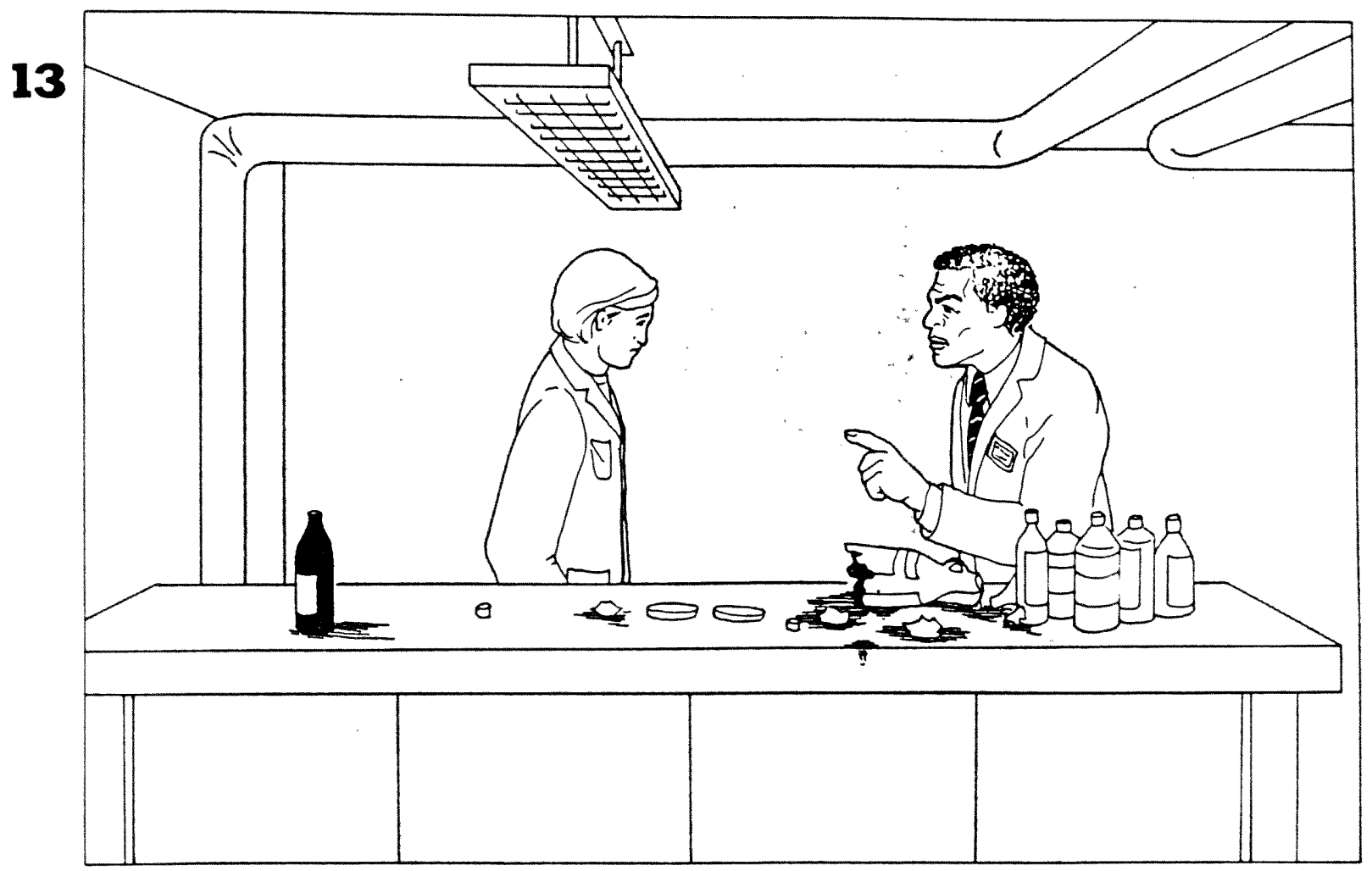


The following list is provided as a guide for the teaching of grammatical structures. It suggests appropriate levels at which the structures may be introduced, reviewed and expanded.

Clearly, any structures (regardless of suggested levels) that arise in class may be touched upon and/or taught.

\section{- VERBAL CONSTRUCTIONS AND ADVERBS}

INTRODUCE $\begin{array}{ll}\text { REVIEIV \& } & \text { CHECK- } \\ \text { EXPAND } & \text { LIST }\end{array}$

- Adverbs of time, frequency, and manner

- Adverb placement

- Causative "have"

- Commands: let's with "be" and other verbs

- Commands: other verbs

- Direct and indirect speech

- Equal and unequal comparisons of adverbs

- Future: going to

- Future: will

- Future continuous

- Future intention in the past

- Future perfect

- Future perfect continuous

- "If" clauses: future

- "If" clauses in unreal conditions: present

- "If" clauses in unreal conditions: past

- Infinitive constructions

- Information question words (simple), who, what, where, how

- Information words (more complex), whose, which, why

- Intensifiers (very, too, so)

- Linking verbs (other than "be"): present and past

- Modals: Ability

\begin{tabular}{lll} 
Can & II & III, IV \\
\hline Be able to (present and past) & II & III, IV \\
\hline Could (past of can) & II & III, IV
\end{tabular}

- Modals: Condition

\begin{tabular}{lll} 
Could & III & IV \\
\hline Could have & IV & \\
\hline Would & III & IV \\
\hline Would have & IV & \\
\hline Should & IV & \\
\hline Should have & IV & IV \\
\hline
\end{tabular}

- Modals: Necessity

Must, have to

Have got to

Had better

Had to (past of must)

Should, ought to

Should have, ought to have

I II, III, IV

\begin{tabular}{ll} 
I & II, III, IV \\
IV & II, IV \\
II & II, IV \\
II & IV \\
III & II, IV \\
II & III, IV \\
II & III, IV \\
II & III, IV \\
II & IV \\
IV & \\
IV & \\
\hline IV & \\
III & IV \\
IV & \\
IV & \\
II & III, IV \\
\hline I & II, III, IV \\
\hline II & II, IV \\
II & III, IV \\
II & III, IV \\
\hline
\end{tabular}

\begin{tabular}{ll} 
II & III, IV \\
III & IV \\
III & IV \\
III & IV \\
III & IV \\
\hline
\end{tabular}

\section{- Modals: Permission
may, can, could (polite form) \\ - Modals: Permission
may, can, could (polite form)}

- Modals: Polite request would II III, IV

Modals: Possibility

may (might)

may have (might have)

\begin{tabular}{ll} 
II & III, IV \\
\hline
\end{tabular}

Modals: Probability

must

must have

supposed to, supposed to have

III IV

IV

Passive voice (with and without agent), past

- Past-simple with regular and most common

irregular verbs

III IV

IV $\longrightarrow$

IV $-+--\cdots$ III IV

II III, IV




\begin{tabular}{|c|c|c|c|}
\hline & INTRODUCE & $\begin{array}{l}\text { REVIEW \& } \\
\text { EXPAND }\end{array}$ & $\begin{array}{c}\text { CHECK } \\
\text { LIST }\end{array}$ \\
\hline - Past conitinuous & II & III, IV & \\
\hline - Past continuous with past & III & IV & \\
\hline - Pastperfect & IV & & \\
\hline - Pastperfect continuous & IV & & \\
\hline - Present: with be & 1 & II, III, IV & \\
\hline $\begin{array}{l}\text { - Present: be, with there, here and it in initial } \\
\text { position }\end{array}$ & 1 & II, III, IV & \\
\hline - Present: with other verbs & T & II, III, IV & \\
\hline - Present continuous & 1 & II, III, IV & \\
\hline Presentperfect & III & IV & \\
\hline Present perfect continuous & IV & & \\
\hline - Tag questions and responses "be" and other verbs & II & III, IV & \\
\hline Two-word verbs (common) & I & II, III, IV & \\
\hline Two-word verbs (separable and non-separable) & II & III, IV & \\
\hline Used to & II & III, IV & \\
\hline (be) used to (accustomed to) & IV & & \\
\hline would rather & IV & & \\
\hline would be better & IV & & \\
\hline
\end{tabular}

- NOUN, CONSTRUCTIONS, PRONOUNS, AND ADJECTIVES

\begin{tabular}{|c|c|c|}
\hline Adjectives (multiple) word order before nouns & II & III, IV \\
\hline Adjective and noun word order & $T$ & II, III, IV \\
\hline Cardinal and ordinal numbers & $T$ & II, III, IV \\
\hline Definite and indefinite articles & $T$ & II, III, IV \\
\hline Demonstrative adjectives and pronouns & I & II, III, IV \\
\hline Direct and indirect object pronouns & I & II, III, IV \\
\hline $\begin{array}{l}\text { Direct and indirect object pronouns (together in } \\
\text { same sentence) }\end{array}$ & II & III, IV \\
\hline Equal and unequal comparisons of adjectives & II & III, IV \\
\hline Equal and unequal comparisons of nouns & TII & TV \\
\hline $\begin{array}{l}\text { Gerunds and past participles used in adjectives } \\
\text { (in contrast) }\end{array}$ & IV & \\
\hline Indefinite adjectives and pronouns & II & III, IV \\
\hline Indefinite adjectives and pronouns: more difficult & III & IV \\
\hline Mass and count nouns & II & III, IV \\
\hline $\begin{array}{l}\text { Prefixes some, any, every, no plus body or thing } /+ \\
\text { somebody }\end{array}$ & III & IV \\
\hline Possessive nouns and adjectives & 1 & II, III, IV \\
\hline Possessive pronouns & I & II, III, IV \\
\hline Reciprocal pronouns (each other, one another) & II & III, IV \\
\hline Reflexive pronouns & II & III, IV \\
\hline Subject position use of: anyone, anybody & IV & \\
\hline Verb + gerund or infinitive (or either) & III & IV \\
\hline
\end{tabular}

- OTHER

\begin{tabular}{|c|c|c|}
\hline - Conjunctions (simple) & 1 & II, III, IV \\
\hline $\begin{array}{l}\text { Conjunctions in complex setences: } \\
\text { who, that, which }\end{array}$ & III & IV \\
\hline $\begin{array}{l}\text { Conjunctions in complex sentences: } \\
\text { despite, because of, regardless of, } \\
\text { in spite of, in account of }\end{array}$ & IV & \\
\hline $\begin{array}{l}\text { Conjunctions in complex setences: } \\
\text { whose }\end{array}$ & IV & \\
\hline $\begin{array}{l}\text { - Conjunctions in compound sentences: } \\
\text { (etther, so too, neither) }\end{array}$ & 111 & IV \\
\hline Exclainatory sentences & III & IV \\
\hline Inter jections (exlamations) & $T$ & II, III, IV \\
\hline Prepositions of time and place (simple) & 1 & $\Pi_{1}, 111$, IV \\
\hline Punctuation and capitalization & ii & III, IV \\
\hline
\end{tabular}


APPENDIX F 
STLDENT'S NAME DATE TIME

I. Tanpri reponn keksyon sa-yo souple:

(Please respond to the following questions:)

1. Konbyen anne ou pase lekòl? (How many years did you go to school?)

2. Eske ou te etidye franse lekòl? Pandan konbyen anne? (Did you study French in school? For how many years?)

3. Eske ou genyen yon travay?

(Do you have a job?)

Pou tout jounen? Yon moso jounen? (Full-time?) (Part-time?)

4. Ki le ou rive nan Etazini? Depi konbyen tan ou isit-la? (When did you arrive in the United States? How long are you here?)

II. Nan plas vid anba keksyon-yo ekri nimewo ki parèy avèk chak repons. (In the space provided, write the number that corresponds to your answer.)

$5=$ byen anpil anpil (extremely well)

4 = byen anpil (very well)

3 = byen (well)

2 = byen ti $k r a s(a$ little $)$

$1=$ pa byen ditou (not at all)

1. Mwen kapab li yon jounal kreyòl/franse. (I can read a newspaper in Creole or French.)

2. Mwen kapab ekri lèt an kreyòl/an franse. (I can write letters in Creole or French.) 
APPENDIX G 
Please complete the following information regarding your student

Rate the degree of correct placement, on a scale of 1-6, for this student in your level. The student would be incorrectly placed if his/her ability is below or above the level of your class according to vour strand. Place a check mark above the appropriate number.

Example: You teach level 3 and the student is correctly placed. Mark 6.

You teach level 3 and the student belongs in level 2. There is a difference of one level. Mark 5.

You teach level 3 and the student belongs in level 4. Mark 5.

Completely

Incorrect
Perfectly

Correct

T $\frac{7}{2} \quad \frac{}{4} \quad \frac{}{5} \quad \frac{}{6}$

The student belongs in my level

(Yes or no)

The student belongs in level

(Write the level.)

Please record informal student comments, if any, as they relate to placement of this student in your level.

Teacher:

Date:

Thank you for your cooperation in completing this questionnaire. 
APPENDIX $\mathrm{H}$ 


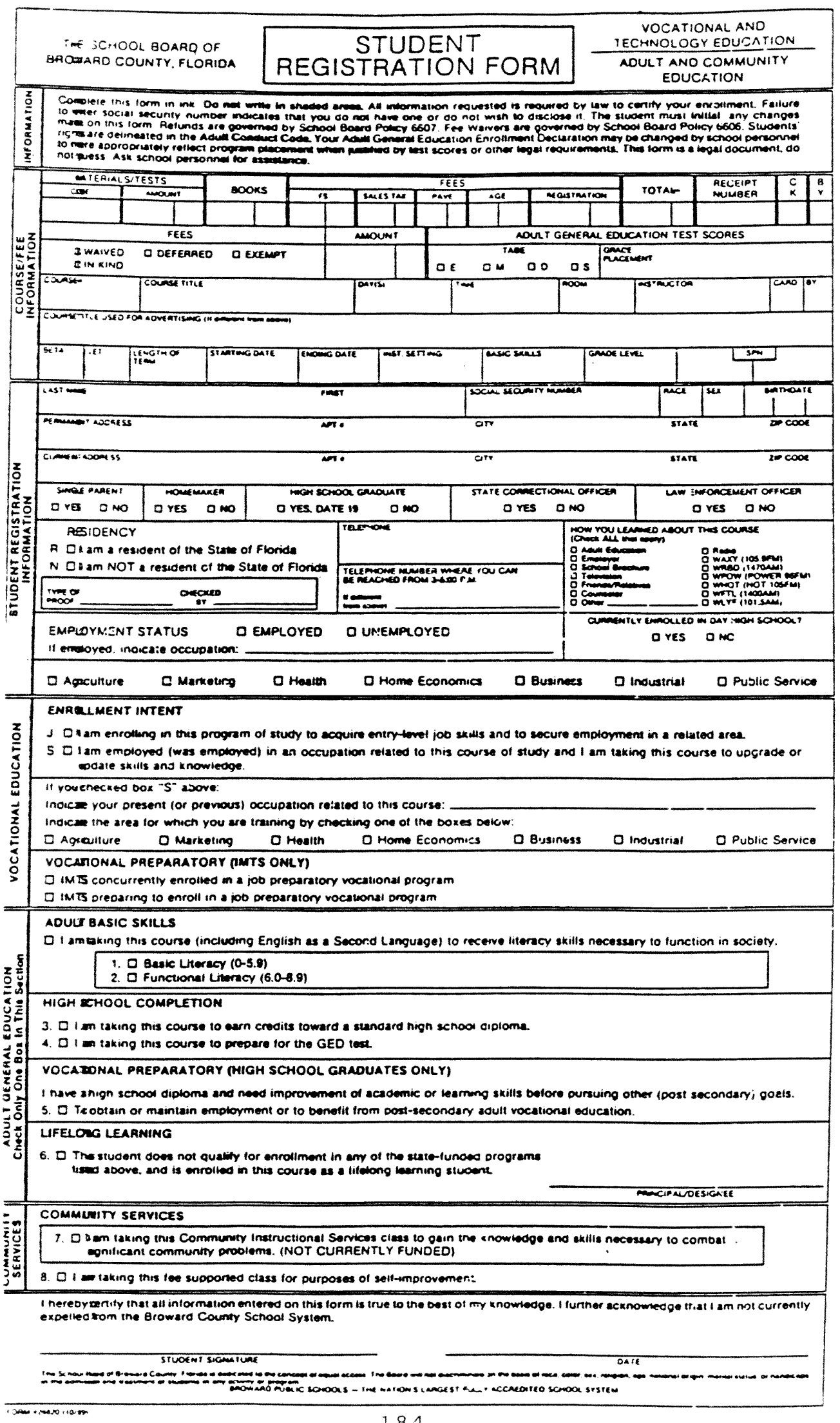




\section{VITA}

August 10, 1947

1968 B.A., Cum Laude,

1975 M.A.,

1985 - present

1992

1991, 1993

1993-94
Born, Brooklyn, New York

French

Brooklyn College

Brooklyn, New York

Liberal Studies

State University of New York

Stony Brook, New York

ESOL Teacher

Gene A. Whiddon Adult Center

Fort Lauderdale, Florida

Teacher-of-the-Year Award

Gene A. Whiddon Adult Center

Adjunct Professor

Florida International University

Miami, Florida

Applied for and received federal, state, and local grant funding in excess of $\$ 750,000.00$ for demonstration projects 